\title{
III. Integrationspolitik und Wirtschaft
}




\section{Dierk Hoffmann}

\section{Vertriebenenintegration durch Arbeitsmarktlenkung?}

\section{Zur Beschäftigungspolitik der SBZ/DDR (1945-1950)}

Die berufliche Eingliederung sozial Außenstehender ist ein wesentlicher Bestandteil des dreistufigen Integrationsmodells, das schon seit längerem bei der wissenschaftlichen Beschäftigung mit Vertriebenen und Flüchtlingen Verwendung gefunden hat. Die „klassische Trias" von Kommerzium, Kommensalität und Konnubium gilt gemeinhin als „Testskala“, um das Verhältnis zwischen Einheimischen und Vertriebenen zu definieren und den Integrationsstand der zuletzt genannten Gruppe zu charakterisieren ${ }^{1}$. Integration ist die eine Seite dieses Prozesses, Ausgrenzung die andere. Die Bereitschaft der Aufnahmegesellschaft zur Eingliederung der Zuwanderer ist somit entscheidend für deren Erfolg und kann letztlich auch - zumindest dem Modell nach - negativ verlaufen. In der historischen Betrachtung sind jedoch weniger die Extrempositionen, sondern vielmehr ein Mischverhältnis von Annäherung und Abgrenzung von zentralem Interesse, das es zu bestimmen gilt. Die berufliche Eingliederung stellt wiederum einen ersten wichtigen Schritt dar, mit dem sich Flüchtlinge und Vertriebene einen Zugang zu der für sie neuen Gesellschaft verschaffen konnten. Wie erfolgte - so wäre hier zu fragen - die Eingliederung der Vertriebenen in den Arbeitsmarkt der sowjetischen Besatzungszone (SBZ) bzw. der frühen DDR? Für die Bundesrepublik hat unter anderem Paul Lüttinger auf die zahlreichen Problemlagen dieses Prozesses hingewiesen und von einem Mythos der schnellen Integration gesprochen ${ }^{2}$. Auf der Grundlage der Mikrozensus-Zusatzerhebung vom April 1971 kommt er zu dem Ergebnis, daß von einer chancenindifferenten Integration der Zuwanderer nicht gesprochen werden kann. Vielmehr müsse bei der Beantwortung dieser Frage nach den einzelnen Kohorten differenziert werden. Demzufolge sei so Lüttinger - die erfolgreiche Integration erst bei den Kindern bzw. den nachfolgenden Generationen der Zuwanderer ,in vollem Umfang erreicht“" worden ${ }^{3}$.

Die archivalische Hinterlassenschaft der DDR macht eine solche, nach Generationen differenzierte Untersuchung nahezu unmöglich. Aus der Sicht der SED-Führung und der DDR-Staatsführung war die Eingliederung der sogenannten ,Umsiedler ${ }^{44}$ Anfang

${ }^{1}$ Frantzioch, Die Vertriebenen, S. 194.

${ }^{2}$ Lüttinger, Integration der Vertriebenen. Lüttinger hat seine Thesen in einem Aufsatz nochmals zugespitzt: Ders., Der Mythos der schnellen Integration.

${ }^{3}$ Lüttinger, Der Mythos der schnellen Integration, S. 35.

${ }^{4}$ Im folgenden werden die Begriffe ,Flüchtling', ,Vertriebener', ,Zuwanderer' und ,Umsiedler synonym verwendet. Eine begriffsgeschichtliche Erörterung bleibt nach wie vor ein Desiderat der Forschung. Es sei noch darauf hingewiesen, daß es sich beim ,Umsiedler'-Begriff um eine offizielle Bezeichnung der Personengruppe von seiten der staatlichen Verwaltung und der SED handelt. Um dies deutlich zu machen, wird der Ausdruck in Anführungszeichen gesetzt. Meinicke spricht sich dagegen für dic Verwendung des Begriffs ,Umgesiedelte` aus, um die Passivität 
der fünfziger Jahre erfolgreich abgeschlossen. Weitere gruppenspezifische Fördermaßnahmen schienen daher überflüssig und nicht mehr notwendig zu sein. Gleichzeitig entfiel auch die Notwendigkeit für die staatlichen Verwaltungen, die ,Umsiedler' weiterhin gesondert zu betrachten und ihren Eingliederungsprozeß weiter zu verfolgen. All dies sind Erklärungen dafür, daß die Aktenüberlieferung der Ministerien und Verwaltungen sowie der Hegemonialpartei SED zu diesem frühen Zeitpunkt abbricht.

Dennoch lohnt es sich, die Frühphase der SBZ/DDR genauer unter die Lupe zu nehmen und nach der Integration der Flüchtlinge und Vertriebenen in den ostdeutschen Arbeitsmarkt zu fragen. Gab es, so müßte eine leitende Fragestellung lauten, entsprechende arbeitsmarktpolitische Pläne, die primär auf die Gruppe der ,Umsiedler' abzielten? Welche Konflikte ergaben sich dabei zwischen der Zentralverwaltung für Arbeit und Sozialfürsorge (ZVAS) ${ }^{5}$ sowie der Zentralverwaltung für deutsche Umsiedler (ZVU) ${ }^{6}$ ? Und: Wie gestaltete sich die Zusammenarbeit von Zentral- und Landesverwaltung? Der folgende Beitrag muß sich aus den oben genannten Gründen auf die Anfangsjahre, also auf die Zeitspanne von 1945 bis 1950 beschränken. In einem ersten Schritt soll der Verlauf des Flüchtlings- und Vertriebenenzustroms in die SBZ kurz skizziert, anschließend ein Überblick über die Arbeitsmarktchancen der ,Umsiedler' in einzelnen zentralen Wirtschaftssektoren gegeben und abschließend auf die Arbeitsmarktpolitik von ZVAS, ZVU und SED sowie der Landes- bzw. Provinzialverwaltungen eingegangen werden.

\section{Phasen der Vertreibung und Neuansiedlung}

Bereits vor dem Ende des Zweiten Weltkrieges war das Gebiet der späteren SBZ durch die massenhafte Flucht Hunderttausender vor der heranrückenden Roten Armee überschwemmt worden. Noch vor der Unterzeichnung der bedingungslosen Kapitulation begannen auch die sogenannten "wilden“ Vertreibungen aus dem ostmitteleuropäischen Raum. Die vier Siegermächte versuchten auf der Potsdamer Konferenz diese unkontrollierte Bevölkerungsverschiebung gen Westen zu ordnen und statt dessen eine geregelte "Umsiedlung" durchzuführen, soweit dies überhaupt möglich war? ${ }^{7}$. Der Alliierte Kontrollrat verabschiedete am 21. November 1945 einen „Umsiedlungsplan " ${ }^{8}$, der von einer deutschen Restbevölkerung in den ehemals deutschen Ostgebieten und Österreichs von etwa 6,65 Millionen ausging. Von dieser Gruppe sollten 2,75 Millionen in der SBZ, 2,25 Millionen in der amerikanischen, 1,5 Millionen in der britischen und 150000 in der französischen Zone aufgenommen werden'. Der Plan blieb zunächst jedoch nur Makulatur, da sich erst ab 1946 die Praxis der geregelten Transporte mit der Eisenbahn langsam durchsetzte ${ }^{10}$.

dieses Prozesses (aus Sicht der Opfer) deutlich zu machen. Vgl. Meinicke, Flüchtlinge, S. 23, Anm. 17. Vgl. zur Durchsetzung des Terminus ,Umsiedler' im Herbst 1945: Schwartz, Zwischen Zusammenbruch und Stalinisierung, S. 61.

5 Vgl. zum Aufbau der ZVAS Hoffmann, Sozialpolitische Neuordnung, S. 24-28.

6 Vgl. den Beitrag von Dieter Marc Schneider im SBZ-Handbuch, S. 239-243; sowie den aktengestützten Aufsatz von Schwartz, Zwischen Zusammenbruch und Stalinisierung.

7 Vgl. Benz, Potsdam 1945, S. 110; Henke, Der Weg nach Potsdam, S. 81; Foschepoth, Die Westmächte, S. $99 f$.

8 Zank, Wirtschaft und Arbeit, S. 142.

9 Zu den Zahlen Foschepoth, Die Westmächte, S. 100.

10 Vgl. dazu ebenda, S. $101 \mathrm{f}$. 
Auf seiten der sowjetischen Militäradministration (SMAD) begannen die Planungen zur Aufnahme und Verteilung der ,Umsiedler' in der SBZ vergleichsweise spät. Erst im Oktober 1945 wurde beispielsweise der systematische Aufbau eines Netzes von Aufnahmelagern in Angriff genommen ${ }^{11}$. Die SMAD beauftragte die neu errichteten deutschen Verwaltungen damit, an den östlichen Grenzen der SBZ zwölf Hauptlager aufzubauen, in denen die ,Umsiedler' registriert und vor allem nach der strapaziösen Flucht medizinisch versorgt werden sollten. Von dort war dann eine Weiterführung ins Landesinnere vorgesehen. In den Lagern herrschten anfangs katastrophale Zustände: So war die Versorgung mit Lebensmitteln äußerst knapp und die Unterbringungsmöglichkeiten schlecht, so daß sich Krankheiten rasch ausbreiten konnten. Berichte der lokalen Behörden über Seuchen in den Lagern sind gerade in den beiden Jahren 1945/46 sehr zahlreich. In der Regel währte außerdem die zeitliche Unterbringung der ,Umsiedler' in den Aufnahmelagern zu lange ${ }^{12}$ - ein Zeichen dafür, daß oftmals kein geeigneter Aufenthaltsort gefunden werden konnte. Die ZVU schob dabei den lokalen Behörden, die für die Leitung und Kontrolle der Lager zuständig waren, die Hauptschuld zu.

Die endgültige Verteilung der ,Umsiedler' erfolgte in der SBZ alles andere als geordnet. Zwar lag bereits am 19. Juli 1945 ein Befehl von Marschall Schukow zur regionalen Verteilung vor ${ }^{13}$, dessen Realisierung aber vor Ort, d. h. in den Städten und Gemeinden, auf zunächst ungeahnte Schwierigkeiten und Widerstände stieß. Dem sowjetischen $\mathrm{Be}-$ fehl zufolge sollten sämtliche Zuwanderer aus den Ostgebieten nördlich der Warthe nach Mecklenburg, die aus den Gebieten südlich der Warthe und östlich der Oder in vier Kreise des östlichen und südöstlichen Brandenburg weitergeleitet werden ${ }^{14}$. Für die Vertriebenen aus der Tschechoslowakei und Jugoslawien war das Gebiet um Torgau und in der Lausitz bestimmt worden. Deutlich erkennbar war das Bestreben der SMAD, den Vertriebenenstrom in die dünn besiedelten Räume der SBZ zu lenken, und zwar unabhängig von der jeweiligen Arbeitsmarktlage. Offenbar hatte die SMAD in den ersten Monaten nach Kriegsende eine völlig unzureichende Vorstellung vom Ausmaß und Tempo der Vertreibung. Nur so läßt sich erklären, warum erst im Herbst mit dem Aufbau der Aufnahmelager begonnen wurde und wieso nicht schon vorher Überlegungen zur Lösung des Aufnahmeproblems angestellt worden waren.

Die Kanalisierung des Vertriebenenstroms ließ sich nur schwer durchführen und hing oftmals von der Mitarbeit der lokalen Behörden ab, welche die ,Umsiedler' in benachbarte Kreise abschieben konnten. Besonders markant ist das Beispiel der sächsischen Landesregierung, die bereits im Juli 1945 die Anweisung gab, sämtliche Neuankömmlinge nach Mecklenburg weiterzuleiten ${ }^{15}$. Daraufhin ordnete die SMAD zwei Monate später einen allgemeinen Stopp der Wanderungsbewegung in der SBZ an. Die Anweisung der sowjetischen Besatzungsmacht richtete sich jedoch nicht nur gegen das eigenmächtige Handeln einzelner Landesregierungen, sondern auch gegen das "planlose“ Umherziehen der ,Umsiedler, das die Anstrengungen zur geregelten Ansiedlung zunichte machte. Zusammenfassend läßt sich für diese frühe Phase, also bis zum Jahres-

11 Vgl. Zank, Wirtschaft und Arbeit, S. 142.

12 Das wurde etwa auf einer Konferenz von Vertretern der ,Umsiedler c aus den Ländern und Provinzen in Berlin am 14.6. 1946 allgemein beklagt, BAB, DO 1/10/4, Bl. 100.

13 Vgl. Zank, Wirtschaft und Arbeit, S. 143.

14 Vgl. Just, Die Integration der Umsiedler, S. 146.

15 Ebenda. Dies, Zur Lösung des Umsiedlerproblems, S. 975. 
wechsel 1945/46 feststellen, daß nur eine unzulängliche Aufnahmeplanung existierte. Erst danach nahm die ,Umsiedler'-Politik geordnetere Züge an. Da die Behörden bei der provisorischen Volkszählung am 1. Dezember 1945 knapp 2,5 Millionen Vertriebene (ohne Kinder unter fünf Jahren) zählten, war bereits weit mehr als die Hälfte der Zuwanderung in der ersten Phase erfolgt und zum großen Teil „planlos" verteilt worden. Auch die Volkszählung im Oktober 1946, bei der 3,5 Millionen ,Umsiedler' registriert wurden, zeigt, daß die anfangs angestrebte Ansiedlung nach dem Herkunftsgebiet gescheitert war. Die "Landsmannschaften“ waren, von wenigen Ausnahmen abgesehen, über die ganze SBZ verteilt. Außerdem wird deutlich, daß die Verteilung der Vertriebenen besonders stark in den dünn besiedelten Gebieten erfolgt war. Nach Berechnungen von Wolfgang Zank waren sogar 86 Prozent in Landkreisen angesiedelt worden ${ }^{16}$. Relativ zur Wohnbevölkerung war der Zuwandereranteil auf dem Land etwa doppelt so hoch wie in den Städten, in Sachsen statistisch gesehen sogar fast dreimal so hoch. Hierfür dürften sicherlich die katastrophale Lage in den ausgebombten Großstädten und die vergleichsweise bessere Versorgung mit Lebensmitteln auf dem Lande eine ausschlaggebende Rolle gespielt haben.

Die Verteilung der Vertriebenen auf die Länder und Provinzen der SBZ erfolgte höchst ungleichgewichtig und unterstreicht nochmals das Zielvorhaben der Besatzungsmacht sowie der deutschen Stellen, die Neuankömmlinge auf dem Land anzusiedeln. Nach einer statistischen Erhebung der ZVU über die Verteilung der ,Umsiedler' mit dem Stichdatum vom 31. Dezember 1946 hatten Mecklenburg und Sachsen-Anhalt die meisten Zuwanderer aufgenommen, nämlich 980773 bzw. 961733 . Sachsen lag mit 781455 an mittlerer Position; dagegen wurden in Brandenburg und Thüringen 580571 bzw. 607390 ,Umsiedler ${ }^{6}$ gezählt ${ }^{17}$. Aufschlußreich sind nun die prozentualen Angaben, also der Vertriebenenanteil an der Gesamtbevölkerung. Demzufolge war Mecklenburg mit weitem Abstand am stärksten belastet: 45,7 Prozent der dortigen Wohnbevölkerung waren Vertriebene. Es folgten Brandenburg, Sachsen-Anhalt und Thüringen mit einem Anteil zwischen 20,5 und 22,8 Prozent. Im bereits zuvor stärker besiedelten Sachsen machten die Zuwanderer nur 13,9 Prozent aus.

\section{Chancen und Hindernisse der beruflichen Eingliederung}

Angesichts der in den ersten Nachkriegsjahren nur geringen Unterstützung durch die öffentlichen Haushalte in Form von Krediten, Zuteilung von Sachmitteln etc., auf die an dieser Stelle nicht weiter eingegangen werden kann, war für die ,Umsiedler die Erlangung eines Arbeitsplatzes von essentieller Bedeutung. Die berufliche Vermittlung von Flüchtlingen und Vertriebenen wurde vor allem dadurch behindert, daß es den Arbeitsämtern bis Anfang 1947 nicht gelang, eine Registrierung der Neuankömmlinge nach Berufen vorzunehmen. Die Rechtsgrundlage dieser Registrierung bildete der Befehl Nr. 3 des Alliierten Kontrollrates vom 17. Januar 1946: Danach mußten sich alle arbeitsfähigen Männer im Alter von 14 bis 65 Jahren und alle arbeitsfähigen Frauen im Alter von 15 bis 50 Jahren beim zuständigen Arbeitsamt melden ${ }^{18}$. Andernfalls drohte der Entzug der Le-

${ }^{16}$ Zank, Wirtschaft und Arbeit, S. 144.

17 BAB, DO 1/10/13, Bl. 43. Zusätzlich zu den Vertriebenenzahlen cnthält dic Statistik auch Zahlenangaben zur Gruppe der Evakuierten, die insgesamt 704118 Personen umfaßte.

18 Amtsblatt, S. 131-133. 
bensmittelkarten. Es hatte in der SBZ schon zuvor entsprechende Anweisungen der sowjetischen Besatzungsmacht gegeben, so z. B. der SMAD-Befehl Nr. 65 vom 15. September 1945, der die Wiedereinführung des Arbeitsbuches bedeutete. Die Austeilung des Arbeitsbuches verzögerte sich jedoch erheblich und hing offensichtlich mit der Papierknappheit zusammen ${ }^{19}$. Darüber hinaus wollte die ZVAS vermulich vermeiden, mit der Wiedereinführung des Arbeitsbuches in die Nähe zur NS-Arbeitsmarktpolitik zu geraten. Erschwerend kam aber vor allem hinzu, daß die SBZ im Herbst 1945 noch gar nicht flächendeckend mit funktionsfähigen Arbeitsämtern versorgt war, so daß die Registrierung noch nicht überall erfolgen konnte.

Die ZVU hatte zwar in einem Rundschreiben im Oktober 1945 angekündigt, ein Fragebogen zur Registrierung der arbeitsfähigen ,Umsiedler' sei geplant und würde den nachgeordneten Verwaltungseinheiten weitergeleitet werden ${ }^{20}$. Da die Registrierung nur von den Arbeitsämtern übernommen werden konnte (die ZVU verfügte auf der lokalen Ebene über eine personell nur schwache Verwaltungseinheit) war eine enge Zusammenarbeit mit der ZVAS erforderlich, der wiederum die Arbeitsämter unterstanden. Diese Kooperation zwischen den beiden Zentralverwaltungen scheint von Anfang an belastet gewesen zu sein. So beschwerte sich die Führung der ZVAS Ende November 1945 darüber, daß ein Mitarbeiter der ZVU, Georg Chwalczyk, die Herausgabe statistischen Materials verweigert habe ${ }^{21}$. Dieses sei aber als ergänzendes Material notwendig, um die „berufliche Seßhaftmachung der Umsiedler“ sicherstellen zu können. Der in der Abteilung Statistik tätige Chwalczyk mußte knapp eine Woche später einlenken und erklären, daß der ZVAS ein „Überblick über die bisher aufgenommenen Umsiedler“ gegeben werden müsse ${ }^{22}$. Es dauerte dennoch ein Jahr, bis die ZVU und die ZVAS am 7. November 1946 gemeinsam eine entsprechende Anweisung zur „Wiedereingliederung der Umsiedler und Heimkehrer in den Produktionsprozeß“ erließen ${ }^{23}$. Demzufolge war es die Aufgabe des Arbeitsamtes, das für das jeweilige Aufnahmelager zuständig war, die ,Umsied-

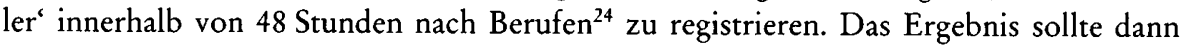
telefonisch oder per Kurier dem Landesarbeitsamt mitgeteilt werden. Dieses wiederum konnte dann einen Aufnahmeort für die einzelnen Vertriebenen festlegen. Fachkräfte, die innerhalb des Landes bzw. der Provinz nicht untergebracht werden konnten, waren der Deutschen Verwaltung für Arbeit und Sozialfürsorge (DVAS), der Nachfolgebehörde der ZVAS, zu melden, die dann in Absprache mit der ZVU ein neues Aufnahmegebiet festzulegen hatte. Damit wurde eine systematische Registrierung erst in Angriff genommen, als der Großteil der Vertriebenen bereits verteilt und untergebracht war. Darüber hinaus muß für die Umsetzung der Anordnung eine zeitliche Verzögerung in Rechnung gestellt werden.

${ }^{19} \mathrm{Zu}$ den Gründen der Verzögerung Zank, Wirtschaft und Arbeit, S. $87 \mathrm{f}$.

${ }^{20}$ Zank, Wirtschaft und Arbeit, S. 148.

${ }^{21}$ Schreiben der ZVAS vom 27. 11. 1945 an die ZVU, BAB, DO 1/10/58, Bl. 98.

${ }^{22}$ Notiz Chwalczyks vom 5. 12. 1945 betr. Zusammenarbeit mit der ZVAS, BAB, DO 1/10/58, Bl. 9.

${ }^{23}$ Eine mit handschriftlichen Bemerkungen und Unterstreichungen versehene Fassung befindet sich in: BAB, DO 1/10/58, Bl. $25 \mathrm{f}$. Die Anweisung war an alle Landes- und Provinzialämter für Arbeit und Sozialfürsorge sowic an die Landesämter für Umsiedler gerichtet.

${ }^{24}$ In der ursprünglichen Fassung war eine Registrierung nach Berufsgruppen vorgesehen. Die Änderung ging auf eine Intervention der SMAD zurück. Vgl. Schreiben des Chefs der Abt. für Arbeitskraft bei der SMAD, Morenow, am 12.12. 1946 an den Chef der 2. Abt. für Zivilangelegenheiten bei KDV-SMAD, Oberstleutnant Ugrjumow, BAB, DO 1/10/58, Bl. 32 . 
Nur in wenigen Fällen, in denen sich beispielsweise Großbetriebe auch schon 1946 direkt mit Arbeitskräfteanforderungen an die Umsiedlerbehörden wandten, erfolgte eine Festlegung des Aufnahmeortes entsprechend der beruflichen Eignung bzw. des Arbeitsplatzangebotes von seiten der Betriebe. Solche Vermittlungen konnten aber an mangelnden Unterbringungsmöglichkeiten oder der Verweigerung der Zuzugsgenehmigung durch lokale Behörden wieder scheitern. Seit dem Frühjahr 1947 häuften sich dann aber die Fälle, in denen Unternehmen eigenständig Arbeitskräfte in den ,Umsiedler'-Quarantänelagern ${ }^{25}$ warben. So meldete die ZVU beispielsweise, daß in Sachsen-Anhalt Vertreter von Großbetrieben „mit Ausweisen des Landesarbeitsamtes“ eine direkte Anwerbung von Fachkräften in den Lagern vornehmen würden ${ }^{26}$. Nach Angaben Chwalczyks hatte sich dieses System gut bewährt. Bereits am 9. September 1946 hatte das Präsidium der ZVU bei der SMAD den Vorschlag unterbreitet, den Großbetrieben mit einem anhaltend hohen Arbeitskräftebedarf eine besondere Genehmigung zur Werbung von Arbeitskräften in den Aufnahmelagern zu erteilen ${ }^{27}$. Dem standen offenkundig anderslautende Verfügungen der sowjetischen Besatzungsmacht entgegen. Ob diese daraufhin revidiert wurden, läßt sich nicht nachweisen. Festzuhalten bleibt aber, daß die Unternehmen an diesen Praktiken nicht gehindert wurden. Die Werbeaktionen einzelner Betriebe besaßen jedoch einen ambivalenten Charakter: Auf der einen Seite wurde dadurch die Arbeit der Arbeitsämter unterstützt, die den Arbeitskräftebedarf der Unternehmen offensichtlich nicht alleine bedienen konnten. Auf der anderen Seite zeigten sich damit aber die Grenzen staatlicher Interventionspolitik, die von einem politischen System, das den Anspruch besaß, den Arbeitsmarkt zentral regulieren zu wollen, nicht ohne weiteres hingenommen werden konnten.

In welchen Wirtschaftssektoren fanden nun die ,Umsiedler' vor allem eine Beschäftigung? Von insgesamt 1344588 in Arbeit stehenden Vertriebenen (Ende 1946) waren 588756 in der Land- und Forstwirtschaft beschäftigt. Das entsprach einem prozentualen Anteil von 43,8 ${ }^{28}$. An zweiter Stelle folgte der Bereich Industrie und Gewerbe mit 261337 ,Umsiedlern' (19,4 Prozent), gefolgt vom Bau- und Baunebengewerbe mit 56237 (4,2 Prozent) und dem Bergbau sowie der Metallindustrie mit 33600 Vertriebenen (2,5 Prozent). Das Schlußlicht bildete die Gruppe der Selbständigen, zu denen 18887 (1,4 Prozent) gezählt wurden ${ }^{29}$. Diese Statistik verdeutlicht, daß in der Anfangszeit vor allem

${ }^{25}$ Die Vertriebenen mußten sich in der Regel 14 Tage in den Quarantänelagern aufhalten, bevor sie in die Aufnahmeorte weitergeleitet wurden. Hintergrund dafür waren gesundheitspolitische Überlegungen der deutschen Verwaltungsstellen, die ein Ausbreiten von Seuchen schon im Keim ersticken wollten. Gleiches traf im übrigen auch die zurückkehrenden Kriegsgefangenen. Die SMAD schaltete sich bei der Seuchenbekämpfung sehr stark ein. Vgl. dazu das Schreiben der ZVU an die Zentralverwaltung der Industrie vom 12. 9. 1947, BAB, DO 1/10/58, Bl. 207.

${ }^{26}$ Aktennotiz Chwalczyks vom 31.7. 1947, BAB, DO 1/10/58, Bl. 204. In dem Zusammenhang werden die Leuna-Werke, die Buna-Werke und die Mitteldeutschen Braunkohlengruben namentlich genannt.

27 Schreiben des ZVU-Präsidenten, Rudolf Engel, vom 9. 9. 1946 an den Chef der Abt. für Zivilangelegenheiten, Statistik und Verteilung der Umsiedler bei der KDV-SMAD (Karlshorst), BAB, DO 1/10/58, Bl. 27-29, bes. Bl. 28. Als Beispiele werden die Leuna- und Buna-Werke, der Mansfelder Kupfer-Bergbau, allgemein der Kohlenbergbau, der Kali-Bergbau und die Textilindustrie angeführt.

${ }^{28}$ Die folgenden Zahlen stammen aus einem Bericht der ZVU vom 18. 12. 1946. Erhebungszeitpunkt war der 1. 12. 1946. BAB, DO 1/10/58, Bl. 41.

${ }^{29}$ Einschränkend muß jedoch hinzugefügt werden, daß 385771 ,Umsiedler ' (28,7 Prozent) unter der Kategorie „Verschiedene“ zusammengefaßt wurden. Ebenda. 
der primäre Sektor Arbeitsmöglichkeiten für die Neuankömmlinge anbieten konnte. Laut ZVU-Statistik waren am 1. Dezember 1946 84,1 Prozent der meldepflichtigen ,Umsiedler' in den Produktionsprozeß eingegliedert. Aufschlußreich waren aber vor allem die Zahlenangaben über die arbeitsfähigen Vertriebenen, machte sich doch hier eine enorme Kluft zur eingesessenen Bevölkerung bemerkbar: Nur 41,6 Prozent der ,Umsiedler galten als arbeitsfähig ${ }^{30}$. Im Gegensatz dazu lag der vergleichbare Wert für die Gesamtbevölkerung um ein Drittel höher, nämlich bei 60,1 Prozent ${ }^{31}$. Die geringere Arbeitsfähigkeit der Vertriebenengruppe im Vergleich zur Gesamtbevölkerung bedeutete eine zusätzliche finanzielle Belastung für die Haushalte der Länder und Kommunen in Form von Fürsorgeunterstützungen ${ }^{32}$.

Einfluß auf die Zuteilung von Arbeitskräften nahm vor allem die sowjetische Besatzungsmacht, die den Arbeitsbehörden immer wieder befahl, Arbeitskontingente für Demontagearbeiten oder aber für den Bereich der Grundstoffindustrie - dabei in erster Linie für die Wismut $\mathrm{AG}^{33}$ - zusammenzustellen. Auf dieses Thema kann allerdings in diesem Zusammenhang nicht weiter eingegangen werden, zumal die Gruppe der ,Umsiedler' nicht im Mittelpunkt des sowjetischen Interesses stand. Die Zugehörigkeit zu einer bestimmten Bevölkerungsgruppe spielte für die SMAD und die für arbeitsmarktpolitische Fragen zuständige Abteilung Arbeitskraft bei der Rekrutierung von Arbeitskräften keinerlei Rolle.

Es überrascht nicht, daß die berufliche Integration der Vertriebenen zunächst nur geringe Fortschritte machte. Dabei war die Arbeitsmarktlage 1945/46 zumindest für die männlichen ,Umsiedler' noch vergleichsweise günstig: Noch im Oktober 1946 zählte man fast eine Million Männer im arbeitsfähigen Alter weniger als 1939. Nach Berechnungen von Wolfgang Zank läge das Arbeitskräftedefizit ohne den Vertriebenenzustrom sogar noch höher, nämlich bei rund 1,8 Millionen ${ }^{34}$. Bemerkenswert war der 1946 allseits gemeldete Arbeitskräftebedarf, unter anderem auch an Hilfsarbeitern und Erntehelfern. Trotz dieser günstigen Ausgangslage waren Anfang 1946 beispielsweise in Sachsen-Anhalt nur 45 Prozent der Vertriebenen im arbeitsfähigen Alter mit einer Arbeitsstelle versorgt, darunter 13 Prozent berufsfremd. Als Vergleichsmaßstab sei die Beschäftigtenrate der erwerbsfähigen Männer in der DDR genannt, die im Oktober 1946 bei 69 Prozent lag. Zu diesem Zeitpunkt lag der Anteil der erwerbstätigen Vertriebenen bezogen auf die Bevölkerung im arbeitsfähigen Alter vermutlich erheblich unter 45 Prozent $^{35}$. Sachsen-Anhalt nahm dabei sicherlich eine Sonderrolle ein, da das Land eine überdurchschnittliche Gewerbedichte und einen etwa im Vergleich zu Mecklenburg geringeren ,Umsiedler'-Anteil aufwies.

Welche Konsequenzen ergaben sich nun aus diesen Rahmenbedingungen für die berufliche Eingliederung der Flüchtlinge und Vertriebenen in den ostdeutschen Arbeitsmarkt ${ }^{36}$ ?

30 Ebenda, Bl. 38.

${ }^{31}$ Zank, Wirtschaft und Arbeit, S. 33.

${ }^{32} \mathrm{Vgl}$. zu diesem Zusammenhang den Beitrag von Boldorf im vorliegenden Sammelband.

33 Vgl. dazu etwa Karlsch, Allein bezahlt, S. 136-150. Die Arbeitskräftemobilisierung für die Wismut AG sowie die Lebens- und Arbeitsbedingungen beschreibt sehr eindringlich Naimark, The Russians in Germany, S. 238-250.

${ }^{34}$ Zank, Wirtschaft und Arbeit, S. 149.

${ }^{35}$ Ebenda.

${ }^{36}$ Unter dem Begriff ,Arbeitsmarkt' wird an dieser Stelle nur der Schnittpunkt verstanden, in dem die Arbeitsnachfrage auf das Arbeitsangebot trifft und in Übereinstimmung gebracht wird. Während in privatkapitalistischen Wirtschaftssystemen dieser Prozeß über den Preismechanismus (Lohn) erfolgt, werden in zentralverwalteten Wirtschaftssystemen, zu denen die der RGW-Staa- 
Zum einen mußten den Zuwanderern neue Beschäftigungsmöglichkeiten geboten werden; zum anderen waren die Umsiedler gezwungen, den Wohnort abermals zu wechseln und sich selber einen Arbeitsplatz zu suchen. Was die Schaffung neuer Arbeitsplätze anbelangte, so nahm die im September 1945 eingeleitete Bodenreform ${ }^{37}$ einen wichtigen Stellenwert ein, den man aber nicht überbewerten sollte. In diesem Zusammenhang sollte nur kurz auf das Gesamtergebnis dieser staatlich verordneten und kontrollierten Neuverteilung von Land eingegangen werden, und zwar in Hinblick auf die Gruppe der ,Umsiedler ${ }^{38}$. Einer statistischen Erhebung vom Sommer 1948 zufolge hatten bis zu diesem Zeitpunkt 88000 Vertriebene Neubauernstellen erhalten; zusammen mit den Familienangehörigen kommt man auf eine Personengruppe von etwa 350000, die durch die Landwirtschaft versorgt werden konnte ${ }^{39}$. Nimmt man die Gesamtgruppe der Vertriebenen zum Maßstab (Ende 1946: 3,9 Millionen), so lag der Anteil unter 10 Prozent. Der Vertriebenenanteil unter den Neubauern lag in allen Ländern der SBZ mit Ausnahme Mecklenburgs - leicht über dem jeweiligen Bevölkerungsanteil. Da die Mehrzahl der Vertriebenen jedoch erst zu einem späten Zeitpunkt in die SBZ gelangte, als sich die Bodenreform schon in einem weit fortgeschrittenen Stadium befand ${ }^{40}$, müssen die angedeuteten positiven Effekte stärker relativiert werden, zumal die weit überwiegende Mehrheit der im primären Sektor tätigen ,Umsiedler' vielmehr als Landarbeiter eine Beschäftigung fand ${ }^{41}$. Weniger von Bedeutung war dagegen die Tatsache, daß eine Reihe von Neubauern, die sich aus Sicht der SED "nicht bewährt hatten“" durch andere Betriebsinhaber ersetzt werden mußten. Für die freiwerdenden Neubauernstellen boten sich - so das SED-Zentralsekretariat - die „antifaschistischen Bauern aus dem Sudetengebiet und aus Polen ${ }^{\text {“43 }}$ an. Diese Zahlen veränderten jedoch das Gesamtergebnis nur unwesentlich. Bei der Behauptung auf dem landwirtschaftlichen Arbeitsmarkt muß ein anderer Zusammenhang noch kurz beleuchtet werden: Für die Vertriebenen, die im Zuge der Bodenreform Land erhalten hatten, bedeutete die Benachteiligung bei der „Verteilung von lebendem und totem Inventar" eine enorme Verschlechterung ihrer Position im Konkurrenzkampf mit den alteingesessenen Bauern ${ }^{44}$. Das führte oftmals dazu, daß zahlreiche ,Umsiedler' schon bald ihre neu erworbenen Höfe aufgeben mußten ${ }^{45}$.

ten zu zählen sind, Preise und Löhne von einer staatlichen Stelle festgesetzt. Insofern kann hierbei nur in einem sehr eingeschränkten Maße von einem Arbeitsmarkt gesprochen werden. $\mathrm{Da}$ zudem aber auch überzeugende, alternative Begriffe fehlen, wird im folgenden vom Arbeitsmarkt die Rede sein. Vgl. zur Unterscheidung der beiden Idealtypen ,Zentralverwaltungswirtschaft' und ,Marktwirtschaft' Gruber/Kleber, Grundlagen, S. 33-52.

${ }^{37}$ Ausführlich zu diesem Themenkomplex der Tagungsband von Bauerkämper, „Junkerland in Bauernhand"?

${ }^{38}$ Vgl. dazu den Beitrag von Bauerkämper im vorliegenden Sammelband.

${ }^{39}$ Zank, Wirtschaft und Arbeit, S. 149. Ende 1946 lag die Zahl der Vertriebenen, die Neubauernstellen erhalten hatten, bei 77971. Vgl. Meinicke, Die Bodenreform und dic Vertriebenen, S. 139.

to Aussprache des Zentralsekretariats der SED mit 30 ,Umsiedlern', vermutlich im Frühjahr 1946, BAB, DO 1/10/4, Bl. 105.

${ }^{41}$ So auch die Schlußfolgerung bei Bauerkämper, Von der Bodenreform zur Kollektivierung, S. 126.

42 Aussprache des Zentralsekretariats der SED mit 30 ,Umsiedlern', vermulich im Frühjahr 1946, $\mathrm{BAB}, \mathrm{DO} 1 / 10 / 4, \mathrm{Bl} .105$.

${ }^{43}$ Ebenda.

${ }^{44}$ Meinicke, Die Bodenreform und die Vertriebenen, S. 140.

${ }^{45}$ Vgl. Schwartz, Vom Flüchtling zum Neubürger, S. 34. 
Daneben erhielt für die Vertriebenen die Heimarbeit zunehmende Bedeutung und wurde staatlicherseits gefördert. Der erhoffte Effekt auf dem Arbeitsmarkt blieb jedoch aus bzw. stellte sich nicht in dem Maße ein, wie es die Arbeitsverwaltung erwartet hatte. Die staatlich unterstützte Gründung von Produktionsgenossenschaften beschränkte sich bei den ,Umsiedlern“ oftmals auf Betriebe, die kunstgewerbliche Produkte herstellten, wie etwa das Beispiel des Gablonzer Kunsthandwerks in Thüringen anschaulich zeigt $^{46}$. Bei der Totalbetrachtung des Arbeitsmarktes in der SBZ und frühen DDR muß die Bedeutung der Produktionsgenossenschaften stark relativiert werden: So arbeiteten 1948 ca. 8000 Vertriebene in 61 Genossenschaften, also 0,6 Prozent der erwerbstätigen ,Umsiedler ${ }^{477}$. Schwierigkeiten ergaben sich für Vertriebene beim Aufbau eigener Handwerksbetriebe. Dies hing mit der unzureichenden Ausstattung mit Werkzeugen, aber auch mit dem Beharrungsvermögen eingesessener Handwerksmeister zusammen, die neue Konkurrenz befürchteten. So wurde auf einer ,Umsiedler'-Konferenz der SED-Führung am 14. Juni 1946 in Berlin allgemein beklagt, daß die Handwerkskammern „Widerstand bei der Selbständigmachung von Umsiedlern“ leisten würden ${ }^{48}$. Die „Niederlassung von selbständigen Umsiedlern“ sei in einigen Orten mit dem Hinweis unterbunden worden, daß ansonsten die „noch in Kriegsgefangenschaft befindlichen Handwerksmeister bei ihrer Rückkehr keine Betätigungsmöglichkeit“ mehr hätten $^{49}$. Der starke Zustrom von Vertriebenen bedeute jedoch ein „Mehrbedarf“ an Arbeitsplätzen im handwerklichen Bereich. Die SED-Führung konnte in dem Zusammenhang nur an die Arbeitsämter appellieren, bei der Vergabe von Arbeitsplätzen ,Umsiedler' bevorzugt zu berücksichtigen. Die eigentlichen Beharrungskräfte gegen eine gleichberechtigte Eingliederung der Vertriebenen befanden sich aber auf der lokalen Ebene. Dort konnte zum Teil erfolgreich der staatlichen Interventionspolitik entgegengesteuert werden.

Da die Bemühungen zur Schaffung neuer Arbeitsplätze am Aufenthaltsort der Vertriebenen insgesamt nur begrenzten Erfolg hatten, waren zahlreiche Vertriebene gezwungen, ihren Wohnort aufzugeben. Ein zweiter Ortswechsel und eine Binnenwanderung waren die Folge. Daneben hatte schon Anfang 1946 eine Weiterwanderung gen Westen eingesetzt. Vor allem die amerikanische Militärregierung empfand diese Zuwanderung als Belastung für die eigene Zone und ging bald dazu über, die Reisen aus der SBZ in die Westzonen - soweit das überhaupt möglich war - zu regulieren und einzuschränken. Ganz anders verhielt sich die britische Besatzungsmacht, die offensichtlich bereit war, alle Neuankömmlinge in ihrer Zone aufzunehmen ${ }^{50}$. Um die massenhafte Abwanderung in den Westen zu stoppen, erließ der Alliierte Kontrollrat auf Antrag der sowjetischen Seite am 30. Juni 1946 eine Grenzsperre für Flüchtlinge aus der SBZ ${ }^{51}$. Eine genaue Quantifizierung dieses Zustroms ist aufgrund der zu diesem frühen Zeitpunkt noch un-

${ }^{46}$ Vgl. Kaltenborn, Der Versuch zur Wiederbelebung des Gablonzer Kunsthandwerks.

${ }^{47}$ Zank, Wirtschaft und Arbeit, S. 150.

${ }^{48}$ Konferenz von Vertretern der ,Umsiedler ${ }^{\star}$ aus den Ländern und Provinzen der SBZ am 14.6. 1946 in Berlin, BAB, DO 1/10/4, Bl. 99.

49 Ebenda, Bl. 100.

${ }^{50}$ Die britische Zone war bei der Behandlung der Deutschen aus der SBZ bis 1949 die treibende Kraft. Vgl. Heidemeyer, Flucht und Zuwanderung, S. 74 u. $83 \mathrm{f}$. Eine konträre Position bezieht Zank, der davon ausgeht, daß die britische Militärregierung am 30.6. 1946 eine vollständige Grenzsperre verhängte. Vgl. Zank, Wirtschaft und Arbeit, S. 150.

51 Heidemeyer, Flucht und Zuwanderung, S. 75. 
vollständigen statistischen Erhebungen kaum möglich; es muß jedoch für die Phase bis zur Staatsgründung der DDR 1949 wahrscheinlich von einigen Tausend ausgegangen werden ${ }^{52}$.

Zielpunkte der eben angesprochenen Binnenwanderung waren vor allem Großbetriebe oder Großprojekte wie beispielsweise der Uranbergbau im Erzgebirge. Nach Ansicht der ZVU war der Arbeitskräftebedarf weitaus größer, als daß er allein von der Gruppe der ,Umsiedler hätte befriedigt werden können ${ }^{53}$. Gleichzeitig wurde aber auch beklagt, daß die Vertriebenen von den Arbeitsämtern oftmals nur als Manövriermasse betrachtet würden. So hätte die Arbeitsverwaltung bei der Durchführung von SMAD-Befehlen zur Zusammenstellung von Arbeitskräftekontingenten „besonders gerne Umsiedler herangezogen ${ }^{454}$. Als Beispiele führte der ZVU-Präsident den Oder-Deichbau und den Bergbau an. Die Notwendigkeit dieser Arbeiten müsse, so Rudolf Engel weiter, „besser popularisiert werden“. Darüber hinaus seien auch die Methoden der Arbeitsverpflichtung zu verbessern. Konkret nannte Engel die katastrophale Lage auf dem Wohnungsmarkt und die Benachteiligung der ,Umsiedler' bei der Vergabe von Wohnraum. In den ersten beiden Nachkriegsjahren war die Versorgung mit Wohnraum und Lebensmitteln etwa für die Bergarbeiter der Wismut AG allgemein schlecht; dies belegen die zahlreichen Berichte der örtlichen Verwaltungen. 1947/48 änderte sich jedoch allmählich die soziale Lage der Beschäftigten im Uranbergbau. In zunehmenden Maße wurden Sonderrationen ausgegeben und bei der Wohnungsvergabe genossen die Wismut-Arbeiter bald Priorität. Diese Entwicklung hing aufs engste mit dem Wechsel der Instrumentarien staatlicher Arbeitskräftelenkung zusammen. Während - vereinfacht gesehen - zuvor die Zwangseinweisung auf der Tagesordnung stand, bemühten sich die Arbeitsbehörden nunmehr, Arbeitskräfte auf freiwilliger Basis zu werben. Dies kam den ,Umsiedlern durchaus entgegen, waren sie doch bei der Vergabe von Wohnraum beispielsweise oft gegenüber der einheimischen Bevölkerung benachteiligt worden. Der Wechsel in der Rekrutierungspolitik gerade für den Uranbergbau, also fort von "harten“ und hin zu „weichen "Maßnahmen, wurde auch dadurch erheblich begünstigt, daß in Gestalt der Vertriebenen ein noch ungebundenes und dringend auf Arbeit und Unterkunft angewiesenes Arbeitskräftereservoir zur Verfügung stand. Im Ergebnis wiesen bereits 1948 die Belegschaften einzelner Großbetriebe einen weit überdurchschnittlichen Anteil an Vertriebenen auf. Für die fünfziger Jahre stellt mit Sicherheit das Eisenhüttenkombinat Ost in Fürstenwalde ein Paradebeispiel für die Eingliederung einer quantitativ nicht unbeträchtlichen Gruppe von ,Umsiedlern' in den Arbeitsmarkt dar. Umfragen zufolge lag der Vertriebenenanteil 1952 in 34 Großbetrieben bei 39 Prozent $^{55}$. An der Spitze befanden sich die Leuna-Werke mit 11800 ,Umsiedlern', was einem Belegschaftsanteil von 47 Prozent entsprach. Auch die Gruben der Wismut AG in Sachsen und Thüringen wiesen einen ho-

52 Nach Angaben Meinickes waren von den mindestens 2,7 Millionen Menschen, die bis zum Mauerbau die DDR verließen, etwa 950000 Vertriebene. Meinicke, Flüchtlinge, S. 79. Vgl. zur Flüchtlingspolitik der Bundesregierung allgemein die detaillierte Studie von Heidemeyer, Flucht und Zuwanderung.

${ }^{53}$ Erfahrungsbericht des Präsidenten der ZVU, Rudolf Engel, o. D. (vermutlich Ende 1947), BAB, DO 1/10/4, Bl. 50 .

${ }^{54}$ Ebenda.

${ }^{55}$ Zank, Wirtschaft und Arbeit, S. 151. Zank stützt sich dabei auf Untersuchungsergebnisse von Seraphim. Vgl. Seraphim, Die Heimatvertriebenen, S. 96. 
hen Anteil auf, in einzelnen Fällen soll der Vertriebenenanteil sogar 80 Prozent betragen haben ${ }^{56}$.

Trotz dieser Erfolge erhöhte sich vom Oktober 1946 bis zum März 1949 die Gesamtzahl der erwerbstätigen Vertriebenen kaum: Zu beiden Zeitpunkten lag sie bei etwa 1,4 Millionen ${ }^{57}$. Der Beschäftigungsanstieg durch Binnenwanderung und Schaffung von Arbeitsmöglichkeiten auf dem Land wurde durch den raschen Anstieg der Arbeitslosigkeit und die zunehmende Konkurrenz mit den Kriegsheimkehrern und die auf den Arbeitsmarkt gedrängten arbeitseinsatzfähigen Frauen wieder zunichte gemacht. Da im selben Zeitraum die Zahl der ,Umsiedler' noch einmal um ca. 700-800000 anstieg, sank somit der Anteil der Erwerbstätigen an der Vertriebenengruppe. Diese Entwicklung kann nur zu einem kleinen Teil durch den andersartigen demographischen Aufbau der Vertriebenengruppe erklärt werden, d. h. also höherer Anteil an Alten, Invaliden und Kranken, die nicht mehr in den Arbeitsmarkt eingebunden werden konnten. Es muß insgesamt festgestellt werden, daß die ,Umsiedler' auf dem Arbeitsmarkt auch noch 1949 erheblich benachteiligt waren. $\mathrm{Da}$ angesichts der Eigentumsverluste und der eher bescheidenen staatlichen Unterstützung, die zunächst nur eine ad-hoc-Maßnahme darstellte und die erste Not lindern konnte, das Überleben von einer Erwerbstätigkeit abhing, waren die Vertriebenen in doppelter Hinsicht benachteiligt. Die Lösung der Integrationsaufgabe stand somit bei der Gründung der DDR im Oktober 1949 noch aus.

\section{SED, staatliche Verwaltung und die, arbeitsmarkt'-politischen Programme zugunsten der, Umsiedler'}

Erste Voraussetzung für eine erfolgreiche Arbeitsplatzvermittlung blieb, wie schon eingangs erwähnt, die Registrierung der arbeitsfähigen Bevölkerung durch die Arbeitsämter. In den Monats- und Quartalsberichten, die auf Landes- und auf Zentralebene gebündelt wurden, tauchen die ,Umsiedler' nur bis Anfang 1949 als Gesamtgruppe auf. Für die Arbeitsverwaltung existierten noch eine ganze Reihe anderer sozialer Gruppen, deren berufliche Integration problematisch erschien. Dies waren vor allem die Frauen und die Schwerbeschädigten ${ }^{58}$. Die statistische Erfassung der arbeitsfähigen, erwerbstätigen und arbeitslosen ,Umsiedler' bricht Ende Mai 1949 aufgrund eines Erlasses der zuständigen Hauptverwaltung für Arbeit und Sozialfürsorge (HVAS) $\mathrm{ab}^{59}$. Inwieweit die SED-Führung hinter diesem Beschluß stand, kann aus der Retrospektive nicht mehr ermittelt werden. $\mathrm{Zu}$ vermuten wäre auch, daß dieser Schritt als verspätete Konsequenz der Auflösung der Flüchtlingssonderverwaltung ZVU und ihrer Eingliederung in die Innenverwaltung erfolgte $e^{60}$.

Aufnahme und Eingliederung von Flüchtlingen und Vertriebenen war in der Anfangszeit zunächst eine Aufgabe der Landes- und Provinzialverwaltungen. Sie konnten sich in dieser frühen Phase (1945/46) den besten Überblick über den genauen Zustrom der ,Um-

56 Seraphim, Die Heimatvertriebenen, S. 97. Der Autor zitiert an dieser Stelle Informationsberichte, ohne deren Herkunft anzugeben.

$57 \mathrm{Zu}$ diesem Urteil kommt Zank. Vgl. Zank, Wirtschaft und Arbeit, S. 151.

58 Vgl. dazu Boldorf, Eingliederung der Kriegsopfer und Schwerbeschädigten.

59 Dies geht aus einem Schreiben des Ministers für Arbeit und Sozialpolitik der Landesregierung Sachsen-Anhalt vom 14. 7. 1949 an die HVAS hervor, BAB, DQ 2/1082.

60 Vgl. zum Auflösungsprozeß der ZVU Schwartz, Zwischen Zusammenbruch und Stalinisierung, S. 57-59. 
siedler' verschaffen, während die im Spätsommer 1945 aufgebauten Zentralverwaltungen noch keine Vorstellungen über die damit zusammenhängenden Probleme besaßen. Die für die Registrierung der ,Umsiedler zuständige ZVAS versuchte allerdings rasch, die Aktivitäten der Länder bzw. Provinzen zu koordinieren. Dabei wurde der berufsmäßigen Registrierung der Vertriebenen große Bedeutung beigemessen, da dies eine zentrale Voraussetzung für die Lenkung des Flüchtlingsstroms war. Anfang Oktober 1945 lagen nur für die Länder Brandenburg, Mecklenburg sowie für die Provinz Sachsen erste Zahlenangaben vor ${ }^{61}$. Eine restlose Zählung der Flüchtlinge konnte nach Angaben der ZVAS erst Ende 1945 beginnen: Es sei anzunehmen, daß „mit Anbrechung der kalten Jahreszeit und Abebben des Zustroms neuer Flüchtlinge, [...], die Flüchtlinge nunmehr im allgemeinen eine feste Unterkunft gefunden haben. ${ }^{\circ 6}$

Aufgrund von ersten Statistiken einzelner lokaler Behörden glaubte die ZVAS einen ersten, vorläufigen Plan zur beruflichen Eingliederung der Vertriebenen ausarbeiten zu können. Sie ging davon aus, daß „der größte Teil der männlichen Bevölkerung [gemeint ist die Gruppe der Flüchtlinge] aus Altersgründen nicht voll arbeitsfähig, aber in der Landwirtschaft als Landarbeiter oder in männerlosen Bauernwirtschaften oder als Siedler untergebracht werden kann. “63 Für die landwirtschaftlichen Berufe sei „erfahrungsgemäß [...] ,Voll-Arbeitsfähigkeit" im städtischen Sinne nicht Voraussetzung der Einsatzfähigkeit". Im primären Sektor müßten daher - so die Schlußfolgerung der Zentralverwaltung - zusätzliche Arbeitsplätze geschaffen werden. Dies könne aber mit Aussicht auf Erfolg nur durch „Zwangsauflage von Arbeitskräften, verteilt auf die einzelnen Betriebe“ erfolgen. Eine solche Maßnahme, die Widerspruch hervorrufen werde, diene unter anderem auch der Intensivierung der landwirtschaftlichen Erzeugung. Die Eingliederung der Jugendlichen in den Arbeitsprozeß schätzte die ZVAS nur als "vorübergehend[es]“ Problem ein. Die Jugend stellte nach den Vorstellungen der ZVAS die wichtigste Arbeitskraftreserve für die Mangelberufe dar. Dagegen wurde die berufliche Eingliederung von Frauen als äußerst problematisch angesehen, da bereits bei der einheimischen weiblichen Bevölkerung eine hohe Arbeitslosigkeit herrsche ${ }^{64}$. Der von der ZVAS ausgearbeitete Plan zeigte, daß die Zentralverwaltung zu diesem Zeitpunkt noch keine genauen Zahlen-• angaben über die Verteilung der ,Umsiedler ' in den einzelnen Ländern bzw. Provinzen besaß und daher nur allgemeine Aussagen machen konnte. Darüber hinaus fällt die besondere Hervorhebung der Landwirtschaft auf. Angesichts der Demontagen industrieller Anlagen, die gleich nach Kriegsende begannen, und der ungelösten Transportprobleme schien für die Zentralverwaltung der primäre Wirtschaftssektor die besten Möglichkeiten zur beruflichen Eingliederung von ,Umsiedlern' zu bieten.

Die unterschiedlichen Arbeitsmarktbedingungen in den Ländern und Provinzen der SBZ machten aus Sicht der Arbeitsverwaltung eine koordinierte Binnenwanderung der ,Umsiedler' erforderlich. Dadurch erhoffte man sich eine rasche berufliche Eingliederung der Zugewanderten entsprechend ihrer Qualifikation. Eine berufsmäßige Erfassung der

61 Bericht der Abt. II (Erfassung und Arbeitseinsatz der Bevölkerung) der ZVAS vom 5. 10. 1945, BAB, DO 1/10/58, B1. 90-94. Die Zahlen lauteten für Brandenburg (700000), Provinz Sachsen (2 Millionen) und Mecklenburg (1 Millionen). Die ZVAS ging zu diesem Zeitpunkt davon aus, daß insgesamt 12 Millionen Flüchtlinge in der SBZ „untergebracht werden müssen“. Vgl. ebenda, Bl. 90.

62 Ebenda.

${ }_{63}$ Ebenda, B1. 92.

64 Ebenda, Bl. 93. 
arbeitsfähigen ,Umsiedler' in 2716 Gemeinden Sachsen-Anhalts hatte ergeben, daß 33 Prozent in ihren erlernten Berufen wieder eingesetzt werden konnten ${ }^{65}$. Ein weiteres Drittel war arbeitslos gemeldet und etwa zwölf Prozent der Vertriebenen mußte in einem fremden Beruf arbeiten ${ }^{66}$. Aus Sicht des Vizepräsidenten der ZVU, Michael Tschesno, waren diese Zahlenangaben aber nur bedingt aussagekräftig. So würden viele ,Umsiedler ihren erlernten Beruf oftmals nicht angeben, um ihre neue Arbeitsstelle nicht wechseln zu müssen.

ZVAS und ZVU erblickten in der auf die Erfordernisse des Arbeitsmarktes zugeschnittenen „Lenkung“ von Flüchtlingen innerhalb der SBZ eine Möglichkeit, den unkontrollierten Zustrom, der bis zum Jahreswechsel 1945/46 angehalten hatte, nachträglich doch noch zu korrigieren. Da sich aber auch schon lokale Verwaltungen anschickten, Vertriebene in andere Gebiete abzuschieben ${ }^{67}$, wollten die beiden Zentralverwaltungen darüber hinaus erreichen, daß der Personentransfer zwischen den Ländern und Provinzen koordiniert, d. h. unter der Regie der jeweiligen Arbeits- und Umsiedlerämter ablief. Vor allem die ZVAS drängte darauf, daß „bei der Lenkung von Umsiedlern aus einer in die andere Provinz vorher die Zustimmung der betreffenden Landesarbeitsämter eingeholt" werden müsse ${ }^{68}$. Es sei „unmöglich, daß einzelne Firmen qualifizierte Arbeiter aus Umsiedlerkreisen, die sich in einer anderen Provinz befinden, ohne die Genehmigung des überbezirklichen Austausches einstellen. ${ }^{69}$ ZVAS und ZVU trafen sogar eine Abmachung, wonach Transporte nur nach vorheriger Vereinbarung mit den Landesarbeitsämtern und den Umsiedlerabteilungen des abgebenden und des aufnehmenden Landes zu genehmigen waren ${ }^{70}$. Obwohl diese Abmachung von der SMAD in Karlshorst gebilligt worden war, setzten sich einzelne sowjetische Dienststellen auf der Landesebene darüber hinweg. So war auf Befehl der SMA Mecklenburg am 8. November 1946 ein Transport von Textilarbeitern nach Sachsen abgeschickt worden, der dort von der Landesverwaltung nicht betreut werden konnte, weil weder die Landesarbeitsämter noch die Umsiedlerämter in diese Aktion eingeweiht waren. Daraufhin wurde die ZVU bei der SMAD in Karlshorst vorstellig und bat, „die SMA in den Ländern und Provinzen auf diese Vereinbarungen hinzuweisen. "71

Die organisatorischen Schwierigkeiten bei der Übersiedlung von arbeitsfähigen Vertriebenen in andere Länder sollen im folgenden am Beispiel der Textil-, Glas- und Bergarbeiter in Mecklenburg veranschaulicht werden. Die Konflikte zwischen den beiden

${ }^{65}$ Denkschrift Tschesnows, o. D. (vermutlich vom Sommer 1946), BAB, DO 1/10/4, Bl. 88.

${ }^{66}$ Der Rest entfiel mit 15 Prozent auf die Kategorie „Hausfrau“ sowie sieben Prozent „Einsatzunfähige“. Vgl. ebenda. Ähnliche Zahlenangaben finden sich auch bei Zank, Wirtschaft und Arbeit, S. 149.

67 $\mathrm{Zu}$ den Motiven der lokalen Verwaltungsstellen zählten neben der jeweiligen Arbeitsmarktlage auch die z. T. katastrophale Lage auf dem Wohnungsmarkt.

${ }^{68}$ Dies geht aus einer Aktennotiz der Organisationsabteilung der ZVU vom 6. 9. 1946 hervor, BAB, DO 1/10/58, Bl. 115.

${ }^{69}$ Ebenda.

70 Vgl. Aktennotiz der Organisationsabteilung der ZVU vom 24. 9. 1946, BAB, DO 1/10/58, Bl. 118. Der ZVU-Präsident teilte der SMAD den Inhalt dieser Vereinbarung einige Wochen später mit. Vgl. Schreiben vom 12.11. 1946 an den Chef der Abteilung für Zivilangelegenheiten, Statistik und Verteilung der deutschen Umsiedler bei der KDV-SMAD, BAB, DO 1/10/58, Bl. 30.

71 Schreiben des Vizepräsidenten der ZVU, Michael Tschesno, vom 28.11. 1946 an den Chef der Abteilung für Zivilangelegenheiten, Statistik und Verteilung der deutschen Umsiedler bei der KDV-SMAD, BAB, DO 1/10/58, Bl. 31. 
Zentralverwaltungen ZVAS und ZVU auf der einen Seite und den Landesverwaltungen auf der anderen Seite treten dabei deutlich hervor. Vertreter der Deutschen Verwaltung für Arbeit und Sozialfürsorge (DVAS), der ZVU und des FDGB hatten bei einer Besprechung gemeinsam festgestellt, daß sich im nördlichsten Land der SBZ zahlreiche Textil-, Glas- und Bergarbeiter aufhielten, die dort nicht benötigt würden ${ }^{72}$ und statt dessen in Sachsen angesiedelt werden sollten ${ }^{73}$. Aufgrund des bei Kriegsende zusammengebrochenen Verkehrsnetzes und der vordringlichen Bereitstellung von Eisenbahnzügen für die sowjetische Besatzungsmacht mußte der Personentransport aus Mecklenburg nach Sachsen mehrmals verschoben werden ${ }^{74}$. Erst Anfang Mai 1947 konnte mit den ersten Transporten begonnen werden ${ }^{75}$.

Die sächsische Landesverwaltung hatte frühzeitig versucht, die Zahl der aufzunehmenden ,Umsiedler' mit dem Aufnahmekontingent, welches Sachsen zu erfüllen hatte, verrechnen zu lassen. Die Umsiedlungsaktion sollte mit anderen Worten dazu genutzt werden, den sächsischen Arbeitsmarkt zu bereinigen: Textilfacharbeiter, die man selber brauchte, sollten aufgenommen werden und im Gegenzug arbeitslose Vertriebene, für die kein Arbeitsplatz bereitgestellt werden konnte, abgeschoben werden. Die ZVU hatte sich ganz entschieden gegen diesen Vorschlag ausgesprochen ${ }^{76}$. In der Praxis schien sich jedoch zunächst der vom sächsischen Landesarbeitsamt favorisierte Weg durchzusetzen: Mecklenburgs Landesverwaltung erklärte sich bereit, im Gegenzug eine entsprechende Anzahl von Vertriebenen aus Sachsen aufzunehmen. Das Zentralsekretariat der SED stoppte diesen Handel im Spätsommer 1947 und erklärte, es könne nicht angehen, daß Sachsen die so dringend benötigten Facharbeiter auf das Aufnahmesoll an ,Umsiedlern angerechnet bekomme ${ }^{77}$.

Als weiterer Konfliktpunkt erwies sich die Frage, aus welchen Haushaltsmitteln die anfallenden Transportkosten zu begleichen waren. Obwohl sich die beteiligten Landesverwaltungen mit der ZVU darauf geeinigt hatten, daß das jeweils „abgebende Land“ die Transportkosten übernehmen sollte, fühlte sich das Landesarbeitsamt Schwerin an diese Vereinbarung nicht mehr gebunden ${ }^{78}$. Auch in dieser Frage scheinen sich DVAS und ZVU gegenüber den Landesverwaltungen durchgesetzt zu haben. Sehr viel größeren Erfolg hatten jedoch die Länder bei ihrer Auseinandersetzung mit den beiden Berliner Zentralverwaltungen, wenn sie auf die eigene angespannte Arbeitsmarktsituation verwie-

72 Bericht über die Besprechung bei der DVAS am 27. 11. 1946, BAB, DO 1/10/30, Bl. 198.

73 Aktennotiz Riedels (Abt. Organisation), o. D. (handschriftlich: 15. 12. 1946), BAB, DO 1/10/30, Bl. 199.

${ }^{74}$ So hatte die SMA in Mecklenburg noch im November angeordnet, daß bis zum 1.12. 1946 kein „Transportraum“ zur Verfügung gestellt werden darf. Vgl. Aktennotiz Riedels (ZVU) vom 28. 11. 1946, BAB, DO 1/10/58, Bl. 144.

${ }^{75}$ Schreiben des Landesarbeitsamtes Sachsen vom 22.5. 1947 an die ZVU, BAB, DO 1/10/58, Bl. 185. Eine Gesamtzahl der umzusiedelnden Vertriebenen taucht nicht auf. Es muß sich jedoch um einige Tausend gehandelt haben. So weigerte sich etwa im März 1947 das Amt für Neubürger in Weimar 20000 Textilfacharbeiter aus Mecklenburg aufzunehmen. Zwischenzeitlich war auch Thüringen als Bestimmungsland für die ,Umsiedler' auserwählt worden. Vgl. Schreiben der DVAS vom 4. 3. 1947 an die ZVU, BAB, DO 1/10/58, Bl. 166.

${ }^{76}$ Schreiben Chwalczyks vom 20. 8. 1946 an das Landesarbeitsamt Sachsen, SächsHStA, Landesregierung Sachsen, Ministerium für Arbeit und Sozialfürsorge, Bd. 416.

77 Schreiben der Abt. Arbeit und Sozialfürsorge beim Zentralsekretariat der SED vom 5. 9. 1947 an den Vizepräsidenten der ZVU, Philipp Daub, BAB, DO 1/10/58, Bl. 208.

${ }^{78}$ Schreiben des sächsischen Landesarbeitsamtes vom 22. 5. 1947 an die ZVU, BAB, DO 1/10/58, Bl. 185 . 
sen. Auf diesem Wege gelang es beispielsweise Thüringen, die Übernahme von 20000 Textilfacharbeitern ${ }^{79}$ aus Mecklenburg abzuwenden. So erklärte das Amt für Arbeit und Sozialfürsorge in Weimar, daß die Textilindustrie in Thüringen aufgrund von Rohstoffmangel „nur noch in halber Schicht“ arbeiten würde ${ }^{80}$. Damit gelang es der thüringischen Arbeitsverwaltung zunächst einmal den Zeitpunkt der Umsiedlungsaktion hinauszuschieben. Ob die Übernahme der Textilfacharbeiter aus Mecklenburg in Thüringen überhaupt verwirklicht wurde, läßt sich an Hand der Aktenüberlieferung nicht mehr klären.

Bei der Arbeitsmarktintegration der Vertriebenen mußten sich zwangsläufig Kompetenzkonflikte auch zwischen den beteiligten Zentralverwaltungen, der ZVAS und der ZVU, ergeben, die aus dem Konkurrenzverhältnis zweier kooperierender Behörden herrührten. Die Zusammenarbeit mußte erst eingeübt werden und verlief keineswegs konfliktfrei. So beklagte etwa der DVAS-Präsident Gustav Brack am 11. Oktober 1946, daß die ZVU noch nicht ihre Zustimmung gegeben habe für die „Umsetzung“ von Textilund Bergarbeitern aus Mecklenburg, die in Halle, aber auch in Sachsen und Thüringen dringend benötigt würden. Es wäre „betrüblich“, wenn diese Aktion am hinhaltenden Widerstand der ZVU scheitern würde ${ }^{81}$. Er unterstrich, daß die Vermittlung von Arbeitskräften ausschließlich der DVAS übertragen worden sei. Die ZVU verwies ihrerseits darauf, daß die Zustimmung für eine Überführung der Arbeitskräfte nur dann gegeben werden könne, wenn die „wohnungsmäßige Unterbringung“ gesichert sei ${ }^{82}$. Der Konflikt hatte deutlich gemacht, daß die Arbeitsvermittlung allein zum Tätigkeitsbereich der DVAS gehörte, was die ZVU auch anerkennen mußte. Der ,Umsiedler'-Sonderverwaltung verblieb nur die Möglichkeit, unter Hinweis auf die schlechte Wohnraumversorgung einzelne ,Umsiedler'-Transporte zeitlich hinauszuzögern.

Auffallend ist, daß die ZVU besonders die Tätigkeit der Arbeitsämter wiederholt kritisierte, denen sie mangelnde Rücksichtnahme gegenüber den Flüchtlingen und Vertriebenen vorwarf. So wurde der Arbeitsverwaltung etwa auf einer ,Umsiedler'-Konferenz am 14. Juni 1946 vorgehalten, daß sie bei der beruflichen Eingliederung versagen würde ${ }^{83}$. An dieser Kontroverse zeigte sich aber auch, daß die berufliche Integration der Vertriebenen aufs engste mit anderen Problembereichen verknüpft war, besonders mit der unzureichenden und mangelhaften Wohnraumversorgung. Die ZVU stellte sich auf den Standpunkt, daß erst nach Zuweisung eines Arbeitsplatzes die Beschaffung von Wohnraum sinnvoll sei. Genau umgekehrt argumentierte die ZVAS sowie die ihr unterstellten Arbeitsämter. Die Wohnungsämter ihrerseits verlangten den Nachweis eines Arbeitsplatzes als Voraussetzung für die Zuteilung von Wohnraum. Auf diese Art und Weise wurden die ,Umsiedler' letztlich von einer Institution zur anderen weitergereicht. Die Auseinandersetzung zwischen Arbeits- und ,Umsiedler'-Verwaltung zog sich trotz Klärung der jeweiligen Zuständigkeitsbereiche noch bis 1948 hin. In einer Denkschrift, die während der Auflösung der ZVU und vor der Neuorganisation innerhalb der Deutschen Ver-

79 Nach Angaben der ZVU handelte es sich hierbei um 20000 ,Umsiedler', d. h. einschließlich der Familienangehörigen. Vgl. Schreiben der ZVU vom 14. 3. 1947 an die DVAS, BAB, DO 1/10/ 58, Bl. 169.

${ }^{80}$ Zitiert nach Schreiben der DVAS vom 4. 3. 1947 an die ZVU, BAB, DO 1/10/58, Bl. 166.

${ }^{81}$ Schreiben Bracks vom 11. 10. 1946 an den ZVU-Präsidenten, BAB, DO 1/10/58, Bl. 120.

82 Schreiben des ZVU-Präsidiums vom 2. 11. 1946 an den DVAS-Präsidenten Brack, BAB, DO 1/ 10/58, Bl. 128.

${ }^{83}$ Bericht über die Konferenz von Vertretern der ,Umsiedler' aus den Ländern und Provinzen der SBZ am 14. 6. 1946 in Berlin, BAB, DO 1/10/4, Bl. 98-101, hier Bl. 99. 
waltung des Innern (DVdI) im Frühjahr/Sommer 1948 entstand, verlangte der bisherige Abteilungsleiter Chwalczyk eine Verbesserung der Tätigkeit der Arbeitsämter. In der ihm eigenen Behördensprache versuchte er nochmals deutlich zu machen, daß die Arbeitsverwaltung die „endgültige Wiederseßhaftmachung “ der ,Umsiedler ${ }^{`}$ zu fördern habe ${ }^{84}$. Es müsse alles getan werden, um den Vertriebenen das Gefühl zu vermitteln, „einen Dauerwohnplatz mit gesicherter Existenz gefunden zu haben." ${ }^{\text {" } 5}$

Aus Sicht der ZVAS blieb jedoch die Vermittlung eines Arbeitsplatzes mit der Wohnraumfrage gekoppelt, die im Untersuchungszeitraum nie befriedigend gelöst werden konnte. Darüber hinaus stellten die ,Umsiedler' für die Arbeitsverwaltung nur eine Personengruppe von vielen anderen dar, die in den Arbeitsmarkt einzubinden war. Im Zuge der anvisierten Steigerung der Erwerbstätigenzahlen waren aus Sicht der Arbeitsämter auch Frauen und Schwerbeschädigte von Bedeutung. Wie bei den ,Umsiedlern' ergaben sich auch hierbei erhebliche Schwierigkeiten bei der beruflichen Eingliederung.

Die Binnenumsiedlung aufgrund von arbeitsmarktpolitischen Überlegungen beschränkte sich jedoch nicht nur auf die Vertriebenen, sondern konnte auch die einheimische Bevölkerung betreffen. Für die ersten Jahre der SBZ wäre vor allem die Arbeitskräftelenkung für den Uranbergbau zu nennen ${ }^{86}$. Auch für andere Wirtschaftsbereiche wie etwa die Landwirtschaft läßt sich eine z. T. umfangreiche Lenkung von Arbeitskräften nachweisen. Einzelne Landesverwaltungen versuchten in dem Zusammenhang entsprechende Verordnungen auszuarbeiten, um dem Umfang und der Durchführung dieser Binnenumsiedlung einen gesetzlichen Rahmen zu geben. So legte beispielsweise die Abt. Bevölkerungspolitik der Landesregierung Sachsen-Anhalt am 27. April 1949 einen ersten Verordnungsentwurf vor, der die „Umsetzung von Personen aus arbeitsmäßigen Gründen" nur in bestimmten, klar abgegrenzten Fällen zulie ${ }^{87}$. Zuerst müßten die „Möglichkeiten einer Arbeitsplatzvermittlung in der Nähe des Wohnortes des Betroffenen oder die Wohnmöglichkeiten für Produktivkräfte in Arbeitszentren [ausge]schöpft" werden ${ }^{88}$. Die DVdI verhielt sich dagegen in dieser Frage sehr viel zurückhaltender: Man könne nicht davon ausgehen, daß allein mit Hilfe der Binnenumsiedlung die bestehenden wirtschaftlichen Probleme zu lösen seien. Als weitere Instrumentarien nannte die DVdI die Wohnraumbewirtschaftung und die Sozialfürsorge. Zunächst einmal sollten die wirtschaftlichen Schwerpunktgebiete, der jeweilige Arbeitskräftebedarf und die konkrete Lage auf dem Wohnungssektor festgestellt werden. Erst danach sei eine Umsiedlung in Erwägung zu ziehen ${ }^{89}$. Einen Monat später wurde die DVdI noch deutlicher, als sie erklärte, daß „die Frage der Umsetzung von Personen aus arbeitsmäßigen Gründen (Binnenumsiedlung) nicht auf dem Verordnungswege gelöst werden kann. ${ }^{“ 90}$ Die „Wechselbeziehungen zwischen Wirtschaft und Bevölkerung“ seien in der SBZ „recht verschie-

${ }^{84}$ Denkschrift Chwalczyks vom 14. 4. 1948, BAB, DO 1/10/1, Bl. 116-123, hier Bl. 117.

${ }^{85}$ Ebenda.

${ }^{86}$ Dies wird ein Aspekt einer geplanten monographischen Darstellung über die Arbeitskräftelenkung zwischen 1945 und 1965 sein, die der Verfasser z.Zt. vorbereitet.

$87 \mathrm{BAB}, \mathrm{DO} 1 / 10 / 58, \mathrm{Bl} .70-72$.

${ }^{88}$ Verordnungsentwurf vom 27. 4. 1949, $\ 2$, Abs. 1, BAB, DO 1/10/58, Bl. 70.

${ }^{89}$ Entwurf über eine Binnenumsiedlung von der DVdI (HA Verwaltung) vom 25. 5. 1949, BAB, DO $1 / 10 / 58, \mathrm{Bl} .73-77$.

90 Stellungnahme der HA Verwaltung der DVdI vom 23.6. 1949 zum Verordnungsentwurf der Landesregierung Sachsen-Anhalt, BAB, DO 1/10/58, BI. 82. 
denartig und bedürfen jeweils grundlegender Vorarbeiten und Verhandlungen mit allen beteiligten Stellen. “91 Gleichwohl befürwortete die Innenverwaltung eine zoneneinheitliche Regelung für die „Umsetzung von Personen über die Landesgrenzen“, für die die bestehenden gesetzlichen Bestimmungen aber ausreichen würden. Damit war der Versuch vorerst gescheitert, eine Verordnung zur Arbeitskräftelenkung der Vertriebenen zu beschließen.

Die Führungsgremien der SED befaßten sich kaum mit dem Problem der Eingliederung der ,Umsiedler' in den Arbeitsmarkt der SBZ/DDR. So zeigt die systematische Durchsicht der Protokolle des Zentralsekretariats, des Politbüros und des Kleinen Sekretariats, daß die Führungsspitze der Hegemonialpartei keinerlei Beschlüsse in dieser Angelegenheit faßte. Auch im Zuge des Aufbaus einer zentralen Wirtschaftsplanung war die berufliche Eingliederung der Vertriebenen von untergeordneter Bedeutung. So versuchte die neu gebildete Hauptabteilung Umsiedler und Heimkehrer der DVdI im August 1948 einen „Ergänzungsplan für den Einsatz der Umsiedler bei der Durchführung des 2-Jahresplans“ einzubringen. Eingangs erklärte der Verfasser und ehemalige ZVUMitarbeiter, Wilhelm Thiele ${ }^{92}$, daß die Erfüllung dieses Wirtschaftsplanes nicht nur von der Erfassung aller „materieller Reserven und Möglichkeiten, sondern auch von der Mobilisierung der vorhandenen Arbeitskräfte und ihrem zweckentsprechenden Einsatz" abhinge ${ }^{93}$. Um den Mangel an Arbeitskräften in der Industrie zu beheben, sei die stärkere Eingliederung der Frauen in den Produktionsprozeß und die Erfassung aller „in der Masse der Umsiedler noch vorhandenen Reserven an arbeitsfähigen Menschen notwendig“. Gleichzeitig wies er auf grundlegende Mißstände hin, die einer Realisierung der im Zweijahresplan formulierten Ziele im Wege stehen würden. So seien zahlreiche ,Umsiedler' berufsfremd eingesetzt worden. Die Gründe dafür lagen nach Angaben Thieles vor allem darin, daß entweder entsprechende Beschäftigungsmöglichkeiten am Wohnort des bzw. der Vertriebenen oder ausreichender Wohnraum fehlen würden. Damit hatte er die bereits bekannten Problemkreise wieder angesprochen. Des weiteren hätten - so Thiele weiter - zahlreiche ,Umsiedler' bevorzugt eine landwirtschaftliche Tätigkeit aufgenommen, da hier in der Regel die Versorgung mit Lebensmitteln und Wohnraum besser sei. Diese Hindernisse waren bestimmend gewesen für die Integrationspolitik in den Jahren von 1945 bis 1950 und konnten nie zur Zufriedenheit der staatlichen Behörden aus dem Weg geräumt werden. Aufschlußreich ist aber in unserem Zusammenhang, daß der Vorschlag des früheren ZVU-Mitarbeiters keinerlei Berücksichtigung fand bei der Ausarbeitung des Zweijahresplanes. Auch dies war ein Indiz dafür, daß die SED-Führung eine gesonderte Förderung der, Umsiedler` im Rahmen der allgemeinen Wirtschaftsplanung ablehnte.

In den wenigen Sitzungen des Kleinen Sekretariats bzw. des Sekretariats des ZK, bei denen die Vertriebenenproblematik auf der Tagesordnung stand, beschränkten sich die Gremienvertreter darauf, einen völlig unverbindlichen Maßnahmenkatalog zur Arbeitsmarktintegration der ,Umsiedler` zu verabschieden. So stimmte das Kleine Sekretariat

${ }^{1}$ Ebenda.

92 Thiele war seit 1946 Leiter der Abt. Arbeitseinsatz der ZVU und wechselte noch im Laufe des Jahres 1948 auf den Posten des Bezirksbürgermeisters von Berlin-Mitte. Zwischen 1956 und 1958 war er stellvertretender Oberbürgermeister von Berlin (Ost). SBZ-Handbuch, S. 1042.

93 Richtlinien für dic Aufstellung eines Ergänzungsplans für den Einsatz der Umsiedler bei der Durchführung des Zweijahresplans vom 4. 8. 1948, BAB, DO 1/10/1, Bl. 199. 
auf seiner Sitzung am 23. Mai 1949 einer Vorlage über „Maßnahmen im Interesse der Umsiedler" $\mathrm{zu}^{94}$. Die HVAS wurde aufgefordert, den Arbeitsämtern die Anweisung zu geben, die arbeitsfähigen ,Umsiedler' zu erfassen, welche noch keinen Arbeitsplatz hatten. Darüber hinaus wollte das SED-Gremium über das Ausmaß des fremdberuflichen Arbeitseinsatzes informiert werden, um so eine Lenkung der frei werdenden Arbeitskräfte zu den Industrieschwerpunkten des Landes veranlassen zu können. Als wirtschaftliche Zentren, die aus Sicht der SED Priorität genossen, wurden die im Aufbau befindlichen Werften Mecklenburgs und der Mansfelder Kupferbergbau genannt. Offenkundig hatte sich dort relativ kurzfristig ein Arbeitskräftemangel bemerkbar gemacht. Der Maßnahmenkatalog erstreckte sich jedoch nicht nur auf die Lenkung, sondern auch auf die Mobilisierung zusätzlicher Arbeitskräfte. Neben den bereits erwähnten arbeitsfähigen ,Umsiedlern' ohne Arbeitsstelle waren damit vor allem die arbeitsfähigen „Umsiedlerfrauen“ gemeint, die mit dem Ziel umgeschult werden sollten, „männliche Arbeitsplätze für die Produktionsschwerpunkte freizustellen." Das Kleine Sekretariat faßte seine Beschlüsse jedoch unverbindlich und ohne zeitliche Vorgaben für die zuständigen Arbeitsämter. Bezeichnend dafür ist auch die Tatsache, daß das SED-Gremium in seinen folgenden Sitzungen auf diesen Beschluß nicht mehr zurückkam.

Einen etwas anderen Stellenwert nahm die Vertriebenengruppe beim Fünfjahresplan ein, den das Politbüro im April 1950 beriet und kurze Zeit später verabschiedete ${ }^{95}$. Darin forderte das Politbüro, daß die ,Umsiedler' als „gleichberechtigte Staatsbürger in den Produktionsprozeß einzureihen" seien ${ }^{96}$. Darüber hinaus sollten sie bevorzugt mit Einrichtungsgegenständen und Gebrauchsgütern versorgt werden; den arbeitsunfähigen $\mathrm{Al}-$ ten sei zudem eine Sozialrente zu gewähren. Über diese unverbindlichen Absichtserklärungen, die immerhin eine Bevorzugung der Vertriebenen auf dem Arbeitsmarkt in Aussicht stellten, ging das Politbüro jedoch nicht hinaus. Eigentlicher Hintergrund für dieses Entgegenkommen - zuvor waren die ,Umsiedler' von der SED-Führung bei den wirtschaftspolitischen Konzeptionen weitgehend ignoriert worden - bildete das Ziel, die Zahl der Erwerbstätigen erheblich zu erhöhen. So sah der Direktivenentwurf des Politbüros für den Fünfjahresplan eine Erhöhung des Beschäftigtenstandes um immerhin ein Drittel vor ${ }^{97}$. Dabei wurden unter anderem die Vertriebenen als eine der Arbeitskraftreserven angesehen, die verstärkt in den Produktionsprozeß einzugliedern waren. Die industriellen Schwerpunkte dieses utopisch anmutenden Programms sollten nach den Vorstellungen der SED folgende Wirtschaftsbranchen sein: Metallurgie, Maschinenbau, Elektrotechnik, Feinmechanik und Optik sowie Chemische Industrie. Ein eigenes arbeitsmarktpolitisches Programm für die ,Umsiedler' wurde allerdings auch zu diesem Zeitpunkt nicht beschlossen.

Obwohl Ministerpräsident Otto Grotewohl in seiner Regierungserklärung am 12. Oktober 1949 unter den Sofortmaßnahmen die weitere Eingliederung der ,Umsiedler' als eine moralische Verpflichtung hervorgehoben und damit indirekt Handlungsbedarf deutlich gemacht hatte, trat erst ein Jahr später das „Gesetz über die weitere Verbesserung der

94 SAPMO, DY 30/J IV 2/3/29, Bl. 9. Die folgenden Zitate stammen aus der Anlage zu diesem Tagesordnungspunkt, in: ebenda, Bl. $21 \mathrm{f}$.

95 Protokoll der Sitzung des Politbüros vom 25. 4. 1950, SAPMO, DY 30/IV 2/2/85, B1. 89. Die Direktive für den Fünfjahresplan ist allerdings nur im Arbeitsprotokoll enthalten.

${ }^{96}$ Direktive des Politbüros der SED zur Ausarbeitung des Fünfjahresplanes der Volkswirtschaft (1951-1955), ebenda, Bl. 79-88, hier Bl. 87.

97 Ebenda, Bl. 86. 
Lage der ehemaligen Umsiedler in der DDR" in $\mathrm{Kraft}^{98}$. Das Gesetz war zwar von der Volkskammer verabschiedet worden, die eigentliche Arbeit hatte aber wieder einmal das SED-Politbüro geleistet. Das Gesetz sah in erster Linie weitere Hilfsmaßnahmen zugunsten der Neubauern in Form von Wohnungsbauförderung und die Vergabe von Krediten an Handwerksbetriebe vor. Gesonderte Beschäftigungsprogramme für arbeitslose ,Umsiedler' enthielt es jedoch auch nicht.

Eine Denkschrift des DWK-Sekretariats im Sommer 1949 machte deutlich, daß auch in Zukunft nicht mit speziellen arbeitsmarktpolitischen Fördermaßnahmen zugunsten der Vertriebenen zu rechnen war ${ }^{99}$. So unterstrichen die Autoren der Denkschrift, die als Informationsmaterial zum SED-Vorsitzenden Wilhelm Pieck gelangte ${ }^{100}$, daß die Arbeitsämter „keine gesonderte Vermittlung für Umsiedler“ durchführen würden ${ }^{101}$. Insgesamt wurde ein positives Bild der zurückliegenden Bemühungen gezeichnet, die Vertriebenen in den ostdeutschen Arbeitsmarkt einzubinden. Ein Vergleich der Zahl der beschäftigten ,Umsiedler' mit der Zahl der im „Arbeitsprozeß stehenden Altbevölkerung“ habe gezeigt, daß die Vertriebenen ,ihrem Anteil nach in gleicher Weise wie die Stammbevölkerung in Arbeit gebracht worden sind. “102 Nur bei den Frauen würde der Beschäftigtenanteil „etwas unter dem der Altbevölkerung“ liegen. Damit habe sich - so die Schlußfolgerungen, die die Autoren der Denkschrift zogen - die „Richtigkeit“ der ,Umsiedler'-Politik in der SBZ gezeigt ${ }^{103}$.

\section{Zusammenfassung}

Formen und Verlauf der Vertreibung machten eine geordnete Ansiedlung der Flüchtlinge und Vertriebenen in der SBZ nahezu undurchführbar. Erst spät wurden die Aufnahmeund Quarantänelager eingerichtet, in welchen die Neuankömmlinge nach ihrer Arbeitsfähigkeit registriert werden sollten. Zu diesem Zeitpunkt befand sich jedoch die Mehrzahl der Ende 1946 registrierten 3,9 Millionen ,Umsiedler' bereits auf dem späteren Gebiet der DDR. Hinzu kamen die Binnenwanderung und die bald einsetzende Westwanderung der Vertriebenen, die es den staatlichen Zentralbehörden unmöglich machten, die Neuansiedlung planvoll und organisiert durchzuführen. Beide Phänomene stellten die Statistischen Ämter sowie die ostdeutschen Arbeitsämter vor nahezu unlösbare Probleme. Das hieß mit anderen Worten, daß die Ansiedlung der Vertriebenen oftmals unabhängig vom jeweiligen Arbeitsplatzangebot vor Ort erfolgte. Dies war wiederum ein entscheidender Grund für die später einsetzende Binnenwanderung der ,Umsiedler'. Dem versuchten die Zentral- und Landesverwaltungen mit einer Lenkung der Vertriebenen nach arbeitsmarktpolitischen Gesichtspunkten entgegenzusteuern. Dies gelang nur partiell und war vor allem nur für die Großbetriebe mit einem enormen Arbeitskräftebedarf von Nutzen; am Beispiel der sächsischen Textilindustrie konnte dies gezeigt werden.

${ }^{98}$ Vgl. dazu Just, Die Integration der Umsiedler, S. 171-173. Das Gesetz ist abgedruckt in: ebenda, S. 172.

99 SAPMO, NY 4036/744, Bl. 80-111.

100 Pieck hielt am 12.8. 1949, zwei Tage vor der ersten Bundestagswahl, eine Rede auf einer öffentlichen ,Umsiedler'-Versammlung im Zirkus Barlay (Berlin). Die Denkschrift hatte er vermutlich für diesen Zweck beim Sekretariat der DWK in Auftrag gegeben. Die Rede Piecks befindet sich in: SAPMO, NY 4036/440, Bl. 104-118.

101 SAPMO, NY 4036/744, Bl. 85.

102 Ebenda, Bl. 87.

${ }^{103}$ Ebenda, Bl. 111. 
Die Chancen der Flüchtlinge und Vertriebenen, eine Anstellung zu erhalten, gestalteten sich ganz unterschiedlich und hingen in der Regel von den lokalen Gegebenheiten am Arbeitsmarkt ab. Zahlreiche Arbeitsplätze wurden in der Landwirtschaft, dem Handwerk und von einigen Großbetrieben (vor allem Bergbau sowie die Stahl- und Walzwerke) angeboten. Im Vergleich zur heimischen Bevölkerung ist eine Benachteiligung der Vertriebenen bei der Arbeitsplatzvergabe jedoch nicht zu übersehen, galten doch die ,Umsiedler' als neue Konkurrenz auf dem Arbeitsmarkt.

Die Eingliederung der Vertriebenen in den ostdeutschen Arbeitsmarkt muß im Kontext der staatlichen Steuerung der Gesamtwirtschaft gesehen werden. Nachdem bereits frühzeitig die Entscheidung für eine Zentralverwaltungswirtschaft in der SBZ gefallen war, die zuvor mit den sowjetischen Beratern und der SMAD abgesprochen worden war, wurde unter anderem der Einsatz der Produktionsfaktoren zentral koordiniert und gesteuert. Eine Folge war notwendigerweise auch die Lenkung des Faktors, Arbeit‘. Für die ,Umsiedler' existierten aber auf zentraler Ebene keine gesonderten Beschäftigungsprogramme. Dies hätte im übrigen auch den ideologischen Vorbehalten widersprochen, die die SED-Führung gegenüber einem Sonderbewußtsein der Vertriebenen hegte, das somit erst gar nicht entstehen sollte. Die Flüchtlinge und Vertriebenen stellten somit eine Personengruppe von vielen anderen dar, die es in den Arbeitsprozeß zu integrieren galt. Während die ,Umsiedler' zumindest in den Anfangsjahren statistisch erfaßt wurden, brach doch ab 1949 die Berichterstattung von seiten der Arbeitsämter fast vollständig ab.

Bei dem Kompetenzgerangel zwischen der ,Umsiedler'- und der Arbeitsverwaltung konnte sich die zuletzt genannte Behörde de facto durchsetzen. Den Arbeitsämtern oblag aufgrund einer sowjetischen Anweisung und dem Kontrollratsbefehl Nr. 3 vom Januar 1946 die Registrierung der arbeitsfähigen Bevölkerung und damit auch der Vertriebenen. Die Registrierung war eine wesentliche Voraussetzung für die Steuerung des Arbeitsmarktes, die auch in den Händen der Arbeitsämter lag. Nur mit ihrer Zustimmung durfte - so zumindest die gesetzlichen Bestimmungen - ein Arbeitsplatzwechsel vorgenommen werden. Damit verfügten die Arbeitsämter über alle technischen Voraussetzungen. Die ,Umsiedler'-Sonderverwaltung, die im Laufe des Sommers 1948 aufgelöst und der Innenverwaltung unterstellt wurde, bemühte sich vergebens um weiteren Einfluß auf diesem Gebiet. Die Tatsache, daß es infolge dieser Auseinandersetzungen zu zeitlichen Verzögerungen etwa bei der Ausarbeitung gesetzlicher Bestimmungen, die das Arbeitsrecht betrafen, gekommen war, mag mit ein Grund für die rasche Auflösung der Sonderverwaltung ZVU gewesen sein.

Abschließend soll noch auf die Eigeninitiative der Vertriebenen bei der Arbeitsplatzsuche verwiesen werden, auch wenn dies nicht Thema des vorliegenden Beitrags war. Diese Form der Arbeitsplatzbeschaffung entzog sich weitgehend der Betrachtung durch die Arbeitsämter, trug aber zweifellos zur Entlastung auf dem Arbeitsmarkt bei. So stellte beispielsweise die Abt. Umsiedlerbetreuung in Halle Anfang 1946 fest, daß ein großer Teil der Flüchtlinge "sich selbst Arbeit besorgt" habe ${ }^{104}$. Auch diese Tatsache unterstreicht den beschränkten Erfolg der Eingliederung von Vertriebenen in den ostdeutschen Arbeitsmarkt, der nur langfristig und damit über unseren Untersuchungszeitraum hinaus festzustellen war.

104 Schreiben der Abt. Umsiedlerbetreuung Halle vom 22. 2. 1946 an den Präsidenten der Provinz Sachsen, LHA Magdeburg, Rep. K, MinPräs., Nr. 415, Bl. 1. 


\title{
Arnd Bauerkämper \\ Die vorgetäuschte Integration.
}

\author{
Die Auswirkungen der Bodenreform und Flüchtlingssiedlung \\ auf die berufliche Eingliederung von Vertriebenen in die Landwirtschaft \\ in Deutschland 1945-1960
}

\section{Flüchtlingsintegration als Problemfeld und Legitimationsbereich}

Die Vorstellung von der schnellen und weitgehend bruchlosen Eingliederung der Flüchtlinge und Vertriebenen ${ }^{1}$ gehört zu den zählebigen Mythen der deutschen Nachkriegsgeschichte. Angesichts der übermächtigen Legitimationsbedürfnisse der beiden deutschen Staaten im Ost-West-Konflikt wurde die Flüchtlingsintegration in den fünfziger Jahren als weitgehend abgeschlossene „Erfolgsgeschichte“ interpretiert - eine Deutung, die noch in der Gegenwart das Geschichtsbild beeinflußt ${ }^{2}$. Besonders schnell erklärten die SED-Führung und die Verwaltungsorgane in der Sowjetischen Besatzungszone (SBZ) und DDR die Eingliederung der Vertriebenen, die seit Herbst 1945 offiziell als „Umsiedler" ${ }^{3}$ bezeichnet wurden, für beendet: bereits im Sommer 1948 wurde die im September 1945 gebildete Zentralverwaltung für deutsche Umsiedler (ZVU) in die Deutsche Verwaltung des Innern (DVdI) integriert, in der die neugebildete „Hauptabteilung Umsiedler" völlig im Schatten der Politik des Zentralsekretariats (ZS) der SED blieb. Nachdem 1948/49 auch alle Umsiedlerabteilungen und -ausschüsse der Länder und Provinzen, der Kreise, Städte und Gemeinden aufgelöst worden waren, wurden in der DDR genuine Flüchtlingsprobleme tabuisiert. Die SED-Führung entzog den Vertriebenen - auch in den Statistiken - ihren Sonderstatus und leugnete die mit der Fluchterfahrung verbundene spezifische Identität. 1952/53 liefen schließlich alle Sondergesetze zugunsten der ,Umsiedler' aus ${ }^{4}$.

Auch in der Bundesrepublik Deutschland wurde lange angenommen, daß die Flüchtlingseingliederung zwar nicht reibungslos, aber letztlich doch erfolgreich bis zum Ende der fünfziger Jahre erreicht worden sei. In ihrer richtungweisenden und für die öffentliche Debatte repräsentativen Studie, die 1959 in drei Bänden veröffentlicht wurde, hielten Friedrich Edding und Eugen Lemberg als Bilanz fest: „Mit der Eingliederung vollzieht

1 Zu den Begriffen „Flüchtlinge“ und „Vertriebene“, die in diesem Beitrag synonym verwandt werden: Frantzioch, Die Vertriebenen, S. $82 \mathrm{f}$.

${ }^{2}$ Für Westdeutschland: Frantzioch-Immenkeppel, Die Vertriebenen, S. 5, 7 f., 11. Dagegen: Lüttinger, Mythos; ders., Integration.

3 Hierzu der begriffsgeschichtliche Überblick in: Frantzioch-Immenkeppel, Vertriebene (Umsiedler). Vgl. auch Meinicke, Flüchtlinge, S. 23 f. (Anm. 17).

${ }^{4}$ Schwartz, Zusammenbruch, S. 57-59, 91-96; Schneider, Zentralverwaltung für deutsche Umsiedler, S. 242; Ther, Vertriebenenpolitik, S. 165-168; Frantzioch-Immenkeppel, Die Vertriebenen, S. 5, 8. 
sich ein Wandel der Gesellschaftsstruktur, eine Umwertung aller Werte oder [...] die Entstehung eines neuen Volkes". ${ }^{5}$ Nachdem sich aber die volkskundliche, soziologische und historische Forschung zu den Flüchtlingen und Vertriebenen in der Bundesrepublik in den achtziger Jahren erneut intensiviert hatte, wurde besonders in geschichtswissenschaftlichen Lokalstudien, volkskundlich-mentalitätshistorischen Langzeituntersuchungen und soziologischen Kohortenanalysen deutlich, daß die Integration keineswegs linear und bruchlos verlaufen, sondern mit erheblichen politischen, wirtschaftlichen und gesellschaftlichen Belastungen sowie einer neuen sozialen Ungleichheit einhergegangen und überwiegend erst im Generationswechsel abgeschlossen worden war. Auch überwand die Forschung - nach dem Vorbild der frühen Untersuchung von Edding und Lemberg - das zuvor überwiegend statische Verständnis von „Integration“, indem diese zunehmend als Interaktionsbeziehung dargestellt wurde. Die vielfältigen Prozesse der Eingliederung in die westdeutsche Nachkriegsgesellschaft erschienen dabei als eine wichtige Dimension und Triebkraft des beschleunigten Wandels und des politischen Neuanfangs nach dem Zweiten Weltkrieg. So behandelten Analysen zunehmend das Wechselverhältnis zwischen dem Flüchtlingszustrom und dem Wandel der Aufnahmegesellschaft ${ }^{6}$.

Die Vertreibung und Eingliederung der Deutschen wird aber weiterhin zu isoliert betrachtet, so daß zu den langfristigen Auswirkungen des Flüchtlingszustroms auf die Entwicklung der gesellschaftlichen Beziehungen, der Mentalitäten und der politischen Kultur nur wenige Studien vorliegen. $\mathrm{Da}$ die von der nationalsozialistischen Besatzungsmacht in Ostmitteleuropa von 1939 bis 1943 erzwungene Bevölkerungsverschiebung, die ein integrales Element der rassistisch-sozialdarwinistischen Vernichtungspolitik bildete, erst in den letzten Jahren eingehend von der historischen Forschung untersucht worden ist, blieb auch die Vorgeschichte der Vertreibung von Deutschen aus ihrer Heimat lange unterbelichtet. Zudem wurde die gesamtdeutsche Perspektive bisher vernachlässigt, denn die Flüchtlingspolitik galt in beiden deutschen Staaten zumindest bis zu den sechziger Jahren als Instrument der Legitimation durch wechselseitige Abgrenzung. Besonders für das Selbstverständnis und die Propaganda der Partei- und Staatsführung in der DDR, deren Zeitgeschichtsschreibung noch in den achtziger Jahren an der Chimäre einer schnellen Integration der ,Umsiedler festhielt, bildeten die Vertriebenenpolitik der Bundesrepublik und die Rolle der Flüchtlinge in der westdeutschen Nachkriegsgesellschaft negative Referenzgrößen. Demgegenüber traten die gemeinsamen Problemlagen und Verflechtungen deutlich zurück?.

Der Zustrom der deutschen Flüchtlinge aus Ostmittel-, Ost- und Südosteuropa erhöhte in Deutschland seit 1944 die geographische und gesellschaftliche Mobilität, nachdem schon die nationalsozialistische Aufrüstungspolitik in den dreißiger Jahren, die Kriegswirtschaft und die Evakuierungen seit 1942/43 einen nachhaltigen Dynamisierungsschub

${ }^{5}$ Edding u. Lemberg, Eingliederung, S. 173.

6 Vgl. z. B. Wette, Gesellschaft. Für ein dynamisches Verständnis von „Integration“ plädieren: Grebing, Begriff; Schwartz, „Flüchtling“, S. 28; Frantzioch, Die Vertriebenen, S. 193. Prägend für die neuere Forschung außer den von Lüttinger vorgelegten Untersuchungen: Lehmann, Im Fremden ungewollt zuhaus. Zum Forschungsstand: Haerendel, Flüchtlinge.

7 Krellenberg, Eingliederung, S. 1-4, 204-206. Exemplarisch für die westdeutsche Sicht die ansonsten instruktive Studie von Seraphim, Die Heimatvertriebenen, bes. S. 28-30. Zur neueren Forschung über die hier nicht ausführlich nachzuzeichnende Vertreibung der Deutschen zusammenfassend: Henke, Flucht. Allg. anregend: Kleßmann, Verflechtung, bes. S. 39 f.; Kocka, Geschichte, S. 14 f. 
ausgelöst hatten. Da im Nachkriegsdeutschland in den Städten kaum Wohnraum zur Verfügung stand und der Zerstörungsgrad in der Industriewirtschaft ebenso überschätzt wurde wie der Stellenwert der alliierten Reagrarisierungskonzepte, ließ sich die Flüchtlingsbevölkerung zunächst auf dem Lande nieder. Hier bot die Arbeit als selbständige Bauern oder Landarbeiter den Vertriebenen zumindest eine gesichterte Versorgung mit Lebensmitteln. In der Subsistenz- und Tauschökonomie der unmittelbaren Nachkriegszeit wurde der Zugang zu den begehrten Nahrungsgütern zur wichtigsten Determinante sozialer Ungleichheit. Die Integration der Flüchtlinge und Vertriebenen in die Landwirtschaft bildete deshalb nicht nur ein wirtschaftliches Problemfeld, sondern war eng mit gesellschaftlichen und politischen Konflikten verknüpft. So vertiefte sich in der Nachkriegszeit in allen alliierten Besatzungszonen der Stadt-Land-Gegensatz ${ }^{8}$.

Die Nachkriegszeit war aber nicht nur durch eine enorme Mobilisierung, sondern auch - besonders in Westdeutschland - durch die Kontinuität gesellschaftlicher Strukturen, die Beharrungskraft festgefügter sozialmoralischer Milieus' ${ }^{9}$ und den fortdauernden Einfluß tradierter Werte gekennzeichnet. Das Spannungsfeld zwischen Kontinuität und Wandel bildete sich besonders auf dem Lande heraus, wo dörfliche Milieus durch den Krieg und den Flüchtlingszustrom zwar erschüttert, aber keineswegs vollends beseitigt worden waren. Deshalb vollzog sich vor allem in den altbäuerlich geprägten Gemeinden ein neuer Unterschichtungsprozeß. Auf dem Lande, wo der gesellschaftliche Status traditionell durch den Besitz festgelegt wird, blieben die überwiegend mittellosen Flüchtlinge bis zu den fünfziger Jahren marginalisiert und von der alteingesessenen Bevölkerung abhängig, die sich gegenüber den Vertriebenen weitgehend abschloß ${ }^{10}$.

Der Zustrom und die Eingliederung von Flüchtlingen und Vertriebenen war im Nachkriegsdeutschland eng mit dem beschleunigten gesamtgesellschaftlichen und -wirtschaftlichen Wandel sowie mit dem politischen Neuaufbau verbunden. In den westlichen Besatzungszonen wurden die zunächst in der Agrarwirtschaft arbeitenden Flüchtlinge seit 1948/49 von einem tiefgreifenden agrarischen Strukturwandel erfaßt, der in den fünfziger Jahren nicht nur das wirtschaftliche Gefüge, sondern auch die Gesellschaft in der frühen Bundesrepublik insgesamt nachhaltig veränderte. In der SBZ war die Flüchtlingsintegration auf dem Lande dagegen eng mit der erzwungenen Transformationspolitik verknüpft, die auf die Zerschlagung der bestehenden sozioökonomischen Strukturen sowie auf eine umfassende wirtschaftliche und gesellschaftliche Konstruktion zielte. Damit sollte der Herrschafts- und Gestaltungsanspruch der kommunistischen Machthaber durch eine gezielte Entmachtung und Privilegierung durchgesetzt werden. Die von der KPD-Führung im Sommer 1945 mit Protektion der sowjetischen Besatzungsmacht eingeleitete Bodenreform löste die in Ostelbien seit der Frühen Neuzeit dominierende großbetriebliche

${ }^{8}$ Kleßmann, Staatsgründung, S. 40 f.; Teppe, Trümmergesellschaft, bes. S. 22-26, 32 f.; Erker, Hunger; Hohenstein, Bauernverbände, S. 271-279; Schwartz, „Flüchtling“, S. 29. Zu den Deindustrialisierungsplänen der Alliierten und zu den ökonomischen Auswirkungen der Kriegszerstörungen, Reparationen und Demontagen: Petzina, Kontinuität, S. 258-269.

9 In Abgrenzung zur Kategorie der sozialen Schichten müssen als konstitutiv für „Milieus“ die „partielle Gemeinsamkeit von Existenzformen und erhöhte Binnenkommunikation“ angesehen werden. Vgl. Schulze, Erlebnisgesellschaft, S. 174.

${ }^{10}$ Kleßmann, Beharrungskraft, S. 152 f.; ders., Haus, S. 167, 175; Teppe, Trümmergesellschaft, S. $26 \mathrm{f}$. Zum Stellenwert des Kriegsendes und der unmittelbaren Nachkriegszeit zwischen gesellschaftlichem Strukturbruch und Kontinuität allg.: Kocka, 1945; ders., 1945 nach 1989/90; Bauerkämper, 8. Mai 1945, S. 12-17. Aus politikgeschichtlicher Sicht: Möller, Relativität. 
Agrarstruktur auf, beseitigte endgültig die - schon zuvor deutlich eingeschränkte - politische Vorherrschaft der Gutsbesitzer und führte zur Bildung von rund 210000 Neubauernstellen. Da auch ,Umsiedler' die Übernahme von Parzellen beantragen konnten, bot die Bodenreform - im Gegensatz zur Siedlungspolitik in der Bundesrepublik - vielen Flüchtlingen und Vertriebenen eine Erwerbsmöglichkeit als selbständige Landwirte. Die Ansiedlung dieser Zwangsmigranten in der SBZ schien damit günstige Bedingungen für die Integration dieser Bevölkerungsgruppe in die ländliche Gesellschaft zu eröffnen ${ }^{11}$.

Als wichtigster Gradmesser der Flüchtlingseingliederung verweist die klassische Trias der Integrationsforschung - das Kommerzium, die Kommensalität und das Konnubium - auf die sozialstrukturelle und die politisch-kulturelle Dimension des Prozesses ${ }^{12}$. Aber nicht alle Bereiche der Vertriebeneneingliederung können in diesem Aufsatz gleichermaBen ausführlich behandelt werden. Die Darstellung konzentriert sich vielmehr auf die Spielräume und Hindernisse der beruflichen Integration in die Landwirtschaft und der sozialen Eingliederung in dörflich-agrarische Milieus in Ost- und Westdeutschland. Die Untersuchung wird sich zwar auf die Auswirkungen der Bodenreform auf die berufliche Integration der ,Umsiedler' in der SBZ/DDR konzentrieren, in komparativer Perspektive aber auch die Flüchtlingseingliederung in die westdeutsche Landwirtschaft einbeziehen, um die Spezifika, aber auch die Gemeinsamkeiten der jeweiligen Prozesse erfassen und erklären zu können ${ }^{13}$.

\section{Die deklamierte Integration: der Stellenwert der Bodenreform für die Eingliederung der ,Umsiedler' in die Agrarwirtschaft und in die ländliche Gesellschaft}

Nachdem schon bis Ende 1945 nahezu 2,5 Millionen deutsche Flüchtlinge und Vertriebene die SBZ erreicht hatten, befanden sich hier im August 1946 3,3 Millionen ,Umsiedler (19,5 Prozent der Gesamtbevölkerung). Ihre Zahl stieg bis Dezember 1947 auf rund 4,4 Millionen; damit stellten Flüchtlinge und Vertriebene in der SBZ 24,3 Prozent der Bevölkerung. Bis Anfang 1949 erhöhte sich die absolute Zahl und der Bevölkerungsanteil der ,Umsiedler' zwar nur geringfügig; die Zahl der Bewohner hatte sich in der SBZ jedoch gegenüber 1939 um fast 18, die Bevölkerungsdichte sogar um 25 Prozent erhöht. Besonders wegen des Mangels an Wohnraum und Erwerbsmöglichkeiten in den Städten hatte die Sowjetische Militäradministration in Deutschland (SMAD) bereits unmittelbar nach dem Kriegsende die Anweisung erteilt, die ,Umsiedler' vor allem in die agrarisch geprägten Regionen Mecklenburg-Vorpommerns und Brandenburgs einzuweisen. Auch das erste Konzept der Zentralverwaltung für Arbeit und Sozialfürsorge sah im September 1945 vor, allein drei Millionen Flüchtlinge und Vertriebene in Mecklenburg-Vorpommern unterzubringen. Sie konzentrierten sich deshalb in den späten vierziger Jahren in den nördlichen Agrargebieten der SBZ: in Mecklenburg-Vorpommern erreichte der Anteil der ,Umsiedler' an der Bevölkerung im März 1949 46,5, in Brandenburg 27,4 Pro-

1 Zum Nexus von Transformations- und Integrationspolitik: Schwartz, Zusammenbruch, S. $93 \mathrm{f}$.; ders., „Flüchtling“, S. 34-36; Ther, Vertriebenenpolitik, S. 160. Mit Bezug zur Bodenreform: van Melis, Denazification, S. 368-370. Zum Herrschafts- und Gestaltungsanspruch der kommunistischen Machtelite allg.: Meuschel, Überlegungen, S. 5-9; Jessen, Gesellschaft, S. 100f.; Kocka, Gesellschaft, S. 547-550; ders., Sonderweg, S. 35-38.

$12 \mathrm{Zu}$ den Integrationsindikatoren der Flüchtlingsforschung: Frantzioch, Die Vertriebenen, S. 193 f.; Lüttinger, Mythos, S. $20 \mathrm{f}$.

${ }^{13} \mathrm{Zu}$ den hier angedeuteten Funktionen des Vergleichs allg.: Kocka, Komparatistik, S. 52, $55 \mathrm{f}$. 
zent. Erst in den fünfziger Jahren bauten die Binnenmigration in die Städte und zu den Standorten der Industriebetriebe, aber auch die Flucht aus der DDR die ausgeprägte regionale Konzentration der Flüchtlinge und Vertriebenen allmählich $\mathrm{ab}^{14}$.

Die ,Umsiedler', von denen bis Dezember 1948 etwa 76 Prozent aus Polen und rund 16 Prozent aus der Tschechoslowakei in die SBZ geflohen waren, ließen sich vor allem in kleinen Gemeinden nieder, da hier die Zerstörung von Wohngebäuden begrenzt geblieben war. So wurde in Brandenburg, wo insgesamt fast 30 Prozent der Wohnungen nach dem Zweiten Weltkrieg nicht genutzt werden konnten, in Gemeinden mit jeweils weniger als 2000 Einwohnern im September 1946 ein Zerstörungsgrad von nur 13, in den kreisfreien Städten dagegen von 43,1 Prozent registriert. Deshalb lebten in dieser Provinz im Dezember 1947 54,8 Prozent der Flüchtlinge und Vertriebenen in Gemeinden mit jeweils weniger als 2000 Einwohnern. Insgesamt hatten sich bis 1946 in der SBZ 47 Prozent der ,Umsiedler' in Dörfern mit bis zu 2000 Einwohnern niedergelassen. In den kleinen Gemeinden nahmen sie zunächst überwiegend eine Erwerbstätigkeit in der Agrarwirtschaft auf, obwohl lediglich 22,3 Prozent der Vertriebenen aus Polen, die bis zum November 1946 die SBZ erreichten, vor ihrer Flucht im primären Sektor gearbeitet hatten; für die Gruppe der ,Umsiedler` aus der Tschechoslowakei wurde sogar nur ein entsprechender Anteil von 17,3 Prozent registriert. Der Zustrom der Flüchtlinge und Vertriebenen vollzog sich 1945/46 noch weitgehend unkoordiniert, vielfach spontan und ungeregelt, so daß es zu einer gravierenden Fehlallokation von Arbeitskräften kam. Die ungünstige regionale und sektorale Verteilung der Flüchtlingsbevölkerung verzögerte in der SBZ nachhaltig den ökonomischen Wiederaufbau ${ }^{15}$.

$\mathrm{Da}$ die Flüchtlingsbevölkerung in den späten vierziger Jahren nur schwer Zugang zum Arbeitsmarkt gewann und zudem einen - im Vergleich zu den Alteingesessenen - hohen Anteil von Frauen, Kindern und Jugendlichen mit einem Alter von weniger als zwanzig Jahren aufwies, blieb die Erwerbsquote der ,Umsiedler' zunächst relativ niedrig. So verfügten Ende 1946 in der SBZ lediglich 33 Prozent aller Flüchtlinge über eine Arbeit, und nach der Währungsumstellung vom Juni 1948 stieg die Zahl der arbeitslosen ,Umsiedler' bis März 1949 sprunghaft von 37000 auf 127000. Die Beschäftigtenstruktur der Flüchtlingsbevölkerung war durch die Konzentration auf die Agrarwirtschaft geprägt. So arbeiteten von den erwerbstätigen ,Umsiedlern“ im April $1946 \mathrm{mehr}$ als 36 Prozent und Ende 1947 noch nahezu 30 Prozent - in Brandenburg sogar 33 Prozent - im primären Sektor. Da der Arbeitskräftebedarf in der Agrarwirtschaft in der unmittelbaren Nachkriegszeit wegen des Mechanisierungsrückstands sowie des Abzugs der Zwangsarbeiter und Kriegsgefangenen („Displaced Persons“) erheblich wuchs, nahmen viele Vertriebene - darunter auch Flüchtlingsbäuerinnen - zunächst eine Beschäftigung auf Bau-

${ }^{14}$ Roesler, Refugee Problem, S. 5; Steinert, Flucht, S. 557, 561, 570; Meinicke, Bodenreform und Vertriebene in der SBZ, S. 71, 83; ders., Integration, S. 874 f.; ders., Probleme, S. 4; ders., Flüchtlinge, S. 31, 33 f., 79 f.; Schwartz, „Flüchtling“, S. 27.

15 Vgl. die Denkschrift in: SAPMO, DY 30/IV 2/2.022/52, Bl. 43. Zusammenfassend: Meinicke, Bodenreform und Vertriebene in der SBZ, S. 71; ders., Integration, S. 873 f.; ders., Flüchtlinge, S. 4547, 51. Allg. auch: Steinert, Flucht, S. 566. Zum Zerstörungsgrad von Wohnraum in den Ländern und Provinzen der SBZ und Brandenburg: BLHA, Ld. Br. Rep. 203, MdI, Nr. 1074, Bl. 49; Meinicke, Probleme, S. 30 (Anm. 23); Barthel, Ausgangsbedingungen, S. 40 f. Zur Bevölkerungsverteilung in Brandenburg im Dezember 1947: BLHA, Ld. Br. Rep. 203, MdI, Nr. 1075, Bl. 87. Zur Herkunft der ,Umsiedler: Roesler, Refugee Problem, S. 6. Zur Berufstätigkeit vor der Flucht: $\mathrm{BAB}, \mathrm{DO} 1 / 10 / 13, \mathrm{Bl} .71,151,171$. 
ernhöfen auf, wo sie ihre Lebensmittelversorgung sichern konnten ${ }^{16}$. So stellten die ,Umsiedler' in der SBZ Ende 1946 in den Agrarbetrieben insgesamt 40,7 Prozent der Landarbeiter und 85,5 Prozent der mithelfenden familienfremden Arbeitskräfte. In Mecklenburg, wo Kriegsgefangene und ausländische Zwangsarbeiter im August 1944 rund 66 Prozent der Landarbeiter gestellt hatten, waren im Oktober 1945 sogar nahezu siebzig Prozent der abhängig Beschäftigten in der Agrarwirtschaft, Umsiedler ${ }^{17}$. In der SBZ eröffnete sich Flüchtlingen und Vertriebenen aber auch die Möglichkeit, als selbständige Landwirte Neubauernstellen zu übernehmen.

Die Bodenreform, die in der politischen Propaganda des SED-Regimes - etwa in dem zeitgenössischen Film „Freies Land“18 - als entscheidende Triebkraft der Integration von ,Umsiedlern' auf dem Lande glorifiziert wurde, war von der Exilführung der KPD in Moskau während des Zweiten Weltkriegs detailliert vorbereitet worden. Nachdem die Partei bereits in den zwanziger und dreißiger Jahren die Enteignung der Großgrundbesitzer und die Verteilung des konfiszierten Bodens an Landarbeiter und Kleinbauern verlangt hatte, präzisierte vor allem Edwin Hoernle, der führende Agrarpolitiker der $\mathrm{KPD}^{19}$, im Moskauer Exil das Bodenreformkonzept. Da die Alliierten ihre Pläne für die Ausweisung der deutschen Bevölkerung aus ihrer osteuropäischen Heimat erst 1943/44 konkretisierten, wurden Flüchtlinge und Vertriebene als Empfängergruppe von Bodenreformland weder in dem Entwurf, der 1942 von Hoernle in Oranki (bei Gorki) ausgearbeitet worden war, noch in dem von Anton Ackermann Ende 1944 vorgelegten "Aktionsprogramm des Blocks der kämpferischen Demokratie" erwähnt. Erst am 4. Februar 1945 hob Hoernle in einem Vortrag über „Die Agrarpolitik des Blocks der kämpferischen Demokratie" in Moskau als "besonders schwierige und wichtige Aufgabe" des Neuaufbaus in Deutschland nach dem Kriegsende hervor: „Ansiedlung von 100000en bäuerlich-landproletarischen Flüchtlingsfamilien aus dem Osten ". ${ }^{20}$

Als das Ausmaß des Flüchtlingszustroms nach dem Ende des Zweiten Weltkriegs deutlich wurde, gewann die Landvergabe an die Vertriebenen in der Bodenreformagitation der KPD-Führung eine wichtige Legitimationsfunktion. In seinem Aufruf vom 11. Juni 1945 forderte das ZK der Partei deshalb die Übergabe des zu enteignenden Bodens und Inventars an die „durch den Krieg ruinierten und besitzlos gewordenen Bauern". ${ }^{21}$ Die Vorbereitung der Bodenreform wurde vor allem von der sowjetischen Staats-

${ }^{16}$ Scholze-Irrlitz, „Umsiedler“, S. 142 f.

17 Schneider, Landproletariat, S. 185. Die weiteren hier aufgeführten Angaben zu den Beschäftigtenanteilen in: BAB, DO 1/10/13, S. 323; MdI 10, ZVU, Bd. 15, Bl. 170; BLHA, Ld. Br. Rep. 203, MdI, Nr. 1075, Bl. 84f.; Meinicke, Bodenreform und Vertriebene in der SBZ, S. 71; ders., Integration, S. 873; ders., Flüchtlinge, S. 64, 66, 69; Roesler, Refugee Problem, S. 13. Zu den angegebenen Arbeitslosenquoten: BAB, DO 1/10/15, Bl. 148; Roesler, S. 15. Zur Alters- und Geschlechterstruktur der ,Umsiedler': Meinicke, Probleme, S. 4-10. Zur Arbeit von Flüchtlingsfrauen auf Bauernhöfen: Scholze-Irrlitz, „Umsiedler“, S. $142 \mathrm{f}$.

18 Mückenberger/Jordan, „Sie sehen selbst“, S. 52-59. Zu dem Film auch: BLHA, Ld. Br. Rep. 203, MdI, Nr. 1074, Bl. 149. Allg.: Heimann, Umsiedler.

${ }^{19}$ Biographische Angaben zu Hoernle (1883-1952) in: Cerny, Wer war wer - DDR, S. 197.

20 Zit. nach: Erler u. a., "Nach Hitler kommen wir", S. 316. Nach dem "Aktionsprogramm" sollte das Bodenreformland nur Landarbeitern und landarmen Bauern übereignet werden; vgl. ebd., S. 296. Der Bodenreformentwurf Hoernles findet sich in: BAB, DK 107/A 421-41. Allg. zur Vorbereitung der Bodenreform: Bauerkämper, Antifaschismus, S. 624-626. Zusammenfassend auch: Piskol, Entwicklung. Zu den Vertreibungsplänen der Alliierten bis 1945: Henke, Weg.

${ }^{21}$ Weber, DDR, S. 36. 
und Parteiführung entscheidend vorangetrieben. Nachdem Stalin bereits in seinem Gespräch mit den KPD-Spitzenfunktionären Walter Ulbricht, Anton Ackermann und Gustav Sobottka in Moskau am 4. Juni 1945 einen unverzüglichen Beginn der Landumverteilung gefordert hatte, erarbeiteten Mitarbeiter des Volkskommissariats für Auswärtige Angelegenheiten der UdSSR für den sowjetischen Diktator bis Ende Juli einen Gesetzentwurf zur Bodenreform. Diese Vorlage wurde weitgehend in der Direktive übernommen, die das ZK der KPD am 23. August 1945 erließ22 $^{22}$

In dieser Anweisung an die Bezirks- und Kreisleitungen rechtfertigte das Führungsgremium der KPD die Enteignung der Grundbesitzer und der - so eingestuften - führenden Nationalsozialisten, Kriegsverbrecher und einflußreichen Repräsentanten des ,Dritten Reiches' mit dem Ziel, „solchen deutschen Volksangehörigen, die Hitlergegner waren und die infolge des Hitlerkrieges gegen fremde Völker Hof und Heim verloren haben, wieder Erwerbsmöglichkeit, Heimat und Zukunft zu geben“".23 Die KPD-Führung drängte im Herbst 1945 auf die Zuteilung auch kleiner, unrentabler Bauernstellen, um möglichst viele ,Umsiedler' politisch an die Partei zu binden und ihnen eine neue Lebensperspektive zu eröffnen ${ }^{24}$. Das Ziel der wirtschaftlichen Subsistenzsicherung fand aber auch in der SPD, Ost-CDU und Liberal-Demokratischen Partei (LDP) durchaus eine begrenzte Resonanz. Obwohl die Kirchen und viele Pfarrer Bedenken gegen die pauschale und rechtsstaatlichen Verfahren widersprechende Enteignung der Gutsbesitzer äußerten, war auch für ihre - überwiegend keineswegs vorbehaltlose - Zustimmung zur Bodenreform die Aussicht auf die Ansiedlung von Flüchtlingen ein wichtiges Motiv ${ }^{25}$.

Die gemäß der ZK-Direktive in den Ländern bzw. Provinzen, Kreisen und Gemeinden zu bildenden Bodenreformkommissionen sollten außer den Landarbeitern, Kleinpächtern und landlosen Bauern auch Flüchtlinge bei der Landzuteilung berücksichtigen. Der KPD-Vorsitzende Wilhelm Pieck verlieh dieser Forderung in seiner richtungweisenden Rede in Kyritz (Provinz Mark Brandenburg) am 2. September 1945 weiteren Nachdruck, und die dort auf einer Bauernversammlung gefaßte, aber gezielt vorbereitete EntschlieBung betonte besonders die Not der Flüchtlingslandwirte. Da die Bodenreform aber auch nach der Verabschiedung der Verordnungen in den Ländern und Provinzen vom 3. bis 10 . September 1945 als „Bewegung von unten her" ${ }^{\text {26 }}$ erscheinen sollte, appellierte die KPD-Führung gezielt an das Interesse der Vertriebenen, Neubauernstellen mit bis zu zehn Hektar (ha) Land zu übernehmen. So forderte der Sekretär der KPD-Bezirksleitung in der Provinz Mark Brandenburg, Willy Sägebrecht, die Kreisleiter und Referenten der Partei am 6. September 1945 auf, in der Bodenreformpropaganda die Flüchtlingsansiedlung hervorzuheben ${ }^{27}$.

${ }^{22}$ Laufer, UdSSR, S. 26-30; ders., "Genossen“, S. 357; Keiderling, „Gruppe Ulbricht“, S. 470. Dazu auch schon der Erlebnisbericht in: Leonhard, Revolution, S. 506-508.

${ }^{23}$ Zit. nach: Benser / Krusch, Dokumente, Bd. 2, S. 14.

${ }^{24}$ Meinicke, Bodenreform und Vertriebene in der Sowjetischen Besatzungszone, S. $137 \mathrm{f}$.

${ }^{25}$ Nowak, Christentum, S. 47, 52. Zu Mecklenburg-Vorpommern: Dokumente, S. 29, 44. Zu den Bodenreformkonzepten der SPD, Ost-CDU und LDP: Weber, Umgestaltung, S. $2828 \mathrm{f}$.

26 SAPMO, DY 30/IV 2/7/227, Bl. 63.

27 BLHA, Ld. Br. Rep. 330, I/2/97, Bl. 3. Allg.: Zank, Gesellschaftspolitik, S. 54. Weitgehend noch der offiziellen pseudodemokratischen Legitimation verhaftet die Darstellung in: Piskol u. a., Umwälzung, S. 43-48. Zu Sägebrecht: Barth u. a., Wer war wer in der DDR, S. $622 \mathrm{f}$. Entschließung von Kyritz in: SAPMO, NY 4182/1052, Bl. 260f. Zum Beginn der Bodenreform in Brandenburg umfassend: Bauerkämper, Bodenreform in Brandenburg, S. 271-281. Zur Rede Piecks in Kyritz auch: Kuntsche, Bodenreform, S. $12 \mathrm{f}$. 
Demgegenüber wies der 1. Vizepräsident der brandenburgischen Provinzialverwaltung, Bernhard Bechler, die Oberlandräte, Landräte und Oberbürgermeister am 19. September 1945 an, „daß bei der Zuteilung von Land in folgender Reihenfolge vorzugehen ist: Landarme Bauern, landlose Bauern, Landarbeiter, Flüchtlinge “ ${ }^{28}$ In den rund 9500 Gemeindebodenkommissionen, die im Herbst 1945 den zu enteignenden Boden sichern, die Landbewerber registrieren und ihre Anträge entgegennehmen sollten sowie zudem Aufteilungspläne zu erstellen und das Land nach der Bestätigung durch die übergeordneten Kreisbodenkommissionen zu übergeben hatten, waren nur 12,1 Prozent der Mitglieder ,Umsiedler', obwohl ihr Bevölkerungsanteil Ende 1945 17,1 Prozent erreichte. Dagegen stellten alteingesessene Landarbeiter in den Gemeindebodenkommissionen nahezu 38 Prozent und Kleinbauern sowie Pächter 35,6 Prozent der Mitglieder ${ }^{29}$.

$\mathrm{Da}$ die Flüchtlinge noch lange auf die Rückkehr in ihre Heimat hofften und - ebenso wie viele Landarbeiter und Kleinbauern - die Aufteilung der Güter in kleine, unrentable Neubauernstellen ablehnten, zögerten sie, die Bewirtschaftung von Bodenreformland zu übernehmen. So konstatierte die brandenburgische Provinzialverwaltung in ihrem Bericht über die Durchführung der Bodenreform am 4. Dezember 1945 ernüchtert: „Bei den Umsiedlern stellte sich eine gewisse Zurückhaltung bei der Beantragung von Land heraus. Insbesondere Bauern, die von östlich der Oder und der Neiße kommen und dort ihre Höfe verlassen mußten, hoffen, noch einmal in ihre Heimat zu kommen, und haben daher keine Bodenzuteilung bei den zuständigen Gemeindekommissionen bean-

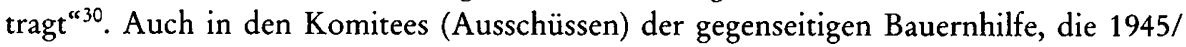
46 gebildet wurden, und in der 1946/47 aus diesen hervorgegangenen Vereinigung der gegenseitigen Bauernhilfe (VdgB) blieben die Flüchtlinge unterrepräsentiert ${ }^{31}$.

1945/46 lehnten zudem viele Bodenreformkommissionen, die von Alteingesessenen beherrscht wurden, die Zuteilung von Land an Flüchtlinge und Vertriebene ab, denn die Qualifikation der ,Umsiedler - vor allem der Berufsfremden und alleinstehenden Frauen unter den Landbewerbern - zur Bewirtschaftung von Neubauernstellen wurde weithin bezweifelt. Gegen die ,Umsiedler' richteten sich in der Nachkriegszeit besonders auf dem Lande die Ressentiments und Vorbehalte der einheimischen Bevölkerung, die ihre tradierten ethnischen Stereotype auf die Fremden projizierte ${ }^{32}$. Gelegentlich enteigneten Kommissionen oder Verwaltungsorgane auch nachträglich Flüchtlingsneubauern, die für unfähig erklärt worden waren. Außerdem teilten sich vielfach die Mitglieder der Bodenreformkommissionen selber Parzellen zu oder begünstigten Verwandte und Bekannte. So beklagte der Präsident der ZVU, Rudolf Engel, im Mai 1947, „daß in sehr vielen Fällen die Vergebung von Siedlerstellen unter dem Gesichtswinkel der Freundschaft oder der persönlichen Bekanntschaft erfolgte“ oder Bauern und Landarbeiter, die Kom-

${ }^{28}$ Zit. nach: Bauerkämper, Neubauern, S. 117. Zu Bechler (geb. 1911): Cerny, Wer war wer - DDR, S. $29 \mathrm{f}$.

${ }^{29}$ SAPMO, DY 30/IV 2/7/227, Bl. 14-18; Meinicke, Bodenreform und Vertriebene in der SBZ, S. 61; Piskol u. a., Umwälzung, S. 49-56. Andere Angaben in: Kuntsche, Umgestaltung, S. 95. Zum Anteil der ,Umsiedler' an der Bevölkerung Ende 1945: Roesler, Refugee Problem, S. 5.

${ }^{30}$ Zit. nach: Berichte, S. 145; Meinicke, Bodenreform und Vertriebene in der Sowjetischen Besatzungszone, S. 137. Allg.: Nehrig u. Piskol, Rolle, S. 325; Meinicke, Bodenreform und Vertriebene in der SBZ, S. 59, 61; ders., Flüchtlinge, S. 44, $59 \mathrm{f}$.

31 Wernet-Tietz, Bauernverband, S. 48-58, 60-62; Bauerkämper, Führungsgruppen, S. 85-88.

${ }^{32}$ Scholze-Irrlitz, „Umsiedler“, S. 140. Zur Zurückweisung von Landbewerbern: Bauerkämper, Strukturumbruch, S. 82. 
missionen angehörten, „mit der Begründung, daß zur damaligen Zeit nicht genügend Anträge vorlagen, 3, 4 und 5 Siedlerstellen für sich und ihre Angehörigen in Anspruch nahmen" ${ }^{33}$.

Auch die seit Herbst 1945 in Kreisen, Städten und Gemeinden konstituierten Umsiedlerausschüsse konnten nicht verhindern, daß weiterhin intakte Beziehungsnetze dörfliche Milieus gegenüber den Ansprüchen der Flüchtlinge abschirmten. Die Anbindung der Vertretungsorgane der ,Umsiedler ' an die Kreis- und Gemeindebodenkommissionen scheiterte weitgehend, so daß die Ausschüsse an der Ansiedlung von Flüchtlingsneubauern kaum beteiligt waren. $\mathrm{Da}$ die Umsiedlerausschüsse auch die regionalen und lokalen Verwaltungen in der unmittelbaren Nachkriegszeit nur unzureichend kontrollieren konnten, blieb die Gleichberechtigung von ,Umsiedlern' und Alteingesessenen in dörflich-agrarischen Milieus vielfach nur ein Postulat. Die Vertriebenen setzten sich trotz der materiellen Unterstützung, die sie von staatlichen Verwaltungsorganen, Parteien und Massenorganisationen erhielten, im scharfen Verteilungskampf der unmittelbaren Nachkriegszeit gegenüber der einheimischen Bevölkerung kaum durch ${ }^{34}$.

Weil Parzellen mit hoher Bodengüte bereits vor der Ankunft der Flüchtlinge in ihrer neuen Heimat an alteingesessene Landbewerber vergeben worden waren, verlangte die ZVU von der Deutschen Verwaltung für Land- und Forstwirtschaft (DVLF), die von Hoernle geleitet wurde, 1946/47 nachdrücklich, die abgeschlossenen Zuteilungsverfahren zu überprüfen, um Verstöße gegen die Bodenreformverordnungen aufzudecken. Besonders nachdem die tschechische Regierung 1945/46 nahezu 50000 Kommunisten aus dem Sudetenland in die SBZ transportiert hatte, forderte die ZVU, die von der SMAD unterstützt wurde, gegenüber der DVLF im Juni 1946 kategorisch eine Kontrolle aller bereits durchgeführten Landzuteilungen: „Die Bodenreform wurde durchgeführt und konnte nicht auf später kommende Umsiedler Rücksicht nehmen. Jetzt kommen laufend im Rahmen der Umsiedlung von weiteren 600000 Menschen aus dem Sudetengebiet und Hunderttausende aus dem Osten auch einige tausend aktiver Antifaschisten [...] in die Sowjetzone. [...] Für die Bodenaufteilung an Antifaschisten kommen ca. 3000 Familien in Frage “35.

Die Aktion sollte aber auch die Gesellschaftsstruktur auf dem Lande erneut dynamisieren, um den Handlungsspielraum der SED-Führung für ihre Konstruktionspolitik zu erweitern und ihre Herrschaft zu festigen. So bereitete die DVLF im Herbst 1946 eine Verordnung zum Entzug von Bodenreformland vor, obwohl allgemein eine Beunruhigung der Neubauern durch Besitzwechsel unbedingt vermieden werden sollte. Trotz der Anweisungen der ZVU und der Umsiedlerämter in den Ländern und Provinzen

${ }^{33} \mathrm{BAB}, \mathrm{DO} 1 / 10 / 63$, Bl. 93 (Interpunktion korrigiert). Hierzu auch die Berichte und Stellungnahmen in: SAPMO, DY 30/IV 2/2.022/52, S. 43; DY 30/IV 2/7/321, Bl. 39f.; BAB, DO 1/10/62, Bl. 4, 94; BLHA, Ld. Br. Rep. 208, Nr. 185, Bl. 23. Zusammenfassend: Bauerkämper, Neubauern, S. 117.

${ }^{34}$ Sandford, Hitler, S. 110-112; Schwartz, Partizipation, S. 165-167, 173, 175; ders., „Flüchtling“, S. 29; Just, Lösung, S. 978 f.; Meinicke, Bodenreform und Vertriebene in der SBZ, S. 66 f.; Bauerkämper, Neubauern, S. 117. Zu Brandenburg: Pape, Flüchtlinge, S. 113, 128f.; Ther, Vertriebenenpolitik, S. $163 \mathrm{f}$.

${ }^{35}$ Zit. nach einem Schreiben vom 6. 6. 1946, in: BAB, MdI 10, ZVU, Nr. 63, Bl. 12. Die ZVU drängte die SMAD im Mai 1946, einer Kontrolle der Neubauernstellen zuzustimmen. Vgl. BAB, DO 1/ 10/64, Bl. 104. Zum Transport tschechischer "Antifaschisten“ in die SBZ: Wille, „Freiwillige Ausreise“, S. 36-49; BAB, DO 1/10/13, Bl. 47-49. Überblick in: Foitzik, Kadertransfer, bes. S. 310, $319 f$. 
konnte aber nur wenig Land für die erst 1946/47 eintreffenden Flüchtlinge bereitgestellt werden. Der noch nicht vergebene Boden war vielfach unkultiviert oder befand sich in den verwüsteten Ostkreisen Brandenburgs und Mecklenburg-Vorpommerns, wo weite Ackerflächen in der Nachkriegszeit vermint waren und siedlungsbereite Flüchtlinge kaum untergebracht werden konnten ${ }^{36}$.

Im Januar 1946 verfügten die ,Umsiedler in Mecklenburg über 39, im Land Sachsen über 38 und in Brandenburg über 37 Prozent des verteilten Landes. In Thüringen und in der Provinz Sachsen wurden entsprechende Anteile von 28 bzw. 25 Prozent verzeichnet $^{37}$. Im Juni 1946 hatten Flüchtlinge in der SBZ insgesamt nahezu 41 Prozent des übereigneten Bodenreformlandes erhalten, und sie bewirtschafteten fast 36 Prozent der Neubauernstellen. Bis zum Abschluß der Bodenreform wurde 94443 Vertriebenen 34,9 Prozent des an Individualempfänger verteilten Landes übergeben ${ }^{38}$. Die Ausstattung der Flüchtlingsneubauern mit technischem Inventar blieb aber trotz der von den zuständigen Behörden gewährten Kredite und des Aufbaus der Ausleihstationen, die vor allem den angesiedelten Landwirten Maschinen bereitstellen sollten, gering. So verfügten in Brandenburg noch Ende 1947 statistisch lediglich 32,4 Prozent der Flüchtlingsneubauern über einen Pferdepflug, 28,2 Prozent von ihnen über Wagen oder Anhänger, 25,5 Prozent über Eggen und 1,4 Prozent über Drillmaschinen ${ }^{39}$.

Obwohl wiederholt Ausgleichsaktionen zwischen den Ländern und Kreisen durchgeführt wurden, blieb auch der Viehbestand der Flüchtlingsneubauern in der SBZ gering. Intakte soziale Beziehungsnetze bewirkten in vielen Dörfern, daß alteingesessene Bauern bei der Verteilung von lebendem und totem Inventar begünstigt wurden. Auch deshalb entfielen Ende 1947 auf je 10 Neubauernstellen in Brandenburg nur 4 Schweine, 4 Milchkühe, 3 Pferde und 2 Hühner. Im Juni 1948 hatten noch 9,2 Prozent der rund 38600 ,Umsiedler', die in Mecklenburg Vollerwerbsbetriebe eingerichtet hatten, keine Milchkuh erhalten, und 63,8 Prozent von ihnen waren ohne Anspannung geblieben ${ }^{40}$.

Daneben erschwerte die völlig unzureichende Ausstattung der Flüchtlingsneubauern mit Wohn- und Wirtschaftsgebäuden eine nachhaltige Festigung ihrer Betriebe. So verfügten im Oktober 1947 von jeweils 1000 Flüchtlingsneubauern in der SBZ statistisch nur 262 über Wohngebäude, 150 über Großviehställe, 131 über Schweineställe und 118 über Scheunen oder Überdachungen. Noch im Oktober 1950 besaßen in der SBZ 22000 Flüchtlingsneubauern weder Wohnhäuser noch Stallgebäude; darüber hinaus hatten

${ }^{36}$ Zum Scheitern der Landumverteilung: Wille, „Freiwillige Ausreise“, S. 50f. Anweisungen zur Kontrolle der Bodenzuteilungen in: Warning, Dokumente, S. 640f.; SAPMO, DY 30/IV 2/ 2.022/52, Bl. 39f.; BAB, DO 1/10/62, Bl. 40 f., 44, 62, 67; DO 1/10/63, Bl. 12, 93; DO 1/10/64, Bl. 31 f., 135-137. Entwurf der Verordnung der DVLF in: BAB, DO 1/10/62, Bl. 17-21.

${ }^{37}$ Meinicke, Bodenreform und Vertriebene in der Sowjetischen Besatzungszone, S. 138.

${ }^{38}$ BAB, DO 1/10/15, Bl. 188; Schulz, Probleme, S. 2 f.; Bauerkämper, Von der Bodenreform zur Kollektivierung, S. 126. Andere Werte in: Meinicke, Bodenreform und Vertriebene in der Sowjetischen Besatzungszone, S. 139; ders., Bodenreform und Vertriebene in der SBZ, S. 63.

$39 \mathrm{BAB}, \mathrm{DO}$ 1/10/65, Bl. 84. Hierzu auch die detaillierten Angaben in: Meinicke, Bodenreform und Vertriebene in der Sowjetischen Besatzungszone, S. 141-143, 149; ders., Die Bodenreform und die Vertriebenen in der SBZ, S. 65, 69. Zu den Flüchtlingsneubauern in Brandenburg: Pape, Flüchtlinge, S. 119; Ther, Vertriebenenpolitik, S. 164. Zu Mecklenburg-Vorpommern: Krellenberg, Eingliederung, S. 106.

40 BAB, DO 1/10/65, Bl. 84; Krellenberg, Eingliederung, S. 106, 115 f.; Meinicke, Bodenreform und Vertriebene in der Sowjetischen Besatzungszone, S. 141-143, 149; ders., Die Bodenreform und die Vertricbenen in der SBZ, S. 65, 68, 82; Roesler, Refugee Problem, S. 9. 
7000 keine Wohnhäuser und 8900 keine Ställe. Allein in Brandenburg mußten für Flüchtlingsneubauern noch rund 3375 einzelne Wohnhäuser, 4882 Ställe sowie 6924 kombinierte Wohn- und Stallgebäude errichtet werden. Nach dem am 8. September 1950 von der Regierung der DDR erlassenen „Gesetz über die weitere Verbesserung der Lage der ehemaligen Umsiedler" konnten Flüchtlingen zwar zinsgünstige Kredite eingeräumt werden; die Bauleistung blieb aber wegen des anhaltenden Mangels an Material, Arbeitskräften und Transportkapazität sowie der Zuteilungsdefizite im sich herausbildenden zentralplanwirtschaftlichen System der DDR weit hinter dem hohen Bedarf zurück ${ }^{41}$. Viele Flüchtlingsneubauern mußten deshalb noch in den späten vierziger und frühen fünfziger Jahren bei alteingesessenen Landwirten oder in baufälligen, kaum beheizbaren Gutshäusern untergebracht werden ${ }^{42}$.

Insgesamt ist der Anteil der ökonomisch gefestigten Höfe von ,Umsiedlern' in der SBZ mit nur 15 Prozent veranschlagt worden. Wegen der wirtschaftlichen Schwäche ihrer Betriebe blieben die Flüchtlingsneubauern noch in den späten vierziger und frühen fünfziger Jahren auf die Unterstützung der alteingesessenen Landwirte angewiesen, besonders beim Zugkrafteinsatz. Die auch daraus resultierende asymmetrische Beziehung, die Armut der Vertriebenen, ihre geringere Qualifikation und ihre spezifische, sich vielfach von den dörflichen Milieus der Aufnahmegesellschaft abhebende kulturell-mentale Prägung führten tendenziell zur sozialen Marginalisierung der Flüchtlingsneubauern. So beschwerte sich eine Frau, die nach der Vertreibung aus der Neumark im brandenburgischen Willmersdorf einen Pachtbetrieb übernommen hatte, in einem Schreiben an Hoernle am 22. Oktober 1948, daß sie in dem Dorf „als unerwünschter Eindringling und Fremdkörper empfunden und behandelt werde. Die Altbesitzer sind mehr oder weniger verwandt, verschwägert oder sonst verbunden. Die Grundsätze der gegenseitigen Bauernhilfe scheinen keine Anwendung zu finden". ${ }^{43}$

Viele angesiedelte Landwirte gaben deshalb ihre Betriebe auf, als die industrielle Produktionskapazität in den späten vierziger und frühen fünfziger Jahren erweitert wurde und damit neue, durchweg attraktivere Arbeitsplätze geschaffen wurden, die auf die Flüchtlingsneubauern - wie auf die Erwerbstätigen in der Landwirtschaft insgesamt eine beträchtliche Sogwirkung ausübten. In der Provinz Brandenburg hatten schon bis Ende 1947 von insgesamt 24406 Flüchtlingsfamilien, die 198136 ha Land übernommen hatten, 2944 (12 Prozent) eine Fläche von 13093 ha (6,6 Prozent des übernommenen Bodens) zurückgegeben, und im Kreis Calau-Senftenberg verließen bis 1950 etwa ein Zehntel der Flüchtlingsbauern ihre Höfe. Insgesamt hatten in der SBZ bis zum Juli 1949 10,7

${ }^{41}$ BAB, DK 1/3035, Bl. 58, 68; Meinicke, Bodenreform und Vertriebene in der Sowjetischen Besatzungszone, S. 140, 144-148; ders., Die Bodenreform und die Vertriebenen in der SBZ, S. 74. Ergänzend: Meinicke, Integration, S. 875; ders., Flüchtlinge, S. 61. Zu Brandenburg: Bauerkämper, Neubauernbauprogramm, S. 194f. Das Gesetz vom 8. 9. 1950 ist abgedruckt in: Gesetzblatt der DDR, Nr. 104-14. 9. 1950, S. 971-973. Allg. zu diesem Gesetz: Meinicke, Flüchtlinge, S. 76; ders., Integration, S. 877 f.; Just, Lösung, S. 983; Ther, Vertriebenenpolitik, S. 166; Schulz, Probleme, S. 16.

42 Bauerkämper, Neubauern, S. $126 \mathrm{f}$. Zum brandenburgischen Landkreis Beeskow/Storkow: Scholze-Irrlitz, „Umsiedler“, S. 143 f.

${ }^{43}$ BLHA, Ld. Br. Rep. 208, Nr. 2758, Bl. 121. Ergänzend die Berichte in: Mecklenburgisches Landeshauptarchiv, Schwerin, Ministerium für Land- und Forstwirtschaft, Nr. 2827, Bl. 170; SAPMO, DY 30/IV 2/7/117, Bl. 6. Zu Mecklenburg: Krellenberg, Eingliederung, S. 168 f. Allg.: Meinicke, Flüchtlinge, S. 61 f. Zur ökonomischen Lage der Flüchtlingsneubauern: Seraphim, Die Heimatvertriebenen, S. 15-17. 
Prozent aller Neubauern ihre Betriebe aufgegeben. Obwohl die Rückgabe von Neubauernhöfen in den frühen fünfziger Jahren durch gesetzliche Regelungen und politischen Druck erschwert wurde, ließen 1950/51 weitere 30000 der angesiedelten Landwirte ihre Betriebe zurück ${ }^{44}$.

\section{Die abgebrochene Integration: Bodenreforminitiativen und Flüchtlingssiedlung in der Bundesrepublik Deutschland}

Die Flüchtlinge aus den verlorenen deutschen Siedlungsgebieten in Ost- und Südosteuropa beeinflußten auch in Westdeutschland tiefgreifend die wirtschaftliche und gesellschaftliche Entwicklung auf dem Lande. Bereits im Oktober 1946 wurden in den westlichen Besatzungszonen nahezu sechs Millionen, im September 1950 schließlich rund 7,8 Millionen Vertriebene registriert. Ihr Anteil an der Wohnbevölkerung hatte damit im Bundesgebiet 16,5 Prozent erreicht. Ebenso wie in der SBZ lebten die Flüchtlinge in Westdeutschland überwiegend in ländlichen, noch agrarisch strukturierten Regionen. So stellten Vertriebene 1950 in Schleswig-Holstein 33,0, in Niedersachsen 27,2 und in Bayern 21,1 Prozent der Bevölkerung. Die Flüchtlinge ließen sich überwiegend in Dörfern nieder: Noch im September 1950 lebten 47,2 Prozent von ihnen - aber nur 32,8 Prozent der alteingesessenen Bevölkerung - in Dörfern mit jeweils weniger als 3000 Einwohnern; 55 Prozent der Vertriebenen waren in Gemeinden mit unter 5000 Einwohnern registriert ${ }^{45}$.

Insgesamt kamen nach Westdeutschland rund 400000 Flüchtlinge, die in ihrer Heimat landwirtschaftliche Betriebe bewirtschaftet hatten. In Niedersachsen wurden 1949 318600 Vertriebene registriert, die in ihrer Heimat als Erwerbstätige in der Landwirtschaft gearbeitet hatten, darunter 60800 als selbständige Bauern. Nachdem sie in der unmittelbaren Nachkriegszeit überwiegend als abhängig Beschäftigte in der Landwirtschaft berufstätig gewesen waren, ging der Anteil der im primären Sektor Erwerbstätigen unter den Flüchtlingen in den späten vierziger Jahren deutlich zurück. Während 1939 noch 39,6 Prozent der später in der Bundesrepublik aufgenommenen Vertriebenen in der Agrarwirtschaft gearbeitet hatten, war dieser Anteil in der neuen Heimat bis 1950 auf 14,5 Prozent gesunken. In den Ländern Schleswig-Holstein, Niedersachsen und Bayern, wo die ländliche Industrialisierung erst in den fünfziger Jahren einsetzte, übertraf die Erwerbslosenquote unter den Flüchtlingen erheblich den Durchschnittswert für das Bundesgebiet ${ }^{46}$. Die berufliche Integration der Flüchtlinge in die Landwirtschaft gewann in den westlichen Besatzungszonen deshalb einen hohen politischen Stellenwert. So wurde in einem 1947 veröffentlichten Aufsatz zur wirtschaftlichen Eingliederung der Vertriebe-

${ }^{44}$ BLHA, Ld. Br. Rep. 203, MdI, Nr. 1166, Bl. 14-16; Meinicke, Bodenreform und Vertriebene in der Sowjetischen Besatzungszone, S. $149 \mathrm{f}$; ders., Die Bodenreform und die Vertriebenen in der SBZ, S. 83; ders., Flüchtlinge, S. 63; Ther, Vertriebenenpolitik, S. 165. Ergänzend die Angaben in: Bauerkämper, Problemdruck, S. 321; ders., Neubauernbauprogramm, S. $200 \mathrm{f}$.

${ }^{45}$ Bethlehem, Heimatvertreibung, S. 22, 30 f.; Reichling, Die deutschen Vertriebenen, S. 32 f., 40 f.; Sommer, Zwischen nationalen Rechtswahrungsansprüchen, S. 407. Ergänzend: Frantzioch, Die Vertriebenen, S. 92-94, 99-117. Zu Bayern: Bauer, Flüchtlinge, S. 161-181; Pscheidt, Flüchtling, S. 110.

${ }^{46}$ Bethlehem, Heimatvertreibung, S. 40-42, 47; Reichling, Die deutschen Vertriebenen, S. 66-73. Zu den Flüchtlingslandwirten: Palmer, Eingliederung, S. 83; Tarnow, Grundlagen, S. 10; Pscheidt, Flüchtling, S. 117. Zum Industrialisierungsschub in Bayern nach dem Zweiten Weltkrieg: Erker, Sehnsucht, S. 486-488. 
nen festgestellt: „Auch die Ansiedlung der Flüchtlinge als Neubauern [...] verdient sicher größere Beachtung, stammen doch recht viele aus der Landwirtschaft. Der Widerstand der Eingesessenen gegen die Abgabe von Boden ist zwar äußerst stark, es ist jedoch zu hoffen, daß die Bodenreform Land für die Ostdeutschen freigibt ". ${ }^{47}$

Angesichts der - hinsichtlichtlich seines Ausmaßes und der Dauerhaftigkeit überschätzten - Kriegszerstörungen in der Industriewirtschaft, des Wohnraummangels in den Städten, der Demontagen und der alliierten Reagrarisierungspolitik, die noch im Potsdamer Abkommen festgelegt war, lag in der unmittelbaren Nachkriegszeit der Übergang zu einer kleinbetrieblichen Struktur mit arbeitsintensiver Veredlungsproduktion in der Landwirtschaft nahe. So sah der "Kleinsthofplan“, der von traditionellen agrarromantischen Utopien geprägt war, Agrarbetriebe mit jeweils 1,5 ha vor, die den Inhabern eine direkte Versorgungsmöglichkeit bieten, den Vertriebenen eine Arbeit vermitteln und die Ernährung der Bevölkerung sichern sollten. Dieses Konzept reflektiert die restriktiven wirtschaftlichen und gesellschaftlichen Rahmenbedingungen der „Zusammenbruchgesellschaft “48 und sollte den wirtschaftlichen Wiederaufbau ebenso wie die Flüchtlingsintegration erleichtern: „Millionen Menschen schreien nach Land, und Land schreit nach intensiv wirtschaftenden Menschen ". ${ }^{49}$ Diese agrarpolitische Forderung erwies sich allerdings in den späten vierziger Jahren, als mit der forcierten Abwanderung aus der Landwirtschaft und der zunehmenden Landflucht langfristige Trends des gesamtwirtschaftlichen und -gesellschaftlichen Wandels wieder einsetzten, vollends als unrealistisch.

Auch eine Bodenreform sollte in den westlichen Besatzungszonen die Eingliederung der Flüchtlinge in die Landwirtschaft fördern. Sowohl die britische Labour-Regierung unter Premierminister Attlee als auch die amerikanische Administration unter Präsident Truman befürworteten in der unmittelbaren Nachkriegszeit eine dauerhafte, aber rechtsstaatlichen Verfahren entsprechende Entmachtung der Großgrundbesitzer, denen eine erhebliche Mitverantwortung für den Aufstieg des Nationalsozialismus und den Zweiten Weltkrieg zugewiesen wurde ${ }^{50}$. Im Gegensatz zur SBZ blieb eine durchgreifende Umverteilung des Grundbesitzes in den westlichen Besatzungszonen jedoch aus, obwohl die alliierten Militärregierungen 1946/47 Gesetze und Verordnungen zur Umverteilung des Landbesitzes erließen. Da die Verabschiedung von Ausführungsbestimmungen aber den neugebildeten Länderparlamenten überlassen wurde, verzögerte sich die Durchführung der Bodenreform. Die Landesregierungen verfügten nur über geringe Finanzmittel, um die Großgrundbesitzer zu entschädigen, und waren zunehmend dem Einfluß der agrarischen Interessenorganisationen ausgesetzt. Eine Enteignungspolitik traf auch in den bürgerlichen Parteien auf entschiedenen Widerstand, zumal eine Aufteilung von großen Agrarbetrieben die ohnehin angespannte Lebensmittelversorgung zu gefährden schien und wegen der kleinbetrieblichen Agrarstruktur Westdeutschlands ohnehin deutlich weniger Land als in der SBZ erfaßt hätte ${ }^{51}$. Als der Ausbruch des Ost-West-Konflikts die frühen Vorbehalte der westlichen Alliierten gegen die Durchführung der Bodenreform

${ }^{47}$ Wittlich, Eingliederung, S. 14.

${ }^{48}$ Kleßmann, Staatsgründung, S. 37.

${ }^{49}$ Jebens, Kleinsthofplan, S. 27. Zusammenfassend: Kluge, Agrarpolitik, S. 68.

50 Für die USA: Marquardt-Bigman, Geheimdienstanalysen, S. 131, $141 \mathrm{f}$.

51 Trittel, „Siedlung“; ders., Scheitern; ders., Bodenreform, S. 40-45. Zum politischen Widerstand gegen die Bodenreform: Weisz, Versuch, S. 124f.; ders., Organisation, S. $198 \mathrm{f}$. 
in der SBZ steigerte, rückten auch ihre Militäradministrationen in Deutschland von der Politik einer weitreichenden Umverteilung des Landbesitzes $a b^{52}$.

In der amerikanischen Besatzungszone wurde am 18. September 1946 zwar das "Gesetz zur Beschaffung von Siedlungsland und zur Bodenreform" verabschiedet; bis Ende 1947 beschränkte sich der Landanfall aber auf 25000 ha. In Schwaben wurden bis März 1948 nur etwa 250 ha Bodenreformland gewonnen. Auch in der französischen Zone blieb die bestehende agrarische Besitzstruktur weitgehend erhalten. Eine Verordnung der Militärregierung vom 18. Oktober 1947 legte zwar eine gestaffelte Landabgabe für Agrarbetriebe mit bis zu 450 ha fest, so daß ein Landanfall von rund 40000 ha erwartet wurde. $\mathrm{Da}$ die Landtage aber die Verabschiedung von Durchführungsgesetzen verzögerten, konnte nur wenig Land zur Ansiedlung von Flüchtlingen genutzt werden ${ }^{53}$.

Nachdem die Außenminister der Alliierten auf ihrer Moskauer Konferenz im April 1947 beschlossen hatten, noch bis zum Jahresende in Deutschland eine Bodenreform durchzuführen, präzisierte auch die britische Militärregierung ihre bereits im Oktober 1946 vorgelegten Grundsätze und erließ am 4. September 1947 eine Verordnung, nach der Grundbesitz von mehr als 150 ha von der Bodenreform erfaßt werden sollte. Aber erst im Frühjahr 1949 hatten alle Länder Ausführungsgesetze vorgelegt, die auch eine progressiv abgestufte Landabgabe für Agrarbetriebe mit einer Fläche von 25 bis 100 ha vorsahen. Diese Gesetze hätten in der britischen Zone rund 235000 ha für die Ansiedlung von Flüchtlingen freigesetzt, wurden jedoch kaum wirksam. Nur in Schleswig-Holstein verabschiedete der Landtag im Dezember 1947 ein Bodenreformgesetz, das auf dem weitreichenden Konzept des sozialdemokratischen Landwirtschaftsministers Erich Arp basierte und eine landwirtschaftliche Siedlung auf etwa 65000 ha ermöglicht hätte, aber von der britischen Militärregierung abgelehnt wurde ${ }^{54}$.

Seit 1949 verdrängte die Siedlungspolitik in Westdeutschland vollends die Bodenreforminitiativen der Besatzungsmächte und Landesregierungen. Im April 1949 forderte die "Arbeitsgemeinschaft zur Eingliederung der Heimatvertriebenen auf dem Lande“, der unter anderem der Direktor der Verwaltung für Ernährung, Landwirtschaft und Forsten, Hans Schlange-Schöningen, angehörte, die Ansiedlung von Flüchtlingen zu beschleunigen. Das Reichssiedlungsgesetz vom August 1919 erfaßte aber lediglich Staatsdomänen nach Ablauf der Pachtverträge, eröffnete eine Enteignungsoption bei Moor- und Ödland, legte ein Vorkaufsrecht bei einem Verkauf von Grundstücken mit mehr als 25 ha fest und begründete für Regionen, die vom Großgrundbesitz geprägt waren, einen staatlichen Anspruch auf ein Drittel der Nutzfläche von Gütern mit jeweils über $100 \mathrm{ha}^{55}$.

$\mathrm{Da}$ von 1919 bis 1941 - vor allem wegen der unzureichenden Finanzmittel der Siedlungsgesellschaften - jedoch insgesamt nur 78000 neue landwirtschaftliche Betriebe ein-

52 Hierzu die Telegramme in: FRUS, 1945/3, S. 1014, 1049-1059; Pelly u. Yasamee (Hrsg.), Documents, S. 130-132. Zusammenfassend: Mai, Kontrollrat, S. 250-255; Heydemann, Sowjetrußland, S. 88; Maetzke, Union Jack, S. 59-63; Marquardt-Bigman, Geheimdienstanalysen, S. 239-242.

53 Trittel, Bodenreform, S. 35-37. Zur amerikanischen Zone als umfassende Studie: Enders, Bodenreform, bes. S. 169-174. Ergänzend: Bauer, Bauernverband. Angabe für Schwaben nach: Sallinger, Integration, S. 182. Allg.: Kluge, Agrarpolitik, S. $68 \mathrm{f}$.

${ }^{54}$ Trittel, „Verwaltung des Mangels“, S. 134-138; ders., Scheitern, S. 165-170; ders., „Siedlung“, S. 183-189; ders., Bodenreform, S. 37-40; Tarnow, Grundlagen, S. 24-35. Als umfassende Regionalstudien: Rosenfeldt, bes. S. 85-91, 136-138; Hügen, Gesetz, bes. S. 208-213.

${ }^{55}$ Schapper, Durchführung, S. 74; Herlemann, Bauern, S. 61; Tarnow, Grundlagen, S. 19-23. Zu Schlange-Schöningen: Trittel, Schlange-Schöningen, bes. S. $56 \mathrm{f}$. 
gerichtet worden waren und das Reichssiedlungsgesetz keine Sonderregelungen für Flüchtlinge enthielt, erließ der Wirtschaftsrat des Vereinigten Wirtschaftsgebietes am 10. August 1949 schließlich das „Gesetz zur Förderung der Eingliederung von Heimat-

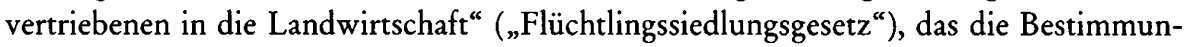
gen des zwei Tage zuvor verabschiedeten "Soforthilfegesetzes“ erweiterte. Nach dem Flüchtlingssiedlungsgesetz konnten Vertriebenen zinslose Kredite und Beihilfen für die Übernahme bestehender landwirtschaftlicher Betriebe durch Kauf, Pacht oder Einheirat eingeräumt werden. Landbesitzer, die Boden verkauften oder auf wenigstens 12 Jahre verpachteten, erhielten steuerliche Vergünstigungen. Den Ländern konnten für angesiedelte Flüchtlinge jeweils $5000 \mathrm{DM}$ gewährt werden. Besonders nicht bewirtschaftete, erbenlose oder auslaufende Höfe sollten von Vertriebenen übernommen werden. Damit konnten Flüchtlinge nicht nur neue landwirtschaftliche Betriebe einrichten, sondern auch durch Aufstockung, Pacht oder Erwerb schon bestehende Höfe übernehmen ${ }^{56}$.

Nachdem das Gesetz über den Lastenausgleich eine Entschädigung für Flüchtlingslandwirte fixiert hatte und in einer im März 1953 erlassenen Durchführungsverordnung des Gesetzes auch Aufbaudarlehen an aus der SBZ geflohene Landwirte festgelegt worden waren, übernahm das am 19. Mai 1953 vom Bundestag verabschiedete „Gesetz über die Angelegenheiten der Vertriebenen und Flüchtlinge“ (Bundesvertriebenengesetz) die Bestimmungen des Flüchtlingssiedlungsgesetzes. Das Bundesvertriebenengesetz verpflichtete die Bundesregierung zu einer unbefristeten Förderung der Flüchtlingsintegration und sah Finanzhilfen besonders für die Einrichtung landwirtschaftlicher Nebenerwerbsstellen vor. Nach einer Intervention des Ernährungsausschusses war im Bundesvertriebenengesetz aber festgelegt worden, daß Flüchtlingen zwar mindestens die Hälfte des Neusiedlerlandes zuzuteilen war, aber auch Einheimische - vor allem Bauernsöhne und Landarbeiter - bei der Bodenvergabe berücksichtigt werden mußten. Diese „Lex Horlacher" verschärfte nach 1953 die Konkurrenz zwischen Flüchtlingen und Alteingesessenen und führte auf dem Lande zu Auseinandersetzungen, die das Verhältnis zwischen den beiden Bevölkerungsgruppen belasteten ${ }^{57}$.

Die Flüchtlingssiedlung, die mit den seit 1959 von den Bundeskabinetten verabschiedeten Fünfjahresplänen bis 1974 auch auf die Zuwanderer aus der DDR ausgedehnt wurde, beanspruchte bis Ende 1958 insgesamt rund 2,8 Mrd. DM, darunter etwa 630 Mio. DM aus dem Bundeshaushalt, nahezu 700 Mio. DM Aufbaudarlehen und fast 650 Mio. DM aus Länderhaushalten ${ }^{58}$. Die Siedlungspolitik wurde nicht nur vom Bauernverband der Vertriebenen, sondern auch von der „Arbeitsgemeinschaft zur Eingliederung der Heimatvertriebenen auf dem Lande“, der "Gesellschaft zur Förderung der inneren Kolonisation“ und der 1947 gegründeten „Agrarsozialen Gesellschaft“ unterstützt. Daneben förderten internationale Verbände wie die von Pastor Birger Forell gegründete „Deutsch-Schwedische Flüchtlingshilfe“ und Stiftungen die Flüchtlingssiedlung in Westdeutschland. Auch kirchliche Organisationen sowie Pfarrer und Pastoren traten nachdrücklich für die berufliche Integration der Vertriebenen in die Landwirtschaft ein ${ }^{59}$.

${ }^{56}$ Ehrenforth, Durchführung, S. 546f.; Palmer, Eingliederung, S. 86-90, 92; Tarnow, Grundlagen, S. 36f.; Kluge, Agrarpolitik, S. $70 \mathrm{f}$, $73 \mathrm{f}$.

57 Herlemann, Bauern, S. 71-75; Palmer, Eingliederung, S. 98f.; Kluge, Agrarpolitik, S. 143.

${ }^{58}$ Ehrenforth, Durchführung, S. 561. Hierzu auch die Angaben in: Herlemann, Bauern, S. 81-84.

59 Palmer, Eingliederung, S. 90-97, 106-114, 116-121. Ergänzend: Rudolph, Kirche, S. 474-479. 
Nach dem Flüchtlingssiedlungsgesetz wurden bis Ende 1950 insgesamt 10670 Vertriebenenbauern als selbständige Landwirte in die westdeutsche Agrarwirtschaft integriert. Ende 1952 bewirtschafteten aber 41 Prozent der etwa 35000 angesiedelten Flüchtlingsbauern Nebenerwerbsbetriebe; 29 Prozent hatten Kleinbauernstellen und nur 26 Prozent Vollerwerbsbetriebe übernommen. Von Juli 1949 bis Juni 1954 gingen 48941 Betriebe mit einer Fläche von 315723 ha an Flüchtlingsbauern über, davon 44 Prozent der Höfe im Siedlungsverfahren, 29 Prozent durch Pacht und 27 Prozent durch Kauf. Von den bis Ende 1958 eingerichteten 105565 Siedlerstellen für Vertriebene entfielen zudem nur 17070 (16,2 Prozent) auf Höfe mit mehr als 10 ha. Insgesamt wurden von 1945 bis 1962 in der Bundesrepublik 121554 neue Agrarbetriebe mit einer durchschnittlichen Größe von 1,88 ha eingerichtet. Anfang der sechziger Jahre waren aber nur etwa 16000 Vollerwerbsbetriebe im Besitz von Flüchtlingen und Vertriebenen, denn mehr als 47 Prozent der angesiedelten Flüchtlinge hatten Nebenerwerbsstellen mit einer Betriebsfläche von jeweils weniger als 0,5 übernommen, und nur rund 3191 Flüchtlingsbetriebe wiesen 1962 eine Größe von mehr als 30 ha auf ${ }^{60}$.

In Niedersachsen hatten bis Ende 1950 rund 4400 Flüchtlinge landwirtschaftliche Betriebe mit zusammen fast 40000 ha Nutzfläche eingerichtet. Auf dieses Bundesland, in dem Mitte der fünfziger Jahre etwa 18000 landwirtschaftliche Flüchtlingsbetriebe - davon aber nahezu 13000 Nebenerwerbsstellen mit jeweils weniger als 0,5 ha Land - bestanden, entfielen rund 28 Prozent der Flüchtlingshöfe. Aber der Anteil der Vertriebenen unter den selbständigen Landwirten blieb insgesamt gering. Auch in Westfalen, wo bis zum Beginn der sechziger Jahre rund 4100 Flüchtlingsbauern zinsverbilligte Darlehen und Beihilfen aus öffentlichen Mitteln erhielten, konnten nur wenige Vertriebene Land erwerben. So waren von insgesamt 4642 selbständigen Landwirten, die 1960 im Landkreis Ahaus einen Hof bewirtschafteten, lediglich 53 Vertriebene, die über nicht mehr als 0,8 Prozent der gesamten Betriebsfläche verfügten ${ }^{61}$.

Eine integrale Komponente der landwirtschaftlichen Siedlung bildete in Westdeutschland bis zu den frühen sechziger Jahren die Moor- und Ödlandkultivierung, zumal die Bodenreformgesetze die bestehende Besitzstruktur weitgehend konservierten und das Landangebot nur wenig erweiterten. Angesichts der geringen Dynamik des Bodenmarktes schien die Erschließung neuer landwirtschaftlicher Nutzflächen die Aussicht auf die Ansiedlung von Flüchtlingen zu eröffnen. Da 1950 allein in Niedersachsen 172795 ha Moore sowie 321737 ha Öd- und Unland registriert wurden, sollten durch die Kultivierung dieser Flächen etwa 100000 bis 150000 ha Boden für die landwirtschaftliche Siedlung bereitgestellt werden. Die Landeserschließung erforderte aber einen hohen Finanzaufwand und war zeitraubend, so daß das Ergebnis weit hinter den Erwartungen zurückblieb. Von 1945 bis 1953 wurden jährlich nur 780 ha kultiviertes Land für Siedlerstellen übergeben. In Niedersachsen hatte die regionale Siedlungsgesellschaft 1951 insgesamt knapp 6000 ha erschlossenes Moor- und Ödland erhalten, das vor allem im hannoverschen Emsland landwirtschaftlich genutzt werden konnte. Hier wurden bis 1965 zwar 75800 ha

60 Becker, Jahre, S. 40, 45-51, 63; Kluge, Agrarpolitik, S. 142 f., 213, 247 f.; Ehrenforth, Durchführung, S. 557-561. Dazu auch die Angaben in: Herlemann, Bauern, S. 76-80; Rudolph, Kirche, S. 479.; Tarnow, Grundlagen, S. 10, 114.

${ }^{61}$ Zur Siedlungsbilanz für Niedersachsen: Malecki, Eingliederung, S. 29; Schulze, „Die Ansprüche kamen erst später", S. 275. Angaben zu Westfalen und zum Landkreis Ahaus nach: Exner, Agrarwirtschaft, S. 201. 
Moor und Ödland kultiviert und 1200 neue Höfe, 4550 Nebenerwerbsstellen und 110 Gärtnereibetriebe übereignet. Nachdem in den fünfziger Jahren ein forcierter Strukturwandel eingesetzt hatte, erwiesen sich viele kleine Siedlungshöfe aber als unrentabel ${ }^{62}$.

Die deutliche Mehrheit der in der westdeutschen Landwirtschaft berufstätigen Vertriebenen arbeitete als abhängig Beschäftigte. In der unmittelbaren Nachkriegszeit hatten Flüchtlinge auf den Höfen die dringend benötigten Arbeitskräfte gestellt und damit einerseits erheblich zur Aufrechterhaltung der Agrarproduktion sowie zur Lebensmittelversorgung beigetragen, andererseits aber auch die Modernisierung der Agrarbetriebe verzögert ${ }^{63}$. Die einheimischen Bauern betrachteten die Vertriebenen vielfach nur als potentielle Landarbeiter, so daß es zu scharfen Konflikten kam, wenn die Flüchtlinge dieser Erwartung und den damit verbundenen Anforderungen nicht entsprachen oder sogar ihre Arbeit in der Agrarwirtschaft zugunsten einer Berufstätigkeit in Gewerbebetrieben aufgaben ${ }^{64}$. Da die alteingesessenen Bauern auch Flüchtlingslandwirte überwiegend nicht als gleichberechtigt anerkannten, verringerte sich die gesellschaftliche Distanz zwischen diesen Gruppen in der Nachkriegszeit kaum, wie das geringe Ausmaß des Konnubiums verdeutlicht ${ }^{65}$. So wurde in einer agrarsoziologischen Untersuchung über den gesellschaftlichen Status von Flüchtlingslandwirten in vier niedersächsischen Landkreisen 1952 resümierend festgestellt: „Der am schwersten zu überwindende Graben ist wohl der zwischen den besitzenden und vertriebenen Bauern“. ${ }^{66}$ Angesichts des sozialen Abstiegs der meisten Vertriebenenbauern verlieh die berufliche Kontinuität bei Flüchtlingslandwirten, die wieder einen Betrieb erhielten und damit selbständige Bauern blieben, diesen unter den Vertriebenen ein hohes Sozialprestige ${ }^{67}$.

Nicht nur der Prozeß der beruflichen Eingliederung, sondern auch die Einquartierung der neuen Bewohner und das enge Zusammenleben in den Dörfern lösten scharfe Auseinandersetzungen aus und blockierten die Integration. Zudem schirmten festgefügte gesellschaftliche Beziehungen dörfliche Milieus vielfach gegenüber Eingriffen der Flüchtlingsverwaltung ab. In vielen ländlichen Regionen - z. B. im Münsterland und Bayern verschärfte besonders der konfessionelle Gegensatz, aber auch die zunehmenden internen Divergenzen im Protestantismus die anhaltenden Verteilungskonflikte zwischen den Flüchtlingen und der alteingesessenen Bevölkerung ${ }^{68}$. Insgesamt blieben die überwiegend mittellosen Vertriebenen in bäuerlichen Gemeinden, wo Besitz Prestige verlieh und die Orientierung auf die Hofwirtschaft noch ausgeprägt war, in der Nachkriegszeit weitgehend isoliert. Die gesellschaftliche Eingliederung wurde - vor allem über Sportver-

62 Palmer, Eingliederung, S. 85; Tarnow, Grundlagen, S. 51-68, 111; Becker, Jahre, S. 151-154; Schapper, Durchführung, S. 83 f. Zum Emsland: Haverkamp, Erschließung; Bauerkämper, Not, S. $90 \mathrm{f}$

${ }^{63}$ Kötter, Vorschläge, S. 242. Zu Bayern: Erker, Revolution, S. 372. Zu Niedersachsen: von der Brelie-Lewien, Spannungsfeld, S. 363; Schulze, „Die Ansprüche kamen erst später“, S. 275.

${ }^{64}$ Dettmer, Konflikte, S. 313. Zu Bayern: Erker, Ernährungskrise, S. 153. Zum Münsterland: Exner, Agrarwirtschaft, S. 200.

${ }^{65}$ Ebd., S. 207-210; ders., Gesellschaft, S. 340-348, $444 \mathrm{f}$. Zur Abwanderung aus der Landwirtschaft für Niedersachsen: Hohenstein, Bauernverbände, S. 279-292.

${ }^{66}$ von Blanckenburg, Lage, S. 57. Anschaulich auch: Arns, Verhältnis, S. 2.

67 Dazu exemplarisch aus erfahrungsgeschichtlicher Sicht: Dettmer, Konflikte, S. 313.

${ }^{68}$ Sommer, Zwischen nationalen Rechtswahrungsansprüchen, S. 398f.; 408, 313. Zum Münsterland: Exner, Agrarwirtschaft, S. 188f., 192-198; ders., Gesellschaft, S. 65-74. Zu Bayern: Erker, Vom Heimatvertriebenen zum Neubürger, S. 37-40; ders., Revolution, S. 397-400. Als Fallstudie zu Norddeutschland: Dettmer, Konflikte, S. 315, 319. 
eine - nur sukzessive erreicht und erst im Generationenwechsel weitgehend abgeschlos$\operatorname{sen}^{69}$. Dabei bildeten die allgemeine Not in der Nachkriegszeit und ihre gemeinsame Überwindung wichtige Erfahrungsdimensionen ${ }^{70}$. Seit den fünfziger Jahren begünstigten schließlich die berufliche und soziale Aufstiegsmobilität, die Zunahme des materiellen Wohlstands und der steigende Lebensstandard, aber auch die Urbanisierung und die Binnenmigration der Flüchtlinge ihre Integration in die westdeutsche Gesellschaft. Aber auch am Ende des Jahrzehnts war die politische, wirtschaftliche und gesellschaftliche Eingliederung der Vertriebenen in der Bundesrepublik zwar „unumkehrbar, aber noch nicht vollendet".71

\section{Integration und Transformation: Flüchtlingsbevölkerung und sozioökonomischer Strukturwandel}

Der Flüchtlingszustrom bildete in allen Besatzungszonen in Deutschland Problemlagen heraus, die sich besonders aus der Unterbringung in ländlichen Regionen und der Erwerbstätigkeit in der Landwirtschaft ergaben. Angesichts der allgemeinen Not, der Zerstörung in den Städten und des sozialpolitischen Zwangs zur beruflichen Integration schien eine Ansiedlung der Flüchtlinge auf dem Lande den wirtschaftlichen und gesellschaftlichen Rahmenbedingungen gerecht zu werden. Die KPD-Führung rechtfertigte die Bodenreform deshalb unter anderem mit der Absicht, den ,Umsiedlern' Neubauernstellen zu übergeben und ihnen damit die Chance auf eine schnelle berufliche und soziale Integration zu eröffnen. So argumentierte Hoernle noch 1947: „Es wäre doch Wahnsinn gewesen, wollte man bäuerliche Familien in den Städten arbeitslos unterbringen oder sie nur mit Mühe und Not in der Industrie unterbringen, wo sie draußen auf dem Lande als gelernte landwirtschaftliche Menschen ihre Lebensmittel selber produzieren können“. ${ }^{72}$

Die retrospektive Begründung Hoernles verdeckt allerdings, daß die Bodenreform vor allem die Herrschaft der KPD-Führung sichern sollte, indem die Gutsbesitzer entmachtet und mit den Neubauern eine neue gesellschaftliche Gruppe gebildet wurde, von der die Parteielite eine weitgehende Loyalität gegenüber dem sich herausbildenden Regime erwarten konnte. Die Ergebnisse der Gemeinde-, Kreis und Landtagswahlen, die im September und Oktober 1946 durchgeführt wurden, deuten tatsächlich auf eine Bindewirkung der Bodenreform hin. Die SED gewann besonders in den Landkreisen Mecklenburgs, wo die Bodenreform bis Anfang 1950 insgesamt 54 Prozent der landwirtschaftlichen Nutzfläche (LN) erfaßt hatte und viele Flüchtlinge Neubauernstellen übernommen hatten, hohe Wähleranteile. So stimmten bei den Gemeinderatswahlen in den mecklenburgischen Städten 49 Prozent, in den Landkreisen aber mehr als 75 Prozent der Wähler

69 Der hier nicht ausführlich nachzuzeichnende Integrationsprozeß ist in vielen Studien dargestellt worden. Zu Westfalen u. a.: Lüttig, Fremde, bes. S. 80-90; Hufschmidt, “... und dann blieben wir doch“, bes. S. 131-147; Exner, Agrarwirtschaft, S. 211-214. Zu Bayern: Bauer, Flüchtlinge, S. 343-380; Erker, Revolution, S. 379-425; Sallinger, Integration, S. 100, 102-106, $111 \mathrm{f}$. Zu Niedersachsen: Brosius u. Hohenstein, Flüchtlinge, S. 15-40, 49-57; von der Brelie-Lewien u. Schulze, Flucht, S. 101-109, 111; Dettmer, Konflikte, S. 320 f. Zu Württemberg: Schwedt, Heimatvertriebene.

70 von Plato, Heimat, S. 202-210. Vgl. auch Schlau, Eingliederung, S. 152, 158, 160.

${ }^{71}$ Holtmann, Flüchtlinge, S. 361. Zu der hier nicht darzustellenden Integration evakuierter Städter: Krause, Vertrieben.

72 SAPMO, DY 30/IV 2/7/211, B1. 377. Zur gemeinsamen Ausgangskonstellation in Deutschland 1945: Kocka, Geschichte, S. 14, 25. Ergänzend: Badstübner, Anfänge, S. 9 f. 
für die SED. In Brandenburg, wo 41 Prozent der LN enteignet worden waren, stellte die Partei nach den Wahlen in 72 Prozent der Gemeinden die Bürgermeister. Der SED gelang aber 1946 kein nachhaltiger Einbruch in bäuerliche Wählerschichten, denn in ländlichen Regionen mit einem hohen Anteil an agrar- und forstwirtschaftlichen Beschäftigten gewann die Ost-CDU relativ hohe Stimmenanteile. Obwohl bis zum Sommer 19474700 neue Ortsgruppen der SED gebildet wurden, blieb auch der Organisationsgrad der Partei unter Bauern in den späten vierziger Jahren gering. Sie stellten Ende Mai 1947 in Mecklenburg nur 15,8 und in Brandenburg knapp zehn Prozent aller SED-Mitglieder ${ }^{73}$.

Die Übernahme von Land hatte vielen Flüchtlingsneubauern als ,Profiteuren“ der Bodenreform zwar durchaus einen sozialen Aufstieg in der ländlichen Gesellschaft eröffnet. Dieser agrarische Transformationsprozeß führte aber nur kurzfristig zu einer Klientelbildung und band die Flüchtlingsneubauern keineswegs durchweg und bedingungslos an die Führung der KPD bzw. SED ${ }^{74}$. Die Vergabe an Parzellen an die ,Umsiedler signalisierte als Symbol der Integrationspolitik des SED-Regimes zwar die Entschlossenheit der Parteiführung, die wirtschaftliche und gesellschaftliche Integration durch eine umfassende Umverteilungspolitik zu fördern, und schien die Chance einer schnellen Eingliederung der Vertriebenen zu bieten ${ }^{75}$. So erhielten bis März 195091155 Flüchtlinge Land. Damit hatte die Bodenreform rund 350000 Personen begünstigt, aber lediglich 8,1 Prozent aller ,Umsiedler' erfaßt. Die ZVU veranschlagte aber im September 1946 die Zahl der sich in der SBZ aufhaltenden Flüchtlinge, die vor der Vertreibung in der Landwirtschaft gearbeitet hatten, mit rund 967000 , so daß die Bodenreform statistisch nur 36 Prozent von ihnen gebunden hatte.

Insgesamt förderte die agrarische Transformationspolitik zwar die gesellschaftliche Mobilisierung und erleichterte insofern die Assimilation der Bevölkerungsgruppen in der $\mathrm{SBZ}^{76}$; die Integration der ,Umsiedler' wurde aber durch die Bodenreform bis zu den frühen fünfziger Jahren keineswegs erreicht. Wegen der desolaten, nicht nachhaltig verbesserten wirtschaftlichen Ausstattung der Neubauernstellen, die zudem weder verkauft, verpachtet, belastet oder verpfändet werden durften und oft rechtlich nur unzureichend gesichert waren, wuchs unter den angesiedelten Flüchtlingen die Desillusionierung, wie die Zunahme der Betriebsrückgaben zeigt. Damit erwies sich die berufliche Integration auf dem Lande weitgehend als Mythos, so daß die SED trotz ihrer glorifizierenden Selbstdarstellung offenbar auch unter Flüchtlingsbauern den Nimbus der ,Umsiedler'-Partei einbüßte ${ }^{77}$.

${ }^{73}$ Müller, Sozialistische Einheitspartei Deutschlands, S. 489, 491, 510. Zu den Wähleranteilen: Braun, Determinanten, S. 347, 351 f., 354; Ottofülling, Blockpolitik, S. 584 f.; Woderich, Zu den Anfängen, S. 121; Krellenberg, Eingliederung, S. 128 (Anm. 207). Zusammenfassend: Bauerkämper, Neubauern, S. $119 \mathrm{f}$.

74 Gegenposition z. B. in: Kuntsche, Bauern, S. 235; Merz, Bodenreform, S. 1162; Stöckigt, Kampf, S. 240 f.; ders., Gründung, S. 203. Zur politischen Funktionalisierung der Bodenreform: Schwartz, Zusammenbruch, S. 90.

75 Meinicke, Bodenreform und Vertriebene in der Sowjetischen Besatzungszone, S. 150. Ähnliche Interpretation in: Schwartz, Partizipation, S. 165.

76 Scholze-Irrlitz, „Umsiedler“, S. 141, $147 \mathrm{f}$.

77 Statistische Angaben nach: BAB, DO 1/10/15, Bl. 226f.; Meinicke, Flüchtlinge, S. 60 f.; ders., Die Bodenreform und die Vertriebenen in der SBZ, S. 63. Zum gebundenen Bodeneigentum: Steding, Agrarrecht, S. 78. Zu den juristischen Mängeln bei der Übereignung von Bodenreformland: Springer-Liepert, „Bodenreformsperrvermerk gelöscht. . “"?, S. 44-48. Allg.: Bauerkämper, Neubauern, S. 117 f.; ders., Strukturumbruch, S. 82, 84. 
Der Ost-West-Konflikt steigerte in den späten vierziger Jahren jedoch die Legitimationsfunktion der Flüchtlingspolitik, so daß ein propagandistischer Wettlauf um die Integration der Vertriebenen bzw. ,Umsiedler' einsetzte. Dabei wurden die Flüchtlinge in der SBZ als Bevölkerungsgruppe mit besonderen Erfahrungen, Werten und Interessen aus der öffentlichen Diskussion verbannt. Das SED-Regime nahm den ,Umsiedlern` damit ihre spezifische Identität und stilisierte die Integration zu einem abgeschlossenen Vorgang. So dekretierte die Abteilung Umsiedler und Heimkehrer im brandenburgischen Ministerium für Arbeit und Sozialwesen im September 1948 in einem Bericht für die Stadt Spremberg eine „weitere Verschmelzung der Umsiedler mit den Alteingesessenen“, wobei die Integration „im ganzen Kreise [Spremberg] als nahezu vollzogen angesehen werden kann“. ${ }^{78}$ Nach der Gründung der DDR wurden die spezifischen Probleme der Vertriebenen vollends tabuisiert. Erst seit den sechziger Jahren bekannten sich einzelne Schriftsteller wie Christa Wolf und Ursula Höntsch zu ihrer Identität als Flüchtlinge ${ }^{79}$.

In Westdeutschland wurde die Vertriebenenpolitik demgegenüber zwar ebenfalls von der weitverbreiteten Illusion einer schnellen und reibungslosen Integration beeinflußt, beseitigte aber nicht gezielt das Selbstverständnis der Flüchtlinge, die ihre Interessen offen artikulieren und auch in Parteien und Verbänden organisatorisch verankern konnten. Auch das Prinzip der freiwilligen Ansiedlung von Flüchtlingslandwirten wurde gewahrt. Die westlichen Alliierten grenzten sich zunehmend von der Bodenreform in der SBZ mit der undifferenzierten und entschädigungslosen Enteignung der Gutsbesitzer ab, und die Bundespolitik griff ebensowenig in die bestehende Struktur des Grundbesitzes ein wie die Länderregierungen und die Landwirtschaftsverwaltung ${ }^{80}$. Obwohl eine Bodenreform in Westdeutschland damit weitgehend unterblieb, verlieh der Ost-West-Konflikt Siedlungskonzepten eine beträchtliche Dynamik. Die traditionelle Vorstellung von der Bodenbindung durch eine landwirtschaftliche Siedlung gewann angesichts der Furcht vor einer politischen Radikalisierung der Flüchtlinge einen hohen politischen Stellenwert.

Die Auswirkungen der Siedlungspolitik auf die berufliche Integration der Vertriebenen in die Landwirtschaft blieben aber begrenzt. In Westdeutschland wurden von 1945 bis 1966700000 ha mit einem Finanzaufwand von nahezu 7 Mrd. DM an 175000 Flüchtlinge vergeben, aber nur rund 30000 rentable Agrarbetriebe eingerichtet. Insgesamt erhielten 169581 Flüchtlingsfamilien Betriebe, davon aber etwa siebzig Prozent Nebenerwerbsstellen. Die Zahl der in der Land- und Forstwirtschaft arbeitenden Selbständigen ging unter den Vertriebenen deshalb von 1939 bis 1950 um 95,7 Prozent zurück. 1950 waren nur 1,1 Prozent aller Erwerbstätigen in selbständiger Stellung in der Landwirtschaft und Tierzucht Vertriebene. Von den Flüchtlingsbauern verfügten 194911000 , 195226000 wieder über Landbesitz. In Bayern hatten im September 1948 lediglich 1,4 Prozent der Vertriebenen, die in ihrer Heimat als selbständige Landwirte gearbeitet hatten, ihre frühere berufliche Stellung wieder erreicht. Auch wegen dieses Statusverlusts wanderten schon in den späten vierziger Jahren viele Flüchtlinge aus der Landwirtschaft ab. So waren 1950 nur noch 14,5 Prozent der Vertriebenen, aber 25,7 Prozent der Altein-

78 BLHA, Ld. Br. Rep. 203, MdI, Nr. 1087, Bl. 189.

${ }^{79}$ Helbig, Gemeinsamkeiten, S. 79-86; Theisen, Vertreibung, S. 21.

${ }^{30}$ Vgl. Rosenfeldt, Nicht einer ... viele sollen leben, S. 102-105; Trittel, Bodenreform, S. 43; Kleßmann, Verflechtung, S. 34. Zum Konzept der freiwilligen Integration in die Landwirtschaft: Kluge, Agrarpolitik, S. 143. Kritisch zur Flüchtlingseingliederung in der Bundesrepublik: Weisbrod, Wiederkehr, S. 1356. 
gesessenen im primären Sektor beschäftigt. 1961 bewirtschafteten 4,9 Prozent der Einheimischen, aber nur noch 0,9 Prozent der erwerbstätigen Vertriebenen landwirtschaftliche Betriebe. Auch die Zahl der mithelfenden Familienmitglieder - überwiegend Frauen blieb in der Flüchtlingsbevölkerung deshalb gering ${ }^{81}$.

Der Strukturwandel, der in den fünfziger Jahren die westdeutsche Landwirtschaft erfaßte, entzog der Flüchtlingssiedlung endgültig die Grundlage, wie auch Agrarwissenschaftler und Politiker erkannten ${ }^{82}$. Die landwirtschaftliche Siedlung wurde deshalb zunehmend durch Flurbereinigungsverfahren und andere Rationalisierungsmaßnahmen ergänzt, um die Arbeitsproduktivität nachhaltig zu steigern und eine „Parität“ der Einkommen zwischen den Beschäftigten in allen Wirtschaftssektoren zu erreichen. Die Ansiedlung von vertriebenen Landwirten trug aber zu dem Wandel der ländlichen Gesellschaft und dem langsamen Zerfall dörflich-agrarischer Milieus in den fünfziger und sechziger Jahren bei. Indem sie außerdem beschleunigt von der Landwirtschaft in die Industrie wechselten, trieben die Flüchtlinge den wirtschaftlichen und gesellschaftlichen Modernisierungsprozeß voran. Die Flüchtlinge wanderten im Zuge ihres Berufswechsels vielfach nicht vom Land ab und förderten damit als Arbeitspendler die Annäherung von städtischen und ländlichen Lebensformen ${ }^{83}$.

Kennzeichnend für die Vertriebenen war im Deutschland der frühen Nachkriegszeit ihre wirtschaftliche Deprivation, die berufliche Dequalifizierung und ihre arbeitsmarktpolitische Pufferfunktion. In Ost- und Westdeutschland bildete sich auf dem Lande ein weitreichender Unterschichtungsprozeß heraus, indem die Flüchtlinge zunächst der Landwirtschaft neue Arbeitskräfte zuführten und damit den Verlust der „Displaced Persons" ausglichen ${ }^{84}$. Nicht nur in der Bundesrepublik, sondern auch in der SBZ/DDR, wo sich eine grundlegende Transformation der Gesellschaftsstruktur vollzog, verdeutlichten die Probleme der Flüchtlingsintegration in der unmittelbaren Nachkriegszeit die Grenzen politischer Lenkung und Intervention gegenüber den wirtschaftlichen Rahmenbedingungen und gesellschaftlichen Traditionen. Bereits in den späten vierziger Jahren trat bei der beruflichen und sozialen Eingliederung der Vertriebenen bzw. ,Umsiedler jedoch eine wachsende Divergenz zwischen den sich etablierenden beiden deutschen Staaten hervor.

Mit dem Aufbau des Systems der Wirtschaftsplanung wurden die Auswirkungen der wirtschaftlichen Differenzierung und gesellschaftlichen Umschichtung in Ostdeutschland eingeschränkt, die in den späten vierziger Jahren auch hier - zum Teil entgegen den politischen Zielen des SED-Regimes - eingesetzt hatten. Vielmehr gerieten die angesiedelten Landwirte vor allem in den Sog der politisch oktroyierten Kollektivierung,

${ }^{81}$ Zur Erwerbstätigkcit der Flüchtlingsbauern: Willenborg, Geflüchtet, S. 128; Bethlehem, Heimatvertreibung, S. 40-43; Reichling, Die deutschen Vertriebenen, S. 66-76. Bilanz der Siedlungspolitik in: Trittel, „Siedlung“, S. 199; ders., Bodenreform, S. 40. Zu Bayern: Pscheidt, Flüchtling, S. 123 (Anm. 117). Zu den mithelfenden Familienmitgliedern: Handl u. Herrmann, Wandel, S. $134 \mathrm{f} ., 138$.

${ }^{82}$ Vgl. z. B. Schapper, Durchführung, S. 94.

83 Aus zeitgenössischer Perspektive: Schwonke, „Pendler“, S. 794 f.; Kötter, Stadt-Land-Soziologie, Bd. 2, S. 605f., 612-617. Allg.: Frantzioch, Integration, S. 245 f.; Lüttinger, Mythos, S. 25 f. Zum gesamtwirtschaftlichen Wandel in Westdeutschland: Abelshauser, Wirtschaftsgeschichte, S. 119128; Ambrosius, Wirtschaftssystem, Frankfurt 1989, S. 11-81. Zum Strukturwandel in der Landwirtschaft zusammenfassend: Bauerkämper, Landwirtschaft, S. 191-195.

${ }^{84}$ Allg.: Bade, Migrationsforschung, S. 150 f.; Wiesemann, Flüchtlingspolitik, S. 43. Für die SBZ: Meinicke, Flüchtlingc, S. 65. 
nachdem die SED-Führung auf der 2. Parteikonferenz den Landwirtschaftlichen Produktionsgenossenschaften (LPG) ihre Unterstützung versichert hatte. Die Kollektivierung, die von den betroffenen Flüchtlingsneubauern offenbar als Verlust wahrgenommen wurde und 1953 die Zahl der in die Bundesrepublik fliehenden Bauern sprunghaft hochschnellen ließ, beseitigte jedoch die gesellschaftlichen Spannungen und Gegensätze zwischen Alteingesessenen und ,Umsiedlern' keineswegs vollständig. Die sozialen Unterschiede beeinträchtigten vielmehr auch die Zusammenarbeit in den LPG. Als die SED in den späten fünfziger Jahren schließlich auf den schnellen Abschluß der Kollektivierung drängte und Agitationstrupps die Bauern bis zum ,sozialistischen Frühling 1960 zum Eintritt in die LPG zwangen, setzte eine Fluchtbewegung ein, die erneut ein konstitutives Merkmal nicht nur der Flüchtlings-, sondern auch der Gesellschaftspolitik der SED insgesamt beleuchtete: die vorgetäuschte Integration ${ }^{85}$.

85 Andere Akzentsetzung in: Meinicke, Bodenreform und Vertriebene in der Sowjetischen Besatzungszone, S. 150f. Zur Kollektivierung in der Perzeption der Vertriebenen: Meinicke u. v. Plato, Heimat, S. 163. Zur Flucht von Bauern aus der DDR: Heidemeyer, Flucht, S. 51 f., 55. Zur Beharrungskraft von sozialen Unterschieden und Abgrenzungen - auch zwischen Flüchtlingen und Vertriebenen - in LPG: Müns, Volksbrauch, S. 373; Bentzien, Bauern, S. 143 f.; Osmond, Kontinuität, S. 164. 


\title{
Manfred Jabn \\ Zur sächsischen Spezifik der Aufnahme von vertriebenen Deutschen 1945 bis 1949.
}

\author{
Das Fallbeispiel Uranbergbau
}

Das Land Sachsen, im Südosten der Sowjetischen Besatzungszone Deutschlands (SBZ) gelegen und weiträumig mit Böhmen und Schlesien benachbart, wurde unmittelbar nach der Beendigung der Kriegshandlungen im Mai 1945 erstes Zufluchtsgebiet für Hunderttausende von Deutschen, die infolge der radikalen Vertreibungsmaßnahmen in der Tschechoslowakei und in Polen, das seine Westgrenze bis zur Oder und Lausitzer Neiße verschieben konnte, unaufhörlich nach Sachsen hineinströmten. Bis Ende Juli 1945 wurden bereits über 448000 Deutsche aus den böhmischen Ländern durch tschechoslowakische Militär- und Zivilformationen nach Sachsen bzw. über Sachsen in von der SMAD vorbestimmte andere Teile der SBZ (Sachsen-Anhalt) zwangsausgewiesen ${ }^{1}$. Mit den Sudetendeutschen kamen gleichzeitig einige Hunderttausend Schlesier, die in den letzten Kriegsmonaten nach Böhmen evakuiert worden waren und denen polnische Militäreinheiten die Rückkehr über das Iser- und Riesengebirge verweigerten, in das Grenzland Sachsen $^{2}$. Als polnische Militäreinheiten im Juni/Juli 1945 entlang des gesamten (200 Kilometer breiten) Ufergürtels östlich der Oder und Lausitzer Neiße Zwangsaussiedlungen durchführten ${ }^{3}$, wurde ein Großteil der betroffenen Deutschen aus dem benachbarten Schlesien in sächsischen Gemeinden untergebracht.

Über 110 schnell eingerichtete Auffanglager, die sich vor allem in Grenznähe (Oberlausitz; Erzgebirge; Görlitzer Raum ${ }^{4}$ ) befanden, dienten der kurzzeitigen Zwischenaufnahme der Vertriebenen und zunehmend organisierten Weiterleitung in die mitteldeutschen Nachbarregionen Sachsens und nach Mecklenburg-Vorpommern ${ }^{5}$. Bis Ende 1945 wurden Hunderttausende zwangsausgesiedelter Deutscher über Sachsen nach bestimmten Transportplänen per Eisenbahn, Elbeschiffahrt und Fußmarsch in außersächsische Zielregionen geleitet ${ }^{6}$. Gleichzeitig fanden ca. 528000 Vertriebene in sächsischen Gemeinden eine dauerhafte Unterkunft (siehe Tabelle 1), obwohl das Land bis zum März

1 Vgl. Stanek, Politischer Hintergrund, S. 133.

2 Vgl. Sächs. HStA, LRS, MdI, 302.

${ }^{3}$ Vgl. Szczególa, Die Aussiedlung, S. 55-56.

${ }^{4}$ Das westlich der Lausitzer Neiße liegende niederschlesische Territorium, d. h. der Westteil des Bezirkes Liegnitz mit den Kreisen Hoyerswerda, Rothenburg und Görlitz, wurde de facto umgehend nach Kriegsende 1945 dem Land Sachsen zugegliedert, danach im SMAD-Befehl Nr. 5 vom 9. Juli 1945 „Zur Verwaltung der Provinzen und Kontrolle der örtlichen Selbstverwaltungsorgane" festgeschrieben (vgl. Broszat/Weber, S. 24, 73 und 126.).

${ }^{5}$ Jahn, Auffang- und Quarantänelager, S. 250-251.

6 Vgl. Harzbecker, Die Ankunft, S. 67-68. 
1946 laut SMAD-Direktiven aufgrund seiner hohen Bevölkerungsdichte offiziell nicht als Ansiedlungsgebiet galt.

Die Doppelfunktion als Transit- und Ansiedlungsland, die bereits in der zweiten Jahreshälfte 1945 sichtbar wurde und durch zeitweilige Übervölkerung und chaotische Versorgungs- und Transportbedingungen geprägt war, stellte ein wesentliches Element sächsischer Spezifik der Aufnahme von Vertriebenen dar. Mit Beginn der zweiten großen Ausweisungswelle ab Sommer 1946 nahm sie wesentlich entspanntere Formen an ${ }^{7}$.

Hinsichtlich der Herkunftsgebiete und -länder von zwangsausgesiedelten Deutschen wurde für Sachsen schon ab 1945 erkennbar, daß die übergroße Mehrheit der dauerhaft aufgenommenen Vertriebenen aus Gebieten östlich von Oder und Lausitzer Neiße kam, darin eingeschlossen über 416000 Personen bis Herbst 1946 aus Schlesien ${ }^{8}$. Die folgende Tabelle gibt einen Zahlenüberblick über aufgenommene Vertriebene nach bestimmten Stichmonaten:

Tabelle 1: Aufnahme zwangsausgesiedelter Deutscher 1945 bis 1948 in Sachsen ${ }^{9}$

\begin{tabular}{|l|r|c|c|r|r|r|r|}
\hline Stand & $\begin{array}{c}\text { insge- } \\
\text { samt }\end{array}$ & $\begin{array}{c}\text { aus der } \\
\text { Tsche- } \\
\text { choslo- } \\
\text { wakei }\end{array}$ & $\begin{array}{c}\text { aus Gebieten } \\
\text { östlich } \\
\text { Oder/Lau- } \\
\text { sitzer Neiße }\end{array}$ & $\begin{array}{c}\text { aus } \\
\text { Ungarn }\end{array}$ & $\begin{array}{c}\text { aus } \\
\text { UdSSR* }\end{array}$ & $\begin{array}{c}\text { aus } \\
\text { Rumä- } \\
\text { nien }\end{array}$ & $\begin{array}{c}\text { aus } \\
\text { anderen } \\
\text { Staaten** }\end{array}$ \\
\hline Januar 1946 & 527893 & 117451 & 399571 & $?$ & $?$ & $?$ & $?$ \\
Januar 1947 & 824111 & 121780 & 688333 & 912 & 3955 & 4209 & 4922 \\
Januar 1948 & 984743 & 125994 & 793916 & 16098 & 31371 & 7386 & 9978 \\
Dezember 1948 & 997886 & 129935 & 763806 & 40798 & 47609 & 6579 & 9159 \\
\hline
\end{tabular}

* Gemeint sind überwiegend Deutsche aus dem Königsberger Gebiet.

** Heimatvertriebene Deutsche aus Jugoslawien, Österreich und aus Kriegsgefangenenlagern der westlichen Alliierten.

Der Überblick verdeutlicht, daß im Dezember 1948 der Anteil der Deutschen aus den Vertreibungsgebieten östlich von Oder und Lausitzer Neiße 76,5\%, aus der CSR $13,1 \%$ und aus anderen Staaten bzw. Gebieten 10,4\% betrug.

Die dauerhafte Aufnahme von vertriebenen Deutschen wurde auch in Sachsen (wie in anderen Teilen des besetzten Deutschlands) grundlegend von den wirtschaftlichen Gegebenheiten beeinflußt. Arbeitsmarktlage und Wohnraumfrage entschieden in erster Linie über die Integration von Vertriebenen in das neue wirtschaftliche und soziale Umfeld.

Im hier untersuchten Zeitraum (1945 bis 1949) entwickelte sich im sächsischen Erzgebirge der Uranbergbau zu einem Wirtschaftsbereich, der die Spezifik der Aufnahme von Vertriebenen in Sachsen maßgeblich prägte. Für die Untersuchungen kommt dem Sachverhalt nicht unerhebliche Bedeutung zu, daß die Landkreise und kreisfreien Städte der Erzgebirgsregion vor der offiziellen Gründung der Sowjetischen Aktiengesellschaft (SAG) Wismut Mitte 1947 keinesfalls von der sachsenweiten Aufteilung zugewiesener Vertriebener verschont blieben. Auch waren die Erzgebirgskreise im Zuge der Zwangsausweisungen von Sudetendeutschen in den Jahren 1945/46 aufgrund ihrer natürlichen Grenzlage in hohem Ausmaße mit Unterkunfts- und Arbeitsvermittlungen für diese Ver-

7 Vgl. Jahn, Überlegungen, S. 274-276.

8 Vgl. Steinberg, Dic Bevölkerungsentwicklung, S. 140.

9 Just, Die Lösung, Bd. 2, S. 146-147. 
triebenengruppe konfrontiert worden. Eine Stichprobe über die Gesamtzahl der bis zum Februar 1947 neuangesiedelten Vertriebenen aus sämtlichen Vertreibungsgebieten und -ländern in ausgewählten Land- und Stadtkreisen des Erzgebirges ergibt folgendes Bild:

Tabelle 2: Vertricbenc Deutsche in ausgewählten Kreisen des Erzgebirges ${ }^{10}$ Stand: Februar 1947

\begin{tabular}{|l|c|c|c|}
\hline Landkreis/Stadtkreis* & $\begin{array}{c}\text { Altansässige } \\
\text { insgesamt }\end{array}$ & $\begin{array}{c}\text { Vertriebenc } \\
\text { insgesamt }\end{array}$ & $\begin{array}{c}\text { Anteil Vertriebener } \\
\text { in \% }\end{array}$ \\
\hline Annaberg & 105104 & 14137 & 13,4 \\
Aue & 123244 & 10826 & 8,8 \\
Chemnitz & 145081 & 27817 & 19,2 \\
Dippoldiswalde & 59851 & 21738 & 36,3 \\
Freiberg & 74688 & 21016 & 28,1 \\
Marienberg & 66338 & 8986 & 13,5 \\
Stollberg & 77532 & 15991 & 20,6 \\
\multicolumn{1}{|c|}{ Aue } & 26243 & 2621 & 10,0 \\
\multicolumn{1}{r|}{ Zreiberg } & 31392 & 9969 & 31,7 \\
\hline
\end{tabular}

$*$ Vor der Kreisreform 1947 war das Land Sachsen in 29 Land- und 23 Stadtkreise aufgegliedert, die nicht immer identisch mit den später gebildeten Kreisen waren.

Ablesbar wird die Tendenz einer ganz offensichtlich schon vor 1947 erfolgten Einschränkung der Vertriebenenaufnahme in den Landkreisen Annaberg, Aue und Marienberg sowie im Stadtkreis Aue. Augenscheinlich beeinflußte das Hineinströmen von zonenweit angeworbenen Arbeitskräften in das traditionelle Uranbergbaugebiet um Annaberg, Johanngeorgenstadt, Aue, Schneeberg und Marienberg ${ }^{11}$ derartige lokale Regulierungsmaßnahmen.

Hinsichtlich seiner territorialen Ausdehnung (nach der sächsischen Kreisreform 1947) umfaßte das Uranbergbaugebiet die 11 Landkreise Annaberg, Aue, Auerbach, Chemnitz, Dippoldiswalde, Dresden/Land, Freiberg, Marienberg, Plauen/Land, Stollberg und Zwickau/Land sowie den Stadtkreis Zwickau ${ }^{12}$. Da die Aufsicht über die im Juni 1947 gegründete SAG Wismut der (damals dem Ministerium des Innern der UdSSR unterstellte) sowjetische Geheimdienst ausübte und das gesamte Uranbergbaugebiet den Charakter einer Sonderregion erhielt, wurden die Befugnisse der SMAD-Behörden für diesen Teil der Besatzungszone weitgehend eingeschränkt ${ }^{13}$. Diesem besatzungspolitischen Sonderstatus waren sächsische Zivilverwaltungen und Bevölkerung des Bergbauterritoriums alläglich ausgesetzt. Die deutschen Selbstverwaltungen auf der Ebene der Landesregierung, der Kreise und der Gemeinden waren im Prinzip gegenüber willkürlichen Eingrif-

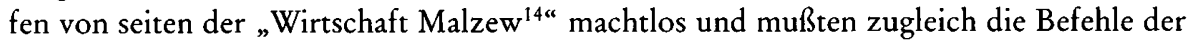
SMAD bzw. SMAS realisieren. Offensichtlich infolge dieser außerordentlichen Verwaltungssituation richtete das sächsische Ministerium für Arbeit und Sozialfürsorge im Juli

10 Sächs. HStA, LRS, MfAS, 918 (Sammelbericht Umsiedler).

11 Feirer/Hiller, Zur Entwicklung, S. 259-260.

12 Sächs. HStA, LRS, MfAS, 419.

${ }^{13}$ Karlsch, „Staat im Staate“, S. 16.

${ }^{14}$ In Schreiben sächsischer Behörden häufig verwendete Bezeichnung für die SAG Wismut; so nach dem von Juni 1947 bis November 1952 amtierenden ersten Generaldirektor M. M. Malzew (im militärischen Rang eines Generals des NKWD) benannt. 
1947 eine „Sonderabteilung Erzbergbau“ mit Sitz in Aue ein, die Fragen der Arbeitskräftelenkung in das Wismut-Gebiet, der Wohnraumzuweisung, der Gebrauchsgüterzuteilung und der allgemeinen Sozialfürsorge zu lösen hatte. ${ }^{15}$ Die Sonderabteilung Erzbergbau berührte innerhalb ihres Tätigkeitsbereiches auch "umsiedler"-politische Fragen.

Aufgrund des unaufhörlich steigenden Arbeitskräftebedarfs durch den forcierten Abbau des für die UdSSR aus militärstrategischem Denken wichtigen Uranerzes wurden die Vertriebenen zu einer attraktiven Zielgruppe der Arbeitskräftewerbung. Im Angesicht der persönlichen Notlage und des vielfachen sozialen Absturzes der Vertriebenen setzten die Werber gerade bei dieser Zielgruppe auf Verlockungen privilegierter Verdienstmöglichkeiten, Kleidungs- und Gebrauchsgüterzuteilung sowie baldigen Wohnraumerwerbs. Gleichzeitig sahen gerade die Sowjetbehörden in den Vertriebenen eine Personengruppe, die durch ihr Schicksal der Zwangsaussiedlung dem willkürlichen $\mathrm{Zu}$ griff der Besatzungsmacht ausgesetzt und deren Ansiedlung - vor allem bei noch zu erwartenden Vertriebenentransporten in den Jahren 1947/49 - nach bergbautauglichen und bergbauerfahrenen Auswahlkriterien sowie in größerer Zahlendimension zu steuern war.

Die Aufnahme von Vertriebenen in den Kreisen des Uranbergbaugebietes wurde ab Mitte 1947 vollends von den Arbeitskräfteanforderungen der Wismut AG bestimmt. Zum einen wurden die Landkreise Aue, Annaberg und Marienberg nun vollständig aus den zentral von der SMAD für das Land Sachsen vorgegebenen örtlichen Aufnahmequoten herausgenommen. Bedingt durch die Priorität der Gestellung von bergbautauglichen Arbeitskräften wies das sächsische Ministerium für Arbeit und Sozialfürsorge die Arbeitsämter der Uranbergbaukreise im Rundschreiben vom 9. 10. 1947 an, Vertriebene, soweit sie bergbautauglich und nicht als Facharbeiter für andere SAG-Betriebe vorgesehen

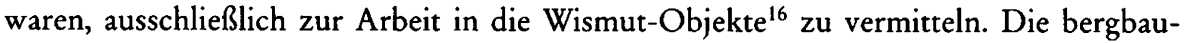
tauglichen Männer waren unverzüglich arbeitszuverpflichten und in "geschlossenen Transporten mit Transportbegleiter" zu den Arbeitsorten um bzw. in Aue, Annaberg und Marienberg in Marsch zu setzen. Ihre Familienangehörigen sollten aufgrund der dortigen akuten Wohnraumprobleme in benachbarten Kreisen untergebracht werden. Die Arbeitsämter wurden ausdrücklich angewiesen, „keinerlei Arbeitskräfte Vertretern der Wirtschaft Malzew zu übergeben “17.

Zum anderen rekrutierten zum gleichen Zeitpunkt NKWD-Offiziere der SAG Wismut in den sächsischen Quarantänelagern ${ }^{18}$ mit Billigung der SMAS hier eingetroffene Vertriebene für spezielle Wismut-Objekte. Rigoros wurden sämtliche arbeitsfähigen Männer im Alter zwischen 18 und 55 Jahren im ärztlichen Schnellverfahren für „bergbautauglich“ befunden, vorgeschriebene Quarantänezeiten verkürzt und die Männer mit ihren Familienangehörigen unter völliger Nichtbeachtung der örtlichen Wohnraumund Ausstattungskapazitäten sowie ohne amtliche Vorankündigung in das Wismut-Kern-

15 Vgl. Sächs. HStA, LRS, MfAS, 415.

${ }^{16}$ Die einzelnen Uran-Lagerstätten und Aufbereitungs- bzw. Montagebetriebe wurden vermutlich aus Geheimhaltungsgründen mit dem lapidaren Begriff „Objekt“ bezeichnet und fortlaufend numeriert, z. B. Objekte 1 bis 5 = Lagerstätten in Johanngeorgenstadt, Oberschlema, Schneeberg, Annaberg und Marienberg (vgl. Feirer/Hiller, S. 261).

17 Sächs. HStA, LRS, MfAS, 391.

18 Größere Quarantänelager mit Aufnahmekapazitäten zwischen 1000 und 3000 Personen existierten ab Mitte 1946 u. a. in Pirna, Löbau, Zittau, Hoyerswerda, Leipzig, Niederoderwitz und Plaue /bei Flöha (vgl. Jahn, Auffang- und Quarantänelager, S. 254). 
gebiet gesandt ${ }^{19}$. Auch die Anfang September 1947 zwischen der Sonderabteilung Erzbergbau (Ministerium für Arbeit und Sozialfürsorge) und dem Vertreter der „FeldpostEinheit 27304“ (SAG Wismut) abgeschlossene Vereinbarung, die Zuführung von „Umsiedlern" in den zentralen Bergbaukreis Aue vorerst einzustellen, hatte nur sehr kurzfristige Realisierungschancen. Immerhin sollten die Bürgermeister der Gemeinden Transporte, die im Zuge von Einzelaktionen der Malzew-Offiziere zugewiesen wurden, nicht annehmen ${ }^{20}$. Diese Vereinbarung ausnutzend, verstärkten betroffene Bürgermeister und Landräte im Kerngebiet ihre Kritik an der Fortsetzung der eigenmächtigen Zuweisungspraxis der Malzew-Offiziere. $\mathrm{Da}$ auch Klärungsversuche über die Berliner Zentralverwaltung für deutsche Umsiedler (ZVU) nicht fruchteten, verweigerten manche der vorbestimmten Ansiedlungsorte (u. a. im Kreis Zwickau) die Aufnahme der Transporte ${ }^{21}$. Es ist jedoch anzunehmen, daß derartige lokale Entscheidungen sächsischer Verwaltungen aufgrund der Sonderbefehlsgewalt der Malzew-Behörde schnellstens aufgehoben wurden, zumal dieser ungleiche Kompetenzstreit ausschließlich auf dem Rücken der an sich schon leidgeprüften Vertriebenen ausgetragen wurde. Ohne Zweifel verschärften die Rekrutierungsmaßnahmen der Malzew-Offiziere, die Ende Januar 1948 durch einen entsprechenden Befehl des Chefs der Unterabteilung Umsiedler der SMAS (Oberstleutnant Wolodin) ${ }^{22}$ unterstützt wurden, die akute Ansiedlungssituation im Uranbergbaugebiet. Obwohl die sächsische Umsiedlerbehörde ${ }^{23}$ wiederholt forderte, zur Deckung des Arbeitskräftebedarfs im Uranerzbergbau alleinstehende Männer und prinzipiell Arbeitskräfte ohne Familienanhang anzusiedeln, verfolgte die SAG Wismut in bezug auf Vertriebene einen konträren Kurs. Insbesondere von Herbst 1947 bis Jahresende 1948 wurden in den Lagern die arbeitsfähigen Männer ausgewählt und ausdrücklich mit ihren $\mathrm{Fa}$ milienangehörigen zur dauerhaften Unterbringung in das Wismut-Gebiet verbracht. Allein im Zeitraum vom 6. September bis 24. Oktober 1947 wurden insgesamt 7279 Vertriebene aus den Lagern Niederoderwitz, Löbau, Pirna (Graue Kaserne; Sonnenstein I), Dresden (Lager "C"; Paul-Schrader-Straße) und Hoyerswerda nach Aue, Auerbach, Zwickau oder Annaberg transportiert ${ }^{24}$. Auf enorme quantitative Unterschiede zwischen in den Quarantänelagern festgestellter und im Ankunftsort überprüfter tatsächlicher Bergbautauglichkeit macht eine Stichprobe zum im Oktober 1947 in den Landkreis Annaberg eingewiesenen Vertriebenentransport aus dem Lager Löbau aufmerksam: Von 378 bergbautauglich gemeldeten Personen wurden nur 19 Männer als für den Bergbau einsatzfähig befunden ${ }^{25}$.

Augenscheinlich zielte der Malzew-Kurs auf die Eindämmung der überaus hohen Fluktuation unter den (zwischen 6 Monaten und 2 Jahren) arbeitsverpflichteten Bergleuten. Daher sah sich die SMAD im Oktober 1947 auch genötigt, die Arbeitsämter zur Ein-

19 Sächs. HStA, LRS, MfAS, 391.

20 Ebenda.

${ }^{21}$ Vgl. ebenda, MdI, 2645.

22 Nach dem Befehl Oberstleutnant Wolodins vom 28. 01. 1948 wurden die Leiter der Quarantänelager in Sachsen angewiesen, Vertretern der Wismut AG unverzüglich Eingang in die Lager zur Auswahl von bergbautauglichen Arbeitskräften zu gewähren (vgl. ebenda, MdI, 2209).

${ }^{23}$ tändiges Amt der LVS), am 12.02. 1946 Kompetenzwechsel zum Vizepräsidenten für Justiz und Gesundheitswesen [Uhle/LDP]- ab Dezember 1946 Hauptabteilung Umsiedler im neugegründeten Ministerium für Arbeit und Sozialfürsorge [Minister: Gäbler/SED] - ab 01. 01. 1949 Zuordnung zum Ministerium des Inneren [Minister: Zaisser/SED] - Auflösung am 01. 12. 1950.

${ }^{24} \mathrm{Vgl}$. Sächs. HStA, LRS, MdI, 2645.

25 Vgl. ebenda, MfAS, 391. 
schränkung der Zwangseinweisungen aufzufordern ${ }^{26}$. Die SAG Wismut wiederum war sehr daran interessiert, eine stabile und motivierte Stammbelegschaft zu schaffen und deshalb zugleich die Familien der Bergarbeiter in Wohnorten des Wismut-Kerngebietes anzusiedel ${ }^{27}$. Offensichtlich sah sie in den Vertriebenen eine Zielgruppe, deren erzwungene Mobilität sie zielgerichtet nutzen wollte, zumal sie dazu aufgrund ihrer Position innerhalb des Besatzungsapparates über ausreichende Möglichkeiten verfügte. Doch Zwangsmaßnahmen gegenüber Vertriebenen waren in der SBZ aus interalliierten Gründen und wohl auch infolge der örtlichen Gegebenheiten im relativ dicht besiedelten Raum des Erzgebirges und des Vogtlandes Grenzen gesetzt. So schieden Überlegungen einer totalen Abschirmung oder nach außen geschlossenen Gruppenansiedlung von "Umsiedlern“ aus. Dagegen konnte im benachbarten böhmischen Uranbergbaugebiet um Jáchymov (Joachimsthal) ein von der Außenwelt isoliertes Repressivsystem der Zwangsverpflichtungen und des massenhaften Einsatzes von Häftlingen, Kriegsgefangenen und in der Tschechoslowakei nach 1945/47 verbliebenen oder zurückgehaltenen Deutschen errichtet werden. Ab Mitte 1948 bis weit in das Jahr 1949 hinein wurden deutsche Familien aus 11 ausgewählten politischen Bezirken der CSR zur Arbeit in die Jáchymov-Region zwangsumgesiedelt. Die genaue Anzahl der zwangsumgesiedelten Deutschen und ihr weiteres Schicksal in den tschechischen Urangruben („Aktion J“) sind der zeithistorischen Forschung bis heute unbekannt ${ }^{28}$.

Der Aufbau der Uranindustrie wurde sowohl in der CSR als auch in der SBZ in hohem Maße von einem übersteigerten Sicherheitsdenken begleitet. Ende 1951 wurde das böhmische Urangebiet zur geschlossenen Grenzzone erklärt und einer völligen polizeilichen Kontrolle unterworfen. Analog zur tschechischen Sicherungspraxis erhielten die Uranförderbezirke in Sachsen den Status eines militärischen Sperrgürtels. Innerhalb dieses Sperrgürtels stellten einzelne Urangruben militärisch streng bewachte Enklaven dar ${ }^{29}$.

Für die Arbeitskräftelenkung in den sächsischen Uranbergbau spielten in den Jahren 1948/49 vor allem die für eine Ansiedlung in Sachsen vorbestimmten Vertriebenentransporte aus Schlesien, Ostpreußen und Ungarn eine wesentliche Rolle ${ }^{30}$. Dies resultierte auch aus der 1948/49 erheblich ansteigenden Fluktuation von größtenteils zwangsvermittelten Arbeitskräften, die 1948 bei $34 \%$ und 1949 bei $44 \%$ lag $^{31}$. Mitte 1948 teilte die Landesregierung Sachsen auf einer Arbeitsberatung über Fragen des Uranbergbaus mit, den Fluktuationserscheinungen nun durch Ansässigmachen von „Umsiedler“-Familien zu begegnen ${ }^{32}$. Damit wurde zwar mit einiger Verzögerung, doch nun gegen alle lokalen Widerstände die bereits praktizierte Malzew-Linie zum durchgängigen Arbeitsprinzip der Umsiedler- und Arbeitsämter in den Wismut-Kreisen erhoben.

Zunächst plante man deshalb, die für die zweite Jahreshälfte 1948 angekündigten Bergarbeitertransporte aus Schlesien (Waldenburger Kohlerevier) geschlossen in günstiger Verkehrsnähe zu Urangruben anzusiedeln ${ }^{33}$. Des weiteren wurde angestrebt, die Anzahl

${ }^{26} \mathrm{Karlsch}$, "Staat im Staate“, S. 17.

27 Kaden, Wismut, S. 12.

$28 \mathrm{Kaplan} / \mathrm{Pacl}, \mathrm{S} .32-33$.

29 Karlsch, Uranindustrien SBZ/DDR und CSR, S. 16.

30 Vgl. Sächs. HStA, LRS, MdI, 2209.

${ }^{31}$ Karlsch, Uranindustrien SBZ/DDR und CSR, S. 14.

32 Sächs. HStA, KT/KR Annaberg, 625.

${ }^{33}$ Ebenda. 
der bisher eingesetzten bergbautauglichen Arbeitskräfte aus dem Personenkreis der „Umsiedler" (bis Dezember 19473291 Personen $^{34}$ ) wesentlich zu überbieten. Experten der sächsischen Sonderabteilung Erzbergbau arbeiteten ortsspezifische Pläne zur Ansiedlung von Vertriebenenfamilien in Verkehrsnähe der arbeitgebenden Wismut-Objekte aus. Beispielsweise sollten in den Sommermonaten 1948 etwa 2200 Familien - in der Mehrzahl aus Schlesien - in den Landkreisen Aue (u. a. in Eibenstock, Schönheide, Schwarzenberg), Stollberg, Zwickau (u. a. in Kirchberg) sowie in der Stadt Zwickau untergebracht werden ${ }^{35}$. Die hauptsächlichen Ansiedlungsorte von Vertriebenen im Landkreis Aue (Frühjahr 1948) zeigt Tabelle Nr. 3.

Sichtbar wird an diesem Fallbeispiel, daß knapp 50\% aller hier angesiedelten Vertriebenen aus Schlesien, Pommern und weiteren Gebieten östlich von Oder und Lausitzer Neiße, fast ein Viertel aus der Tschechoslowakei und etwa $12 \%$ aus dem inzwischen dem polnischen Staat zugegliederten ostpreußischen Landesteil ausgewiesen worden waren. Es wird weiterhin eine breite Streuung der Vertriebenenansiedlung auf sämtliche Gemeinden des Landkreises Aue deutlich.

Durch den ständigen Zulauf von Arbeitskräften blieb das sich verschärfende Problem des akuten Wohnraummangels bestehen. Eine Arbeitstagung der Landesregierung unter Leitung des zuständigen Ministers für Arbeit und Sozialfürsorge Gäbler, die am 16. Januar 1948 in Dresden stattfand, stellte die Wohnraumfrage und das Problem der steigenden Fluktuation in den Mittelpunkt ihrer Diskussion. Das Ministerium forderte von den teilnehmenden Landräten der Uranbergbaukreise und von der Hauptabteilung Umsiedler, an den Brennpunkten der Erzförderung zusätzlichen Wohnraum zu schaffen. Man wollte an die Stelle der bisherigen Praxis der Arbeitszwangseinweisungen grundsätzlich das Freiwilligkeitsprinzip setzen, die freiwillige Arbeitsaufnahme durch ein Anreizsystem von akzeptablen Barackenunterkünften und Wohnungen absichern. Die Verkehrsbedingungen zwischen Arbeits- und Wohnort sollten zudem spürbar verbessert werden. Die Behebung des akuten Wohnraummangels wurde jedoch primär über Zwangsumsiedlungen derjenigen altansässigen Bevölkerungsteile, die ohne Beschäftigung (Arbeitslose; Alte) waren, sowie der bergbauuntauglichen Vertriebenen in Nichtbergbaugebiete angestrebt $^{36}$. Damit wurden erneut ministerielle Planspiele aufgegriffen, die bereits im August 1947 eine derartige rigorose Entscheidung für die Schwerpunktgebiete um Annaberg, Aue und Marienberg ins politische Kalkül gezogen hatten ${ }^{37}$. Sowjetische Besatzungsmacht und deutsche Verwaltungsstellen hatten schon 1947 mit der sog. Re-Umsiedlung von bis dahin angesiedelten bergbauuntauglichen Kriegsflüchtlingen und Vertriebenen aus Schlesien und Böhmen in Nichtbergbaugebiete begonnen ${ }^{38}$. Bemerkenswert erscheint aus damaliger Sicht, daß gleichzeitig der Landrat des Kreises Annaberg dagegen entschiedenen Protest eingelegt und konkrete Vorschläge zur menschenwürdigen Unterbringung gerade von heimatvertriebenen Deutschen dem sächsischen Landesumsiedleramt unter-

${ }^{34}$ Sächs. HStA, LRS, MfAS, 390/1. - Es ist anzumerken, daß in Akten angegebene Daten zur Arbeitskräftegestellung für 1947 voncinander abweichen. So ging - im Gegensatz zur hier befragten Hauptabteilung Umsiedler - das sächsische Landesarbeitsamt von 3738 „Umsiedlern“ und 2236 „heimatlosen Heimkehrern“ aus, die zur Arbeit im Uranbergbau vermittelt wurden (vgl. Sächs. HStA, LRS, MfAS, 426.).

${ }^{35}$ Ebenda, 418.

36 Ebenda, MdI, 2645

37 Vgl. ebenda, MfAS, 391.

${ }^{38}$ Beycr/Kaden/Raasch/Schuppan, Wismut, S. 60-61. 


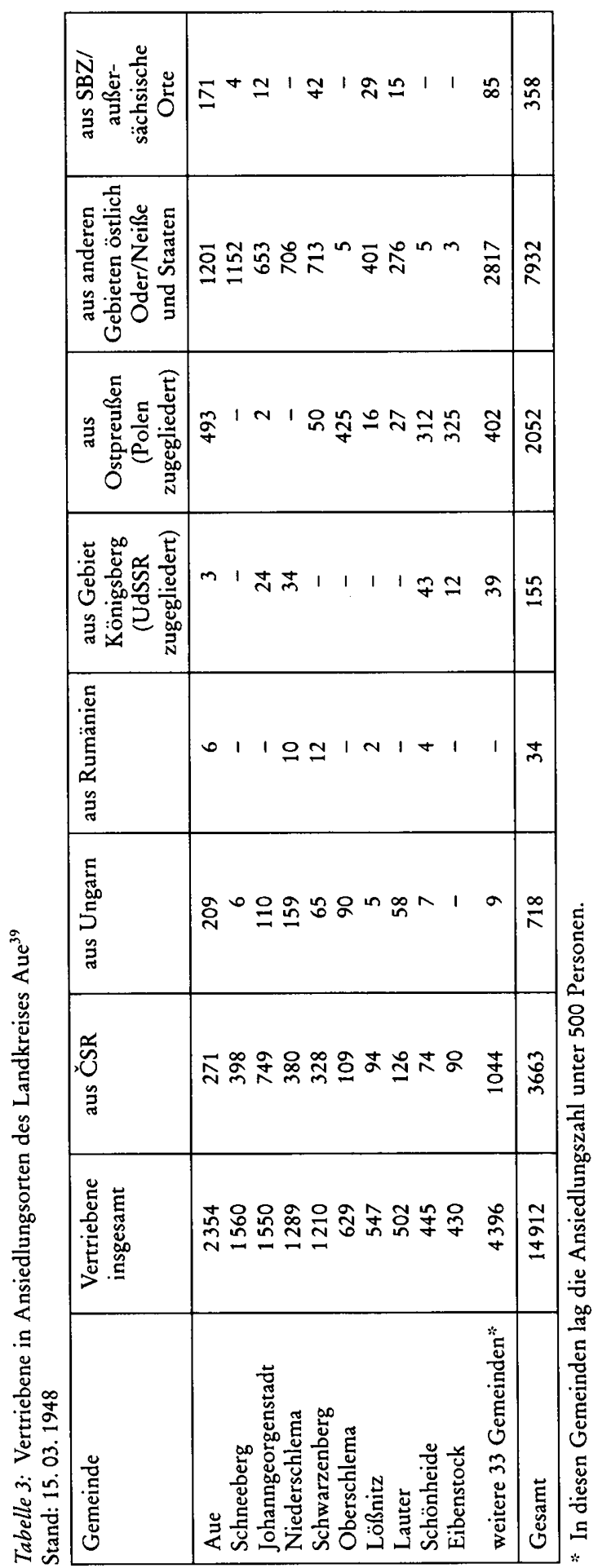


breitet hatte. Sein vehementer Protest verwies zwar auf die Dringlichkeit eines großzügigen Bauprogramms und lehnte Entscheidungen zur nochmaligen Umsiedlung von Vertriebenen in andere Regionen Sachsens ab, zielte jedoch letztlich auf eine Reduzierung des Aufnahmesolls für den Kreis Annaberg ${ }^{40}$.

Einige Akten der insgesamt spärlichen Aktenlage deuten durchgeführte Umsiedlungsaktionen nur an, ohne konkrete Zahlen und Zielorte zu nennen. So wurden aus dem Kreis Marienberg bereits bis Ende 1947 „ohne Beschäftigung lebende und überalterte Personen" ausgesiedelt ${ }^{41}$. Die ab Frühjahr 1947 in Erscheinung getretenen Planungen zur zwangsweisen Freimachung von Wohnraum beruhten auf einer SMAD-Direktive vom April 1947. Die Besatzungsmacht beauftragte die ZVU mit der Korrektur der Fehlleitungen von industriellen, landwirtschaflichen, handwerklichen und gewerblichen Fachkräften sowie mit einer „gezielteren“ Koordinierungstätigkeit der ZVU bei den Landes- und Provinzialregierungen ${ }^{42}$. Im Klartext bedeutete dies das Freimachen von Wohraum für in wirtschaftsstrategisch wichtigen Ballungszentren benötigte Fachkräfte durch erzwungene Umsiedlung von arbeitsunfähigen Altansässigen.

Im Frühjahr 1948 warfen verschiedene Regierungsstellen die Frage auf, bergbauuntaugliche Vertriebene aus dem Kreis Annaberg in andere Teile Sachsens umzusiedeln ${ }^{43}$. Im März 1948 wurde die Stadt Freital mit der Unterbringung von 3000 Bergleuten (einschließlich der Familienangehörigen) (u. a. Transporte aus dem Gebiet Königsberg) beauflagt. Hier sollten Fachkräften für die Uranminen des Döhlener Beckens (Wismut-Objekt Nr. 6) feste Quartiere zugewiesen werden. Die Stadt Freital teilte in einem Bericht zur dortigen Wohnraumsituation mit, daß die Einquartierung alleinstehender Bergarbeiter realisiert werden könne, doch die zusätzliche Aufnahme der Familienangehörigen die Aussiedlung eines bestimmten Teils der Kernbevölkerung notwendig mache. Der sowjetische Stadtkommandant schlug in diesem Zusammenhang vor, einen ganzen Stadtteil von Altansässigen zu räumen und hier die Bergleute einzuquartieren. Von der Unmöglichkeit eines solchen willkürlichen Vorhabens schließlich überzeugt, wurde entschieden, die Bergarbeiter mit ihren Familien in umliegenden Gemeinden des Landkreises Dresden unterzubringen ${ }^{44}$.

Auf Regierungsebene ging man Anfang 1949 dazu über, Aussiedlungen aus den Erzbergbaukreisen nicht durch $Z$ wang, sondern auf freiwilliger Basis durchzuführen. Die sächsische Hauptabteilung Umsiedler stellte in einem Bericht an die Unterabteilung Umsiedler der SMAS Mitte Januar 1949 fest, daß die „Personen, die sich bisher für eine freiwillige Aussiedlung bereiterklärten, [...] durchweg, da sie beruflich nicht an ihren Wohnort gebunden sein dürften, entweder alt, arbeitsunfähig oder krank und invalid oder aber alleinstehende Frauen mit ihren Kindern [sind] “45. Die Aussiedlung der erzgebirgischen Kernbevölkerung würde große Unruhe ins Land bringen, und freiwillig Umgesiedelte hätten Anspruch auf zurückgelassene gleichwertige Wohnraum- und andere Lebensbedingungen im neuen Ansiedlungsort. Die Leiterin der sächsischen Hauptabteilung Umsiedler, Ruth Fabisch, war daher der Ansicht, daß „die von der Sonderabteilung

39 Zusammengestellt und errechnet nach statistischen Angaben aus: Ebenda, MdI, 2648.

40 Vgl. Sächs. HStA, LRS, MfAS, 391.

41 Vgl. ebenda, MdI, 2645.

${ }^{42} \mathrm{Vgl}$. Wille, Zentralverwaltung für deutsche Umsiedler, S. 46.

${ }^{43} \mathrm{Vgl}$. Sächs. HStA, LRS, MdI, 2645.

$44 \mathrm{Vgl}$. ebenda.

45 Ebenda. 
Erzbergbau geplante Umsiedlung der bodenständigen erzgebirgischen Bevölkerung zunächst solange zurückgestellt wird, bis die gesicherte Unterbringung der letzten Umsiedlertransporte aus den Ostgebieten abgeschlossen ist ${ }^{\alpha 46}$. Zudem lehnten vorgesehene Empfängerkreise im Osten und Nordwesten Sachsens ${ }^{47}$ die Aufnahme freiwilliger Umgesiedelter ab. Der Landrat des Kreises Grimma verwies beispielsweise darauf, daß in seinem Kreis absolut keine zusätzlichen Unterbringungsmöglichkeiten bestünden. Dafür in Frage kommende enteignete Schlösser, Gutshöfe und Herrenhäuser seien per SMADBefehl inzwischen restlos abgebrochen und abgetragen worden. In den Kreis Grimma zentral eingewiesene „Umsiedler" müßten teilweise in Massenlagern Unterkunft suchen $^{48}$.

Bisher nachweisbar sind etwa 3400 Umsiedlungen aus dem Uranbergbaugebiet, die jedoch erst nach 1951 unter der zentralen Regie eines Sonderkommissars der DDR-Regierung durchgeführt wurden ${ }^{49}$. Inwiefern und in welcher Dimension Vertriebene davon betroffen waren, bedarf der weiteren Klärung.

Im Jahre 1948 trafen 60 Vertriebenentransporte aus Ostpreußen (sowohl aus dem Polen zugegliederten Teil als auch aus dem Königsberger Raum), aus Ungarn, Pommern und Schlesien sowie aus der Tschechoslowakei mit insgesamt 80338 Personen in Sachsen ein. Laut Jahresbericht des sächsischen Landesarbeitsamtes für 1948 wurden davon 7351 Fachkräfte mit 18349 Familienangehörigen zur Arbeit in verschiedene industrielle Schwerpunktbereiche vermittelt; 3859 Arbeitskräfte wurden aus ihren Reihen dem Uranbergbau zugewiesen ${ }^{50}$. Aus dem Kreis der heimatlosen zurückgekehrten Kriegsgefangenen fanden etwa 450 Männer eine Arbeit in Uranbergwerken. Da die bisher vom Autor aufgefundenen Akten keine konkreten Schlüsse zur direkten Arbeitsaufnahme von Vertriebenen in Wismut-Objekten zulassen, sind aus gegenwärtiger Sicht gesicherte Aussagen zum Anteil von Vertriebenen an der ständig wechselnden Gesamtzahl der Beschäftigten sowie an der Stammbelegschaft der Wismut AG noch nicht möglich ${ }^{51}$. Für das Jahr 1948 kann davon ausgegangen werden, daß die oben genannten 3859 Fachkräfte aus den Reihen der neuangesiedelten Vertriebenen in ihren Bergbauberufen bzw. wenigstens berufsnah in verschiedenen Uranbergwerken eingesetzt wurden. Ungefähr $9000 \mathrm{ar}-$ beitsfähige Vertriebene meldeten sich sachsenweit bei den Arbeitsämtern für Umschulungen zum Einsatz im Erz- oder Kohlebergbau ${ }^{52}$. Aus der Sicht des Autors ist anzunehmen, daß zu den 100000 Beschäftigten, die im Dezember 1948 bei der Wismut AG regi-

46 Ebenda.

${ }^{47}$ Gemeint waren u. a. die Kreise Döbeln, Hoyerswerda und Rochlitz.

${ }^{48}$ Vgl. Sächs. HStA, LRS, MdI, 2645.

49 Karlsch, „Staat im Staate“, S. 20. - Da Vertriebene generell für Polizei- und Staatssicherheitsbehörden eine ständig zu beobachtende Zielgruppe darstellten, ist ihre Einbeziehung in erzwungene Umsiedlungen aus politischen Gründen zu überprüfen.

50 Sächs. HStA, LRS, MfAS, 419.

${ }^{51}$ Hierzu ist die intensive Durchsicht der Personalakten der Belegschaft für den untersuchten Zeitraum notwendig, die zum Teil im Wismut-Archiv Chemnitz auffindbar sind. Die von der sowjetischen Wismut-Behörde nach Moskau ausgelagerten Aktenbestände werden wohl auf längere Sicht nicht zur Verfügung stehen. Das am Dresdner Hannah-Arendt-Institut für Totalitarismusforschung von Heidi Roth in Angriff genommene Projekt zur Tätigkeit der SED-Gebietsleitung der Wismut AG kann Auskünfte zur Bewertung der Aktenlage vermitteln.

52 Vgl. Sächs. HStA, LRS, MfAS, 419. - Vor allem ungelernte oder berufsfremde junge Männer aus dem Personenkreis der Vertriebenen kamen über Umschulungen oder als Anlernlinge in die indusriellen Ballungsgebiete der SBZ (vgl. Wille, Integration, S. 166). 
striert waren ${ }^{53}$, zwischen 10000 bis 15000 Vertriebene aus 1947/48 nach Sachsen gekommenen Transporten sowie etwa 3000 aus Kriegsgefangenenlagern entlassene Heimatvertriebene zählten.

Insbesondere die 1948 im Wismut-Gebiet eingetroffenen Bergarbeitertransporte aus der Waldenburger Region (Schlesien) halfen mit, den Facharbeitermangel in den Bergwerken zu mindern. Die Waldenburger Familien wurden größtenteils in Gemeinden der Landkreise Aue, Auerbach, Zwickau und Annaberg angesiedelt ${ }^{54}$.

Die Aufteilung von Vertriebenengruppen entsprechend ihrer Herkunftsregion oder ihres Herkunftslandes auf die Uranbergbaukreise und ihr Anteil an der Vertriebenenmigration auf Kreisebene soll exemplarisch anhand der Unterbringung der Ungarndeutschen mittels der folgenden Tabelle gezeigt werden:

Tabelle 4: Unterbringung von Ungarndeutschen in zum Kerngebiet der Wismut gehörigen Kreisen Sachsens ${ }^{55}$

Stand: 28. 02.1949

\begin{tabular}{|l|c|c|c|}
\hline Landkreis/Stadtkreis & Ungarndeutsche & $\begin{array}{c}\text { Vertriebene } \\
\text { insgesamt }\end{array}$ & $\begin{array}{c}\text { davon Anteil } \\
\text { Ungarndeutscher in \% }\end{array}$ \\
\hline Auerbach & 5073 & 21422 & 23,7 \\
Zwickau & 2865 & 42234 & 6,8 \\
Stollberg & 2149 & 14460 & 14,9 \\
Dresden Zwickau & 1123 & 23278 & 4,8 \\
Marienberg & 888 & 35237 & 2,5 \\
Aue & 782 & 8929 & 8,8 \\
Dippoldiswalde & 663 & 16786 & 3,9 \\
Freiberg & 600 & 19174 & 3,1 \\
Plauen & 393 & 26936 & 1,5 \\
Annaberg & 318 & 17432 & 1,8 \\
Chemnitz & 101 & 15338 & 0,7 \\
\hline Gesamt & 69 & 18707 & 0,4 \\
\hline
\end{tabular}

Ein Drittel aller 15024 in den 12 Kreisen zur Ansiedlung gekommenen Ungarndeutschen fanden im Landkreis Auerbach Unterkunft. Auch die Landkreise Zwickau und Stollberg wurden relativ stark frequentiert. Etwa 38 Prozent aller in Sachsen aufgenommenen Ungarndeutschen (von insgesamt 39809 Personen) lebten Ende Februar 1949 in den Uranbergbaukreisen.

Das Land Sachsen trug ohne Zweifel die Hauptlast der bis Anfang der 1950 er Jahre ständig steigenden Arbeitskräftezuführung für den Uranbergbau. Noch im ersten Halbjahr 1950 mußten die sächsischen Arbeitsämter 50000 Arbeitskräfte für die SAG Wismut bereitstellen ${ }^{56}$. Die langzeitlich andauernde katastrophale Wohnraumsituation in der Wismut-Region betraf Familien von Vertriebenen in einem besonderen Ausmaße. Die Bürgermeister der größeren Gemeinden und die Landräte forderten eindringlich den Neubau von Wohnungen. Doch das immer mehr greifende bergbautypische Privilegien-

53 Karlsch, „Staat im Staate“, S. 18.

54 Sächs. HStA, LRS, MfAS, 418.

55 Zusammengestellt und errechnet nach statistischen Angaben aus: Sächs. HStA, LRS, MdI, 303.

56 Vgl. Ebenda, MfAS, 390/1. 
system kam den Vertriebenenfamilien vielfach entgegen und ließ sie auch unter schlechten Wohnbedingungen ausharren.

Ende 1948 lebten (unter Zugrundelegung der unten folgenden Tabelle 5) 262515 vertriebene Deutsche (einschließlich der aus der Kriegsgefangenschaft heimatlosen Rückkehrer), das heißt fast ein Viertel aller in Sachsen bis zu diesem Zeitpunkt aufgenommenen Vertriebenen, in den Uranbergbaukreisen des Erzgebirges und des Vogtlandes.

Tabelle 5: Ansiedlung von vertriebenen Deutschen im Land Sachsen ${ }^{57}$

Stand: 30.11 .1948

[W $=1946 / 48$ zum Kerngebiet der Wismut zugehörig]

\begin{tabular}{|c|c|c|c|c|}
\hline \multicolumn{2}{|c|}{ Landkreis/Stadtkreis* } & \multirow{2}{*}{$\begin{array}{c}\text { Gesamtbevölkerung } \\
129958\end{array}$} & \multirow{2}{*}{$\begin{array}{c}\begin{array}{c}\text { davon Anzahl } \\
\text { Vertriebener }\end{array} \\
14797\end{array}$} & \multirow{2}{*}{$\begin{array}{l}\begin{array}{c}\text { Anteil Vertriebener } \\
\text { in } \%\end{array} \\
11,4\end{array}$} \\
\hline Annaberg & W & & & \\
\hline Aue & W & 205130 & 16972 & 8,3 \\
\hline Auerbach & W & 136010 & 22078 & 16,2 \\
\hline Bautzen & & 182126 & 40304 & 22,1 \\
\hline Borna & & 137234 & 35714 & 26,1 \\
\hline Chemnitz & W & 166313 & 19456 & 11,7 \\
\hline Dippoldiswalde & W & 83276 & 19507 & 23,4 \\
\hline Döbeln & & 159468 & 38907 & 24,4 \\
\hline Dresden & W & 247941 & 35702 & 14,4 \\
\hline Flöha & & 119325 & 20738 & 17,4 \\
\hline Freiberg & W & 140181 & 26934 & 19,2 \\
\hline Glauchau & & 182826 & 31846 & 17,4 \\
\hline Grimma & & 154673 & 35653 & 23,1 \\
\hline Großenhain & & 144090 & 41904 & 29,1 \\
\hline Hoyerswerda & & 69735 & 13665 & 19,6 \\
\hline Kamenz & & 93633 & 16915 & 18,1 \\
\hline Leipzig & & 176575 & 32656 & 18,5 \\
\hline Löbau & & 143779 & 44977 & 31,3 \\
\hline Marienberg & W & 78900 & 8919 & 11,3 \\
\hline Meißen & & 179884 & 47960 & 26,7 \\
\hline Niesky & & 122862 & 36109 & 29,4 \\
\hline Oelsnitz & & 77166 & 12317 & 16,0 \\
\hline Oschatz & & 84524 & 25619 & 30,3 \\
\hline Pirna & & 212146 & 43793 & 20,7 \\
\hline Plauen & W & 109656 & 17797 & 16,2 \\
\hline Rochlitz & & 153290 & 30381 & 19,8 \\
\hline Stollberg & W & 95118 & 14784 & 15,5 \\
\hline Zittau & & 128569 & 41505 & 32,3 \\
\hline Zwickau & W & 214145 & 42932 & 20,1 \\
\hline Chemnitz & & 257867 & 10470 & 4,1 \\
\hline Dresden & & 466544 & 19506 & 4,2 \\
\hline Görlitz & & 102020 & 37225 & 29,4 \\
\hline Leipzig & & 633158 & 77012 & 12,2 \\
\hline Plauen & & 84799 & 2541 & 3,0 \\
\hline Zwickau & W & 129230 & 22637 & 17,5 \\
\hline Gesamt & & 5802151 & 1000232 & 17,2 \\
\hline
\end{tabular}

* Nach der sächsischen Kreisreform von 1947.

57 Zusammengestellt und teilweise errechnet nach statistischen Angaben aus: Sächs. HStA, LRS, MdI, 303. 
Es wird sichtbar, daß der Anteil Vertriebener an der Gesamtbevölkerung des jeweiligen Aufnahmekreises im Uranbergbaugebiet in 10 von 12 Fällen unter $20 \%$ lag (Ausnahme: Dippoldiswalde und Zwickau), während Nichtbergbaukreise wie beispielsweise Löbau, Niesky, Großenhain oder Meißen Quoten zwischen rund 26 bis $31 \%$ aufwiesen. Den geringsten prozentualen Anteil (8,3\%) unter diesem Aspekt beanspruchte der Landkreis Aue. Ganz offensichtlich hatten Aufnahmebeschränkung und -stop für die Wismut-Kreise zu dieser augenfälligen Entwicklung beigetragen. Nur die sächsischen Großstädte Dresden und Chemnitz sowie die Stadt Plauen lagen aufgrund der schweren Kriegszerstörungen und besatzungspolitischer Entscheidungen unter der oben angeführten Acht-Prozent-Aufnahmequote (Aue).

Stichproben zum Anteil der Fürsorgeempfänger unter Vertriebenen verweisen ebenfalls auf die Ausnahmestellung der Wismut-Zentren um Aue und Annaberg. So waren unter allen in diesen Landkreisen aufgenommenen Vertriebenen nur 3 bis $4 \%$ sozial hilfsbedürftig, während sich in den anderen Uranbergbaukreisen die Quote zwischen 7 und $13 \%$ bewegte $^{58}$. Der Anteil der Männer unter den Vertriebenen wies in den Landkreisen Annaberg und Aue (Stichprobe Mitte 1949: 40,9\% bzw. 36,5\%) im Gegensatz zu den anderen Wismut-Kreisen (zwischen 22,8\% und 30,4\%; ausgenommen die Stadt Zwickau mit 35,2\%) erheblich überdurchschnittliche Werte aus. ${ }^{59}$

Zieht man die Untersuchungsergebnisse zur Vertriebenenmigration in das Braunkohlenbergbaugebiet Borna ${ }^{60}$ - sachsen- und zonenweit ein Zentrum der Kohleförderung und Brennstofflieferung - zum Vergleich heran, so lassen sich sowohl analoge als auch erheblich differente Prozesse und Tendenzen erkennen:

A. Wie die Wismut-Region wurde das Bornaer Braunkohlenrevier aufgrund des hohen Arbeitskräftebedarfs bevorzugtes Zielgebiet für Vertriebenentransporte aus Schlesien, Ostpreußen, Pommern und aus der Tschechoslowakei. Doch im Gegensatz zum Sonderstatus des Uranbergbaus erfolgte hinsichtlich der zentral vorbestimmten Ansiedlungsquoten für den Landkreis Borna und die ebenfalls zur Arbeitskräftegestellung für die Braunkohlentagebaue einbezogenen Landkreise Grimma und Leipzig (Südteil) keine Einschränkung. Erst mit der Gründung von Braunkohlenkombinaten (Borna, Espenhain) und dem forcierten Ausbau des Böhlener Kombinates wurden diese Kreise Anfang 1949 aus den Ansiedlungsquoten herausgenommen ${ }^{61}$. Bis dahin wurden Proteste des Bornaer Landratsamtes gegen die Aufnahme von (vor allem bergbauuntauglichen) Vertriebenen von Besatzungsmacht und sächsischer Landesverwaltung stets zurückgewiesen. So geriet hier die Vertriebenenzuweisung in einen temporären Konflikt zu den vorhandenen Wirtschaftsstrukturen. Ende 1948 (siehe Tabelle 5) betrug der Anteil Vertriebener an der Gesamtbevölkerung des Landkreises Borna rund $26 \%$, was einer für Sachsen überdurchschnittlichen Aufnahmequote gleichkam.

B. Auch im Bornaer Braunkohlenrevier herrschte zeitweilig das System der Arbeitsverpflichtungen. Es betraf generell arbeitsfähige und vor allem qualifizierte Männer. Wie im Uranbergbau wurden Herausnahme von bergbautauglichen Arbeitskräften aus ankommenden Vertriebenentransporten in den sächsischen Quarantänelagern und Verschickung in das Braunkohlerevier gefordert und mehrfach realisiert. Nur so ist u. a. die

58 Vgl. ebenda, 304.

59 Vgl. ebenda.

${ }^{60}$ Vgl. Pietsch/Jahn, Regionale Spezifika, S. 81-89.

${ }^{61} \mathrm{Vgl}$. StAL, KT/KR Borna, 1533 und 1567. 
im Landesvergleich überdurchschnittliche Quote der Arbeitsfähigkeit unter aufgenommenen Vertriebenen (Landesebene: $32 \%$; Borna: $43 \%$ ) zu erklären, die den Größenordnungen in den Schwerpunktkreisen Aue und Annaberg ( 45 bis $46 \%$ ) sehr nahe kam ${ }^{62}$. Hinsichtlich der Auswahl von Vertriebenen nach der beruflichen Qualifikation gelang es nur im Juli 1946, drei Transporte mit schlesischen Bergleuten fast vollständig in das Revier Borna zu leiten ${ }^{63}$, da zu dieser Zeit der Uranbergbau die Arbeitskräftewerbung noch nicht dominierte. Auch der Männeranteil unter den Vertriebenen wies für die damaligen Hauptwohnbezirke im Uran- und Braunkohlebergbau um Annaberg (40,9\%), Aue (36,5\%), Zwickau/Stadt (35,2\%) bzw. Borna (38,2\%) überdurchschnittliche Werte (ansonsten um 26 bis $28 \%$ im Landesdurchschnitt) aus ${ }^{64}$. Der von vornherein ungleiche "Kampf“ um einsatzfähige Arbeitskräfte und insbesondere um Fachkräfte wurde nach 1946 eindeutig zugunsten der Wismut AG entschieden.

C. Ebenso wie zuständige Institutionen im Uranbergbaugebiet suchten das Kreisumsiedleramt und die Hauptverwaltung der Braunkohlenwerke Borna über sog. „Freilenkungen" von Wohnraum die auch im Raum Borna katastrophale Unterbringungsfrage zu lösen. Bereits angesiedelte, aber aus fehlenden Arbeitsplatzgründen (vor allem für Frauen) und aus Altersgründen nicht arbeitsfähige Vertriebene sollten in Nichtbergbaugebiete umgesiedelt werden ${ }^{65}$. Obwohl die Hauptabteilung Umsiedler der Landesregierung Sachsen diese Forderung einerseits empört zurückwies, unterstützte sie andererseits die geplante Umsiedlung von arbeitsfähigen Vertriebenen ohne Erwerbsmöglichkeit (mehrheitlich aus dem Kreis alleinerziehender und alleinstehender Frauen) ${ }^{66}$.

D. Gerade im Wismut-Gebiet und im Kohlerevier Borna zeigte sich in der unmittelbaren Nachkriegszeit der enge Konnex zwischen wirtschaftlichem Wiederaufbau (hier bei beschleunigter Wirtschaftsentwicklung dieser Schwerpunktbereiche) und Vertriebenenintegration ${ }^{67}$. Die hier relativ schnell vollzogene berufliche Integration als entscheidende Basis zur gesellschaftlichen Neufindung innerhalb der Aufnahmeregion führte m. E. in den Bergbaugebieten zu einer weitaus rascheren dauerhaften Seßhaftwerdung von Vertriebenen als in wirtschaftlich anders geprägten Regionen. Offensichtlich konnte vor allem im Uranbergbau, der 1947/49 12 Land- und Stadtkreise mit (Ende 1948) rund 263000 Vertriebenen (26,2\% aller Vertriebenen in Sachsen) erfaßte, das stark auf Berufsbezogenheit ausgerichtete „umsiedler"-politische Integrationskonzept der SED im Sinne der ab 1948 forcierten Assimilation ${ }^{68}$ unter den Sonderbedingungen relativ weiträumig greifen. Allerdings sollte untersucht werden, inwieweit das Privilegiensystem der Wismut AG daran Anteil hatte. Auch aus der Sicht der schon 1947 von der ZVU gegenüber allen „Umsiedler"-Institutionen der SBZ angemahnten Beachtung des sozialen Konfliktpotentials zwischen alteingesessener Bevölkerung und „Umsiedlern“ und daraus resultie-

62 Vgl. ebenda, 910 sowie Sächs. HStA, LRS, MfAS, 419.

${ }^{63}$ Pietsch/Jahn, Regionale Spezifika, S. 84.

${ }_{64} \mathrm{Vgl}$. Sächs. HStA, LRS, MdI, 304.

${ }^{65}$ Planungen zur Zwangsumsiedlung aus Arbeitslenkungsgründen waren keine ausgesprochen sowjetzonale Erscheinung, sondern wurden 1948 auch in der Amerikanischen Besatzungszone (Württemberg-Baden, Bayern) von Flüchtlingsverwaltungen thematisiert, jedoch nicht realisiert (vgl. Schraut, S. 190-192).

${ }^{66} \mathrm{Vgl}$. Pietsch/Jahn, Regionale Spczifika, S. 84.

67 Vgl. Schwartz, Vom ,Flüchtling' zum Neubürger, S. 32.

68 Vgl. Wille, Zentralverwaltung für deutsche Umsiedler, S. 45 und 53. 
renden notwendigen integrationspolitischen Veränderungen ${ }^{69}$ sollten tiefergehende Regionalforschungen Auskunft zu im Uranbergbau vollzogenen Prozessen einer keinesfalls konfliktfreien gesellschaftlichen Eingliederung von „Umsiedler“-Familien geben.

Die Aufnahme von vertriebenen Deutschen in der Uranbergbauregion Sachsens verlief deutschlandweit einmalig und hinsichtlich der Arbeitskräftelenkung sowie -zuweisung und Wohnraumfrage wohl auch außergewöhnlich. Die massenhafte Zuwanderung von Zwangsmigranten aktivierte ohne Zweifel soziale Umverteilungsprozesse im Wismut-Gebiet und brach bis dahin entstandene Bevölkerungsstrukturen auf. Auch Wertungen zum Einfluß der spezifischen Integrationsbedingungen dieser Region auf Prozesse zur Bewahrung, Wandlung oder Überformung der Identität von Vertriebenen müssen beim derzeitigen Forschungsstand noch offen bleiben und bedürfen weiterer Detailuntersuchungen.

\section{Resümee}

Der in der zweiten Hälfte der 1940 er Jahre expandierende Uranerzbergbau prägte die Aufnahme von vertriebenen Deutschen im Land Sachsen in einem ganz spezifischen Maße. In den 12 Land- und Stadtkreisen dieser Region lebte Ende 1948 etwa ein Viertel aller bis zu diesem Zeitpunkt in Sachsen aufgenommenen Vertriebenen (rund 263000 Personen).

Die Vertriebenen, die sowohl den Ansiedlungsdirektiven der SMAD bzw. SMAS und der mit Sondervollmachten ausgestatteten sowjetischen Wismut AG als auch der sächsischen Umsiedlerbehörde unterworfen waren, wurden hinsichtlich Arbeitskräftewerbung und -lenkung eine attraktive Zielgruppe. Der Wismut AG gelang es, vor allem aus den deutschen Ostgebieten, aus Ungarn und aus der Tschechoslowakei ankommende Vertriebenentransporte - in der Regel mit berufserfahrenen Bergarbeitern oder mit einem hohen Männeranteil - vorrangig in die Uranbergbauregion zu leiten und zugleich in den sächsischen Quarantänelagern willkürliche Rekrutierungen von arbeitsfähigen Männern für den Uranbergbau durchzusetzen. Die breit gestreute Ansiedlung von Vertriebenen im von akuten Wohnraummangel gekennzeichneten Wismut-Gebiet zielte auf die Eindämmung der hohen Fluktuation der hier bereits arbeitsverpflichteten Beschäftigten und hatte zum Teil eine $Z$ wangsumsiedlung nicht im Uranbergbau tätiger alteingesessener Bevölkerung sowie nicht einsatzfähiger Vertriebener in andere Gebiete zur Folge. Die zentralen Wismut-Kreise Aue und Annaberg nahmen unter dem Aspekt der ab 1947 erfolgten Aufnahme von fast ausschließlich bergbautauglichen und sozial kaum hilfsbedürftigen Vertriebenen eine Ausnahmestellung ein. Insgesamt lag der Anteil von Vertriebenen an der Gesamtbevölkerung in den sächsischen Nichtbergbaukreisen teilweise weit über den Aufnahmequoten der Wismut-Kreise.

Ein Vergleich mit der Zuwanderung von Zwangsmigranten in das Braunkohlenrevier Borna verdeutlicht Gemeinsamkeiten und Unterschiede. Offensichtlich führten der forcierte Wirtschaftsaufbau in den Bergbaugebieten, das materielle Privilegiensystem im Uran- und Kohlebergbau sowie berufsbezogene Integration von Vertriebenen zu ihrer schnelleren dauerhaften Seßhaftwerdung als in wirtschaftlich anders geprägten Regionen. Die Wismut AG dominierte eindeutig die Arbeitskräftelenkung in den Bergbau. Aufgrund der spärlichen Aktenlage in sächsischen Archiven bedürfen Fragen nach Konflikten der gesellschaftlichen Eingliederung von Vertriebenen, nach Wandlungen der Bevölkerungsstrukturen und lokalen Integrationsbedingungen weiterer Untersuchungen.

69 Vgl. Schwartz, Zwischen Zusammenbruch und Stalinisierung, S. 52-53. 